\title{
TRABAJAR PARA EL PRÍNCIPE. LOS SALARIOS DE LOS SERVIDORES DE LA CASA DEL PRÍNCIPE DE ASTURIAS Y GERONA (JUAN DE ARAGÓN Y CASTILLA, 1478-1497) ${ }^{1}$
}

\author{
WORKING FOR THE PRINCE. \\ THE SALARIES OF PUBLIC SERVANTS \\ OF THE HOUSE OF THE PRINCE OF ASTURIAS AND GIRONA \\ (JOHN OF ARAGON AND CASTILE, 1478-1497)
}

Resumen: Este trabajo muestra una relación completa de los oficiales que sirvieron en la casa del príncipe Juan, heredero de los Reyes Católicos, a lo largo de su vida. También una serie de nóminas de los mismos entre 1487 y 1495 , donde se recogen sus salarios. Además, se realiza una división por categorías entre los servidores. Se analiza la forma de pago de los salarios, se explica en qué consistieron y se agrupan los totales por secciones de la casa.

Palabras clave: Casa real; Príncipe Juan; Sirvientes; Salarios.

\section{JoSÉ DAMIÁN GONZÁLEZ ARCE Universidad de Murcia}

Abstract: This work shows a complete list of officers who served in the house of Prince Juan, heir to the Catholic Kings, throughout his life. A number of payroll of them between 1487 and 1495, where they collected their salaries. In addition, there is a division between the level servers. Discusses how to pay wages, explained what the totals and are grouped in sections of the house.

Keywords: Royal house; Prince Juan; Servants; Wages.

\section{SUMARIO}

1. Introducción; 2. Los servidores; 3. Los salarios; 3.1. El responsable de los pagos; 3.2. Quitaciones y raciones; 3.3. Análisis comparativo; 4. Conclusiones; 5. Apéndices (tablas y gráficos).

\section{INTRODUCCIÓN}

El trabajo que a continuación se presenta es un adelanto de una investigación de mayores dimensiones, ya prácticamente concluida, sobre la Casa del príncipe Juan, heredero varón de los Reyes Católicos.

Con el mismo, pretendo dar a conocer los salarios ordinarios percibidos por sus servidores desde que contó con casa propia, dentro de la

${ }^{1}$ Quiero agradecer al evaluador del presente trabajo las oportunas apreciaciones que ha realizado sobre el mismo que, sin duda, han contribuido a mejorar esta versión final. 
de su madre, la reina, hacia 1487, hasta que ésta se emancipó de la anterior, en 1495. Además, voy a aprovechar para adelantar una relación completa de todos los servidores que trabajaron para don Juan a lo largo de su existencia (1478-1497), así como de sus retribuciones dinerarias (tabla 2). Otros aspectos, como las ayudas extraordinarias, los pagos en especie, los salarios de los servidores de la Casa y Corte principescas una vez emancipadas de la casa real castellana, así como las deudas y gratificaciones satisfechas tras la muerte del heredero, habrán de quedar para otros trabajos.

De esta manera, este artículo va a servir para mostrar los honorarios de los trabajadores mejor retribuidos de la Castilla de finales del siglo $\mathrm{XV}$, los empleados de la casa real. O lo que es lo mismo, se trata de una serie de salarios más o menos completa que nos habla del nivel de ingresos de los trabajadores mejor remunerados del momento. Lo que en sí mismo resulta de una gran utilidad, cuando, como es de sobra sabido, para este período es casi imposible la elaboración de series salariales de otra naturaleza, tanto por la escasez de fuentes, como por la disparidad económica regional existente en las tierras castellanas durante toda la baja Edad Media. Pero, además, las relaciones nominales aquí contenidas resultan de gran ayuda para otros fines historiográficos, más allá de los puramente económicos, relativos a las cuantías de los ingresos y a los niveles de vida, pues se pueden utilizar, asimismo, para conocer la procedencia, filiación y naturaleza de los sirvientes del príncipe de Asturias y Girona, y, con ello, ser una contribución inestimable en los campos de la historia social y política del momento.

Para la elaboración de las tablas y gráficos que aquí se recogen se han utilizado las fuentes impresas que más adelante se detallan, así como gran cantidad de documentación inédita, fundamentalmente conservada en el Archivo General de Simancas².

\section{LOS SERVIDORES}

Los trabajadores de la casa del heredero de las Coronas de Aragón y Castilla, que, por estar cerca de su persona y encargase de las necesidades de la misma, también eran conocidos como "familiares" del mismo, fueron de tres calidades diferentes: funcionarios, oficiales y asalariados, tanto por el cometido que desempeñaron como por su extracción social, también condicionada por éste.

Funcionarios. Los cargos de más alto rango eran los ocupados por la alta nobleza castellana, los ricos hombres o sus familiares directos, y a veces por el alto clero. Algunos de ellos, además de contar con grades títulos nobiliarios, también desempeñaron oficios en la casa de la reina de Castilla y más raramente en la del rey aragonés. A estos altos servidores les acompañaba el calificado de "mayor" junto a su cargo, y aquí los voy a denominar como

${ }^{2} \mathrm{La}$ tabla 2 ha sido elaborada a partir de toda la documentación manejada para el estudio de la casa del príncipe. 
"funcionarios", siendo sus "funciones" meramente representativas y a veces sólo simbólicas. De manera que no entrañaban actividad física alguna, ni mucho menos trabajo manual, impropio de la dignidad de quienes las desempeñaban. De forma que, en muchas ocasiones, dicho cargo no era ejercido por los propios titulares, que bien podían delegar en alguien que los representase o en sus subordinados ${ }^{3}$. Las atenciones que prestaban al príncipe eran más bien nominales o teóricas, siendo relativas al mundo de lo aparente más que de lo material. Se trató de cargos honoríficos que más que para prestar servicios al heredero sirvieron para "hermosear su corte", es decir darle relevancia a través de la presencia y prestación teórica de servicios por parte de personajes de gran prestancia y talla política, religiosa, económica, social o intelectual; que, por su parte, también extrajeron beneficios personales de tal actividad, más a través de influencias y favores que de su salario.

Se podría argumentar que el término "funcionario", por su raíz semántica (persona que desempeña un empelo público) podría no resultar adecuando para designar a estos empleados de más alto rango de la casa real, y por tanto vinculados al ámbito más "privado" de la monarquía, frente a los de la Corte o los de la administración periférica del Estado, con una proyección más "pública”. No obstante, hay que recordar que en la Edad Media, también todavía durante el siglo XV, la distinción entre lo público y lo privado, en el ámbito de la administración del Estado, no estuvo clara en absoluto. De esta forma, no se debe ver en la casa solamente el conjunto de los oficios domésticos. Mientras que tampoco la corte, que deriva del término "curia" o "cross", estaría relacionada únicamente con las labores de gobierno. El origen de la confusión entre el ámbito privado y público de las casas reales hay que buscarlo en la propia formación de los reinos germánicos, en cuya rudimentaria organización central se fundieron el palatium romano y el hall germano. En dicha fusión, los oficios romanos se simplificaron mientras que los de la casa germánica, más domésticos, fueron ganando en contenido público. Así, aunque para el período bajomedieval algunos autores quieren ver en la "casa" el conjunto de actividades desempeñadas de puertas adentro del palacio, mientras que la "corte" representaría la acción de asomarse el monarca al "patio" para establecer contacto con el pueblo y administrar justicia, sin embargo, esta distinción no se desprende de los textos legales, porque los grandes pilares de la Administración estuvieron implicados tanto en las labores de gobierno de la casa como de la corte. Por ello he elegido el término "funcionario", aunque no resulte del todo apropiado, para denominar

${ }^{3}$ En términos similares a los aquí establecidos, en la administración central castellana bajomedieval se diferenció entre los oficios provenientes de la etapa altomedieval, desempeñados por poderosos magnates y vasallos regios, con una labor meramente simbólica y honorífica, y los surgidos de las necesidades burocráticas del período bajomedieval, ocupados por gentes corrientes. Así, a los que ejercían los primeros se les solía denominar como "dignidades", por ser sus titulares poderosos nobles o grandes prelados, mientras que a los segundos se les conocía como simples "oficiales", puestos ocupados por plebeyos o hidalgos; término éste que sirvió para denominar tanto a los criados domésticos como a los funcionarios públicos (D. TORRES SANZ, $L a$ administración central castellana en la baja Edad Media, Valladolid, 1982, pp. 53-57). 
a los empleados de mayor nivel de la casa del príncipe Juan; porque, por su elevado rango social, algunos desempeñaron al tiempo labores de gobierno; porque el prestigio de trabajar en la casa del príncipe les acercó a dichas labores de gobierno (algunos servidores, y no sólo los principales, acabaron por promocionarse a partir de su trabajo en la misma y por ocupar puestos en la Administración; mientras que a algunos otros se los puede ver, durante el tiempo que sirvieron en la casa y a modo de "continos", desempeñando labores administrativas de carácter estatal, tales como ser mensajeros o ejecutores de las órdenes y disposiciones reales); y, porque, desarrollar "funciones" en la casa del titular del Estado, en este período, era casi tanto como hacerlo para el propio Estado.

Si bien el nombramiento, así como el despido, de todos los sirvientes reales dependían de la libre voluntad del monarca, en el caso del príncipe Juan fue su madre la que desempeñó este cometido antes de emanciparse el heredero, quien sería el encargado de hacerlo una vez que su casa fue independiente. Sin embargo, dicho nombramiento no sólo estaba condicionado por las preferencias personales, sino que, y sobre todo en el caso de los funcionarios, se vio envuelto en la alta política, pues los poderosos del reino ambicionaron estos cargos que les reportaban interesantes ingresos y prestigio social, por lo que los reyes debieron distribuirlos poniendo cuidado en mantener los frágiles equilibrios entre las principales familias nobiliarias, prestas, en caso de quedar insatisfechas sus ambiciones, a intrigas palaciegas en las que usaron todas sus influencias, incluidas las derivadas de los cargos obtenidos en la corte y casas reales, las cuales costaron incluso la corona a más de un rey. De las tres condiciones que debían reunir estos funcionarios, amistad hacia la persona del monarca, buen linaje y ventajas políticas ${ }^{4}$, parece ser que en el ánimo de Isabel I pesó sobre todo la última cuando seleccionó a los magnates que desempeñarían los cargos en la casa de su hijo, pues procuró que hubiese una representación de las principales familias nobiliarias, más que su amistad con ellas o su abolengo. Teniendo en cuenta para ello el poder que en esos momentos tenían sus titulares, o que tendrían en el futuro, caso de los herederos de las mismas que actuaron como pajes para don Juan.

Entre los funcionarios más relevantes podemos encuadrar a los siguientes servidores de don Juan (tabla 2): los miembros de su Consejo (presidente, secretarios, escribano, letrados...), los contadores mayores de la Hacienda y de la Despensa, ayo y acompañantes, así como a los oficiales mayores de las respectivas áreas de la Casa, mayordomo, maestresala, cazador mayor, camarero...

Oficiales. En un segundo nivel, pero todavía desempeñando por personas de cierta dignidad, en algunos casos nobles no incluidos entre los ricos hombres o alta nobleza, mayormente caballeros e hidalgos de la mediana y baja nobleza, estaban los servidores de los oficios secundarios. Aquéllos subordinados a los primeros, a modo de oficios "menores" o de tenientes de

${ }^{4} \mathrm{~J}$. DE SAlazAr Y ACHA, La casa del rey de Castilla y León en la Edad Media, Madrid, 2000, p. 101 y ss. 
los principales oficios. Su cometido era más organizativo, intelectual, frente al representativo y simbólico de los funcionarios, y, en menor medida que en el caso de los asalariados, requería de actividad manual; que, no obstante, podía estar presente, dada la inferior condición de sus titulares. A éstos los vamos a denominar como "oficiales". Empleados de menor rango, pero que todavía desempeñaron labores de cierta entidad de carácter organizativo. Actividades cuyo salario todavía permitía a sus titulares mantener una condición desahogada. Dentro de esta categoría se incluirían los tenientes o delegados de los oficios más principales, de cuyo desempeño directo, o de las partes más burdas del mismo, se solían desentender generalmente sus titulares, confiándolo a estos sirvientes de segundo rango, directamente dependientes de ellos.

Este de "oficial" es el término más común empleado por los historiadores para referirse de manera genérica a los servidores reales y principescos, al conjunto de personas relacionadas con la casa u hotel, no en vano es el más usado en la época por los contemporáneos y, por tanto, el que más aparece en la documentación con relación a las personas que desempeñaban un "oficio" o "cargo" 5

El nombramiento de delegados o lugartenientes que sustituyesen a los titulares de los oficios, en principio, se hizo a voluntad de los mismos sin limitaciones, aunque luego, sobre todo en los oficios con jurisdicción, el rey se reservó la facultad de supervisar al delegado, de prohibir la delegación o de nombrar al mismo, concediendo así a unos la dignidad y a otros el desempeño del cargo. En este sentido habría que distinguir entre delegación y sustitución, temporal la primera y permanente la segunda, a modo de usufructuario o arrendatario del oficio. En la casa del príncipe, en algunos casos se dieron delegaciones temporales del oficio en otras personas cuando el titular, generalmente por su importancia o dignidad, no podía estar presente de continuo; delegación de la actividad, que no del puesto, que se hacía provisionalmente en otro funcionario u oficial de la Casa. Asimismo existieron lugartenientes que más que sustituir en el cargo al titular desempeñaron algunas de sus funciones bajo sus órdenes, las de carácter más grosero, sin que se aprecien delegaciones de carácter permanente, que más pudieron estar relacionadas con los oficios de la Corte que con los de la Casa, pues en el segundo caso el desempeño directo del cargo aseguraba un contacto casi cotidiano con el monarca, o en este caso con el heredero, con las ventajas que ello reportaba ${ }^{6}$.

Entre los oficiales más destacados encontramos a los lugartenientes de los jefes de las principales áreas de la casa, a algunos de estos jefes, como el cerero mayor, caballerizo mayor o cocinero mayor, que no tuvieron tanta relevancia como los anteriores, y toda suerte de empleados intermedios que

${ }^{5}$ E. GONZÁLEZ, Un Prince en su Hôtel. Les serviteurs des ducs d'Orleans au XVe siècle, Paris, 2004, pp. 51-58.

${ }^{6} \mathrm{~J}$. DE SAlAZAR Y ACHA, La casa del rey, pp. 117-120. 
destacan por sus puestos, trinchante, copero, repostero, etc., o por la habilidad técnica de su labor, como capellanes y médicos.

Asalariados. Finalmente, a aquellos sirvientes que trabajaron con sus manos para el príncipe, a las órdenes de los funcionarios y oficiales, encargados de las labores propias de la atención de su persona, casa, invitados y resto de domésticos, y por ello de condición humilde, les vamos a llamar simplemente "asalariados". Pues, si todos los servidores de la casa del príncipe percibieron un salario o quitación, los funcionarios y también los oficiales ocuparon dichos puestos además por el prestigio y las influencias que se derivaban de los mismos, mientras que los meros sirvientes lo hicieron básicamente a cambio de una remuneración. Este último escalafón lo ocuparon los simples mozos o peones, que raramente eran de origen noble, con salarios y raciones también de poca importancia. Se trató de los más bajos de los sirvientes domésticos, quienes, a modo de operarios dependientes de las categorías superiores de servidores, realizaban las tareas manuales o las partes más pesadas y burdas de las mismas.

\section{LOS SALARIOS}

El salario de los servidores varió en función de su calidad, como a continuación veremos, siendo los emolumentos del personal, dentro de los gastos de la casa principesca, una de las principales partidas, tanto por el volumen de algunos sueldos como por la cantidad de empleados que trabajaron al servicio de la misma.

\subsection{El responsable de los pagos}

Los pagos de los salarios del personal al servicio del heredero corrieron a cargo del secretario de la reina, Francisco Ramírez de Madrid, aunque, en teoría, debía haber sido el contador mayor de la despensa y raciones su responsable. Y por tanto, de llevar los libros donde estaban anotados los servidores de la casa del príncipe. Nóminas en las que constaban además de sus nombres, oficios y funciones, sus respectivos salarios, en forma de quitaciones y raciones. Una vez nombrado un nuevo servidor, el albalá original de su nombramiento, mandado redactar por el secretario del heredero o de la reina, y firmado por este último, era llevado ante el mayordomo mayor y el contador mayor de la despensa para que asentasen al nuevo servidor en los libros de raciones y quitaciones de la casa, en poder de ambos. Tras ser asentado dicho nombramiento y la ración y quitación correspondientes, era devuelto el albalá original al interesado, a modo de credencial de su nombramiento, a la que se había añadido una nota dando 
constancia del mencionado asiento, firmada del puño del mayordomo y del contador mayores, o de sus lugartenientes, en su caso ${ }^{7}$.

Al pago de los salarios se procedería de la siguiente forma: los funcionarios, oficiales y asalariados, una vez recibida su quitación anual, o trimestral, o su ración en dinero, semanal o diaria, únicamente firmaban un recibo que quedaba en poder del pagador, el mencionado secretario de la reina. Quien anualmente daba cuenta de su gestión a la persona de la que recibía los fondos con los que hacer frente a los pagos, el contador mayor del príncipe, presentando para ello los correspondientes recibos de los servidores ${ }^{8}$. Las raciones en comida, o en bienes de similar valor, recibidas de la despensa por parte de algunos servidores no requerirían de recibo alguno; cosa diferente sería el caso de las raciones en vestidos, zapatos u otros objetos de valor, recibidas de la despensa o de la cámara, que sí se hicieron contra la firma de recibos con los que justificar por los titulares de estas áreas el destino de los mismos.

Si los servidores del príncipe se encontraban escasos de recursos para cubrir sus necesidades personales y no podían esperar a recibir sus emolumentos anuales o trimestrales para atender a las mismas, podían recurrir a la solicitud de préstamos, bien a cambistas y banqueros particulares, o bien preferentemente al banquero de la reina, quien no tendría gran inconveniente en prestar las sumas solicitadas, que quedaban garantizadas por las quitaciones de dichos sirvientes. Se trató de un banco de corte de carácter privado al que acudían los servidores de la casa real además de a solicitar créditos a realizar depósitos, para lo que abrían cuentas corrientes.

Igualmente, si el tesorero real andaba escaso de fondos para pagar las cuentas de la casa de la reina, o de sus hijos, ésta podía remitir a los acreedores a dicho banco privado, para salir de forma momentánea del aprieto mientras se resolvía la falta de liquidez ${ }^{9}$.

${ }^{7}$ Tal y como ocurrió con un nuevo repostero de camas, Luis de Legazpi, y con el portero de cadena Juan de Aguilar, nombrados en 1496 (R. PÉREZ BUSTAMANTE y J.M. CALDERÓN ORTEGA, Colección diplomática del Príncipe don Juan, Madrid, 1999, pp. 189-194).

${ }^{8} \mathrm{Se}$ han conservado numẹrosos de estos recibos, pero en su mayor parte no corresponden a los pagos de los salarios propiamente dichos, sino al abono de los retrasos habidos en los mismos. Tal fue la cantidad de deudas e impagados de la casa real, y de la del príncipe, que la reina destinó una sección especial de su tesoro y un tesorero específico para hacerse cargo de los mismos, ya se tratase de salarios, como de bienes y servicios. Se trata de la sección de Descargos de la casa real, que en el caso de la reina incluía también a sus hijos y nietos. Descargos que en algunos casos eran pagados con varios años de retraso, contra la firma de los correspondientes recibos por parte de los beneficiarios, una vez que el tesorero recibía de la reina la orden de pago y tras ser comprobada la veracidad de la deuda (A. PRIETO Y CANTERO, Casa y Descargos de los Reyes Católicos, Valladolid, 1969). De forma similar se procedía al pago de los salarios en la corte ducal de los Orleans (E. GonZÁLEZ, Un Prince, pp. 110-121).

${ }^{9} \mathrm{Se}$ ha conservado el libro mayor de uno de los banqueros de Isabel I, el cual comienza en 1498, una vez muerto el príncipe, aunque en el mismo se contienen algunos de los servidores que trabajaron para él, que luego pasaron a la casa de la reina, de ahí que aparezcan en dicho libro de contabilidad ( $\mathrm{F}$. RUIZ MARTÍN y A. REPRESA RODRÍGUEZ, Libro mayor del "Banquero de Corte" de los Reyes Católicos (1498-1500), Bilbao, 1980, pp. 20-21; F. RưIZ MARTín, Demanda y oferta bancarias (1450-1600), "Histoire économique du monde méditerranéen 1450-1650: Mélanges en l'honneur de Fernand Braudel", Toulouse, 1973, pp. 525-526). 


\subsection{Quitaciones y raciones}

En cuanto a la retribución de los oficios de la corte y casa del príncipe, existieron cuatro tipos de remuneraciones: dinero, alimentos, alojamiento y regalos en forma de bienes. Aquí, como ha sido dicho, nos vamos a ocupar de los dos primeros.

El salario, sueldo o quitación se cobraba de forma anual, a veces por tercios del año, aunque no era la única retribución de los oficiales. Cuyos puestos, en ocasiones, llevaban anexas porciones o alícuotas de las rentas que administraban. Junto a estas quitaciones y aranceles, los oficiales tenían ingresos complementarios denominados ayudas de costa, para sufragar su alimentación y vestido, o sus gastos extraordinarios, como bodas. Estas ayudas pasaron a veces de ser complementarias y extraordinarias a inherentes al oficio, en forma de raciones, que se concretaron en entregas de comida o manutención, aposentamiento y percepción de cera, vestidos u otros bienes materiales precisos para la vida cotidiana. A veces las raciones en lugar de en especie fueron cobradas diariamente en dinero de la despensa o cámara reales. Si bien se rechaza que las quitaciones tuviesen una naturaleza pública y las raciones otra privada, algunos autores consideran que la ración provenía de la despensa real asimilada a una especie de manutención diaria del oficial, o especie de paga por los servicios continuos y actuales, frente a la quitación que era un sueldo percibido por el hecho de ser un oficial sin más. De ahí que ambas se pudiesen cobrar simultáneamente, o que los mismos oficiales unos cobrasen ración y otros quitación. Para otros autores, la diferencia entre quitación y ración no estaba en función de que la primera se pagase por el puesto y la segunda por un servicio concreto, sino en su periodicidad, anual o trimestral la primera, diaria o semanal la segunda. Con el tiempo, puede que algunas raciones quedasen subsumidas dentro de las quitaciones y se cobrase el sueldo de una sola vez, juntas quitación y raciones. Por norma general, todos los practicantes de un mismo oficio cobraban el mismo sueldo, salvo excepciones ${ }^{10}$.

Como veremos, casi todos los servidores del príncipe percibieron ambas formas de salario, aunque podemos apuntar que la ración solamente la cobraron cuando trabajaban de forma efectiva para el mismo, pues algunos oficiales que percibían por su puesto una quitación anual y únicamente trabajan de forma temporal u ocasional para éste, sólo durante ese período de tiempo efectivo recibirían su ración. Caso de los monteros de Espinosa, que lo hacían en períodos de 6 meses; de los maestresala, que se turnaban por semanas; o de los oficiales mayores, que, al ser sustituidos por tenientes en sus labores, probablemente percibiesen su quitación anual, pero solamente sus raciones durante el tiempo efectivo al servicio del príncipe, ya que las mismas irían a parar a sus lugartenientes cuando los sustituyesen.

${ }^{10} \mathrm{D}$. TORRES SANZ, La administración, p. 68; J. DE SALAZAR Y ACHA, La casa del rey, pp. 123-124; M.C. GONZÁLEZ MARRERO, La Casa de Isabel la Católica. Espacios domésticos y vida cotidiana, Avila, 2005, pp. 43-47. 
A diferencia de los gastos en bienes, que se presupuestaban por adelantado para ser pagados al poco tiempo de la compra a los suministradores, las quitaciones o salarios de los servidores se abonaban a posteriori, una vez terminado el año. Aunque previamente dichos servidores hubiesen recibido a lo largo de la anualidad, en diversas ocasiones o plazos, raciones para su mantenimiento, en forma de dinero, comida o bienes; las cuales, si se trataba de adelantos, se descontaban luego del salario o quitación. En algunos casos, como luego veremos, es posible saber a cuánto ascendían las quitaciones y raciones anuales para algunos oficios, diferenciándolas entre ellas.

En la casa real castellana, para la cámara, despensa, caballeriza, acemilería y otros servicios destinados al sostenimiento personal del monarca, solía reservarse un $10 \%$ del total de los arrendamientos de las rentas de la Hacienda, era el llamado "diezmo de la cámara". Otra partida diferente la constituían las raciones cobradas, en teoría diariamente, por los servidores de los oficios de la casa del rey, que, como en origen eran privados, en parte las mismas se solían librar también del dinero de la cámara real. En el pago de estas raciones actuaban los delegados del despensero y mayordomo mayores, así como un contador, que cobraba el $2 \%$ de arancel como salario. Las quitaciones, otra de las partidas, eran cobradas una o varias veces al año por los empleados de la corte y de otros organismos públicos de la monarquía de carácter no militar, tales como los del Consejo Real, la Audiencia, las Contadurías, la Cancillería y los "continos", o personas que servían permanentemente a los reyes en las más diversas misiones. Los sueldos percibidos por las gentes de armas al servicio del rey constituían otra partida diferente $e^{11}$.

Se han conservado varias nóminas mediante las que la reina Isabel ordenó pagar sus salarios (raciones y quitaciones) a los oficiales de su casa, y de las de sus hijos mientras estuvieron incluidas en la misma. La primera

${ }^{11}$ M.A. LADERO QUESADA, La Hacienda Real en Castilla en el siglo XV, La Laguna, 1973, pp. 52-53. Sobre el numero de oficiales de los Reyes Católicos y su retribución, M.A. LADERO OUESADA, Casa y Corte. L'Hotel du roi et la Cor comme institutions économiques au temps des Rois Catholiques (1480-1504), en M. Aymard et M.A. Romani (dirs.), La cour comme institution économique, Douzieme congés international d'histoire économique, Sevilla, 1998, p. 47 y ss. Ver También, A. PRIETO CANTERO, Casa y Descargos; A. DE LA TORRE Y DEL CERRO, La Casa de Isabel la Católica, Madrid, 1954; A. DE LA TORRE Y DEL CERRO y E.A. DE LA TORRE, Cuentas de Gonzalo de Baeza, tesorero de Isabel la Católica, Madrid, 2 vols, 1955-1956; F. RUIZ MARTÍN y A. REPRESA RODRÍGUEZ, Libro mayor; y F. LLANOS Y TORRIGLIA, En el hogar de los Reyes Católicos, Madrid, 1946. En Navarra, los servidores reales percibían dos tipos de emolumentos, los "gajes" o salario que cada empleado recibía diariamente por su trabajo, aquí se incluirían también las dietas o indemnizaciones pagadạs por servicios especiales, como viajes; y las "pensiones", cantidad fija, por lo general anual, asignada para el mantenimiento del estado del oficial del que se tratase (M. NARBONA CÁCERES, La corte de Carlos III el Noble, rey de Navarra: espacio doméstico y escenario del poder, 1376-1415, Pamplona, 2006, p. 137). En este sentido, los gajes se corresponderían con las raciones castellanas, al igual que las pensiones con las quitaciones. En Navarra también se pagaron donos o regalos en metálico o en especie, que se corresponden con las ayudas de costa castellanas. En la corte de los Orleans, los "gajes" eran la remuneración pagada por los servicios prestados para el mantenimiento del oficial, mientras que el "salario" eran los gajes recibidos por los oficiales menores ligados a labores manuales, a los que nosotros hemos dado en llamar "asalariados"; por su parte, la "pensión" era una gratificación distintiva, recibida además de los gajes por los miembros más eminentes del hotel. A estas remuneraciones hay que añadir las "Tibreas", o recepción de vestimentas, las "livraisions" o recepción de comidas, los "dons", o suplementos, y el reembolso de gastos diversos (E. GONZÁleZ, Un Prince, pp. 103-105). 
en la que se contienen servidores del príncipe corresponde a 1487, cuando apenas contaba con 9 años y ya sus oficiales aparecen diferenciados de los restantes. Entre los años 1487-1495 la reina mandó a su secretario y despensero mayor de las raciones de su casa, Francisco Ramírez de Madrid, que pagase las raciones de los oficiales de la misma, de la de su hijo, el príncipe Juan, de los de su hija Isabel, la princesa de Portugal, de sus otras hijas, Juana, Catalina y María, así como en 1495 también de la archiduquesa de Austria, la reciente esposa por poderes del príncipe, la princesa Margari$\mathrm{ta}^{12}$. En la tabla 1 se recogen aquéllos que explícitamente son referidos al

${ }^{12}$ En 1487 fueron pagados por Francisco Ramírez de Madrid a los oficiales de la reina y sus hijos, se dice que por sus raciones, aunque sería el sueldo anual (raciones y quitaciones), un total de 2.798.686mrs., en tercios anuales, en presencia del comendador Gonzalo Chacón, mayordomo y contador mayor de la reina, y del adelantado del reino de Murcia, Juan Chacón, contador mayor de la despensa y raciones de la casa de la misma, así como de sus lugartenientes y oficiales en sus oficios; sin que debiese de tomar de los oficiales más que una fe, con la cual, y con esta nómina, la reina ordenaba a sus contadores mayores que le fuesen recibidos al secretario Francisco Ramírez de Madrid dichos sueldos y pasados en cuenta. Dicho secretario y despensero recibiría por salario de su trabajo $150.000 \mathrm{mrs}$., a razón de 50mrs. por millar, del total de los 3 millones que le fueron entregados para pagar los citados sueldos; por lo que tenían que serle recibidos en cuenta 2.958.786mrs. En 1488 los salarios de los oficiales montaron 2.840.226; las condiciones y el salario del secretario fueron los antedichos, y también su sueldo; por lo que el total ascendió a 2.990.226. Si el primer año y el segundo las nọminas aparecen completas, del tercero, 1489, se han conservado dos nóminas, posiblemente incompletas, con solamente una parte de los salarios del mismo. Por la primera (1489a) la reina mandó pagar a Francisco Ramírez apenas $568.800 \mathrm{mrs}$., con destino a los oficiales de la misma y de sus hijos, los cuales le mandó librar a Francisco de Pinedo; el total de los salarios fue de $549.180 \mathrm{mrs}$., por lo que el sueldo del secretario ascendió a $28.900 \mathrm{mrs}$., y las condiciones, las antedichas. Mientras que la segunda (1489b), también incompleta, no contiene el albalá de la reina ni el monto total de la nómina; y termina con una serie de oficiales de la casa de la misma y del príncipe a los que se adeudaban parte de sus salarios de 1493. De nuevo, en 1490, le fueron librados al secretario 3 millones de maravedís, 2.800 .000 para las raciones y quitaciones por tercios anuales; el resto, 150.000mrs., para su salario, hasta completar, en números redondos, los 3 millones iniciales. Para el siguiente año, 1491, fueron librados $3.200 .000 \mathrm{mrs}$., pero esta nómina está también incompleta. Eñ 1492, otros 3 millones; 2.930.164 para los salarios y 69.836 de quitación para el secretario. Esa anualidad se ve que quedaron algunos oficiales por ser pagados, por lo que la reina mandó a los contadores mayores que de los 3 millones librados le fuesen tomados en cuenta los contenidos en una nueva nómina de sus oficiales y de la casa de sus hijos; en la cual, por lo que respecta al príncipe, solamente se recogen dos, Juan de Villoria, el tenedor de la tapicería (que ya aparecía en la otra nómina) y un repostero de camas, Cosme de Vallejo. Al año siguiente, 1493, se gastaron 3,5 millones; 3.419 .983 para salarios y 80.017 como sueldo del secretario. En 1494, $3.700 .000 ; 3.641 .800$ para los sueldos y 58.200 para el secretario. Del año siguiente, 1495, se conservan de nuevo dos nóminas. En la primera (1495a) no se pagaron completos los salarios de todos los oficiales del príncipe, porque éste estaba en trance de emanciparse y establecer casa propia, por ello en el epígrafe correspondiente de la nómina no pone "oficios del príncipe", como en las anteriores, sino "oficios de la casa". En ella aparecen por vez primera los oficiales de la archiduquesa Margarita, que ese año se casó por poderes con el príncipe, y a la que su suegra comenzo a prepararle casa y sirvientes propios en espera de su venida a España. En total fueron $2.084 .074 \mathrm{mrs}$. . en salarios, más 59.681mrs. para el secretario, 41.681 de su ración (a razón del $2 \%$ de lo pagado), y los otros 18.000 de quitación; lo que hacía un total de $2.143 .745 \mathrm{mrs}$., con las condiciones antedichas. La segunda nomina de 1495 (1495b) fue dada en febrero de 1496 , cuạndo la reina ordenó a su tesorero, Juan de Morales, el pago de las raciones (más bien quitaciones) de sus oficiales correspondientes al referido año P495. O mejor dicho, que se terminase de pagar lo que se les adeudaba. Como se puede ver en la tabla 1, hasta 1494 los oficiales al servicio del príncipe estuvieron incluidos en la casa de la reina, pero en 1495, al producirse la emancipación del mismo, se debió proceder a la segregación de sus oficiales de los de la casa de la misma. Sin embargo, todavía ésta corrió con el pago de los salarios de la casa de su hijo durante 1495, con cargo a sus rentas, por lo que ordenó completar los adeudados y no pagados mediante la primera nomina. En total, fueron $1.096 .698 \mathrm{mrs}$. los que montaron el remate de dichas quitaciones, que habían sido adelantados por el tesorero de lo extraordinario, Alonso de Morales, para ser pagados por otro tesorero de la reina, Ruy López de Toledo, en presencia del secretario y despensero mayor de la misma, Francisco Ramírez de Madrid, sin tomar carta de pago de los sirvientes, salvo una fe del citado secretario de cómo habían sido pagadas las mismas (Archivo General de Simancas, Casa y Sitios Reales, leg. 46, fols. 1-4, 147-150, 158, 191-201; leg. 43, fols. 18, 19, 24, 49, 51, 61, 72; R. PEREZ BUSTAMANTE y J.M. CALDERÓN 
servicio del heredero, o que se deduce que para él trabajaban. Los datos de la misma se resumen en los gráficos 1 y 2 .

Como se aprecia en el gráfico 1 , y como resulta lógico a priori, conforme avanzamos en el tiempo el número de oficiales al servicio del heredero se vio multiplicado, así como también, por tanto, los gastos destinados a los mismos. Debido a que al ganar en edad el príncipe igualmente lo hizo en funciones $y$, por ese motivo, con ellas se vieron incrementadas sus necesidades. Por lo que también hubo de ganar, por ello, en servidores que atendiesen esas funciones y necesidades crecientes. De manera que en vísperas de su emancipación la casa de don Juan ya tenía una estructura compleja, similar por la cantidad y variedad del número de sus oficiales a la de cualquier corte real europea, o al menos a las de otros príncipes herederos, en las cuales oscilaba entre los 200 y 400 sirvientes $^{13}$. Sobre todo si a los 192 sirvientes de 1495 le sumamos otros 17 que atendieron la casa de la princesa Margarita (cuya retribución ascendió a $63.321 \mathrm{mrs}$. en total); otro buen número de servidores de alto rango, como el mayordomo, maestresala, ayo, maestros, acompañantes y otros que no figuran en las nóminas arriba vistas; algún que otro oficio menor de carácter más ocasional, como gallinero, joyero o sombrero, que tampoco están; o los numerosos oficios administrativos del Consejo o de la Hacienda, como secretarios, letrados, contadores, despensero, etc., que prácticamente tampoco están recogidos. De esta manera, el número de servidores de la casa y corte podría rondar el primer año de la emancipación del heredero los 250 , cantidad que hubo de incrementarse al siguiente, 1496, el primero de independencia efectiva cuando el mismo contrató por su cuenta a nuevos sirvientes además de los que ya contaba cuando su casa estaba incluida en la de la reina.

De esta forma, la cantidad de maravedís a que ascendió cada año el total de lo gastado en los sueldos de las personas al servicio del heredero sería muy superior a lo expresado en el gráfico 2, pues, además de incluir los oficiales antedichos, así como otros dedicados a la seguridad del mismo que

ORTEGA, Colección diplomática, pp. 120-127). En algunos casos, como en la nómina de 1487, se especifica que los pagos se hacen en concepto de ración; en otros de quitación; en alguna ocasión se aclara que se pagaba junta la ración, o quitación, más una ayuda de costa, como para el camarero, y el aposentador Pedro de Salazar, en 1487, o para el bordador, en 1490; otras veces se trata no de pagos completos, sino de porcentajes correspondientes al tiempo trabajado durante cada año, en cuyo caso se ha calculado el total anual y no se ha recogido lo efectivamente pagado, șino dicho total; otras veces se contienen pagos de atrasos de años anteriores, que aquil hemos incluido en cadạ total anual. Para otras nóminas de salarios de servidores reales, caso de los de padre del príncipe, Fernando el Católico, cuando éste era todavía infante de Aragón, M. GUAL CAMARENA, Servidores del infante don Fernando (1458-1462), "Estudios de Edad Media de la Corona de Áragón", VI (1956).

${ }^{13}$ A. FERNÁNDEZ DE CÓRDOVA MIRALLES, La Corte de Isabel I. Ritos y ceremonias de una reina (1474-1450), Madrid, 2002, p. 138. Los servidores de la casa de la reina Isabel oscilaron en torno a los 300-400 entre 1489 y 1497 (M.C. GONZÁLEZ MARRERO, La Casa de Isabel, p. 40). Hacia finales del siglo XIV en una de las principales casas nobiliarias de la Corona de Aragón, la del conde de Denia y marqués de Villena, sirvieron entre 90-145 personas, también de diferente extracción social según el puesto ocupado: nobles al frente de los oficios principales, baja nobleza a cargo de los intermedios y gentes corrientes en los restantes (J. SÁIZ SERRANO, Una clientela militar entre la Corona de Aragón y Castilla a fines del siglo XI: caballeros de casa y vasallos de Alfons d'Aragó, conde de Denia y marqués de Villena, "En la España Medieval", 29 (2006), p. 103 y ss.). 
no se recogen, tales como monteros de Espinosa y compañías de soldados, habría que añadir las raciones y las ayudas de costa recibidas por sus servidores. Que en algunos casos fueron muy importantes, como se comprueba en la tabla 3. Que ha sido incluida a modo de comparación, para poder comprobar cómo, en algunas ocasiones, las ayuda de costa se aproximaron a las retribuciones ordinarias. Como por ejemplo con el ayo, Sancho de Castilla, cuyo salario ordinario, el más abultado de toda la casa, era de $200.000 \mathrm{mrs}$., mientras que las ayudas de costa recibidas, casi de forma habitual, oscilaron entre los 90.000-100.000 anuales, esto es, supusieron el $50 \%$ del mismo. Un caso parecido fue el del maestro, Diego de Deza, con un salario de $100.000 \mathrm{mrs}$. y ayudas de costa de entre 10.000-30.000, de casi un tercio del mismo, por tanto. Como vemos, estas mercedes extraordinarias en dinero fueron otorgadas de manera arbitraria, atendiendo más a la persona, según la simpatía que por ella profesaban la reina o su hijo, que al puesto que desempeñaba. También dependieron de las circunstancias del momento, por lo que variaron en el tiempo. En todo caso, carecemos de suficientes datos acerca de las mismas como para hacer una valoración sobre su importancia en el volumen de ingresos totales de los servidores de la casa. Que recordemos, además de estas ayudas extraordinarias en dinero, recibieron también otras en forma de bienes materiales, algunos percibidos de manera más o menos habitual; caso de las libreas de los cazadores, en cuya confección, en 1495, fueron empleados $120.725 \mathrm{mrs}$.

Por lo que respecta a la distribución cualitativa de los servidores, si seguimos la hecha por las propias nóminas por áreas de actividad, en 1495 tendríamos la recogida en el gráfico 3. Mientras que el gasto en salarios se distribuiría según el gráfico 4. Hay que aclarar que la distribución de los sirvientes de la casa hecha por las nóminas no atiende a una estructuración coherente de la misma, sino que, como se ve, simplemente se agrupan algunos de ellos más numerosos según el oficio que desempeñaron, apareciendo los restantes recogidos en un apartado genérico al que he denominado como "oficios diversos". Para una estructuración jerarquizada de la casa por áreas de actividad véase el gráfico 5 y el apartado siguiente.

\subsection{Análisis comparativo}

A partir de la documentación manejada para el estudio de la casa del príncipe, se puede reconstruir la relación de todos, o la mayor parte, de los funcionarios, oficiales y asalariados que sirvieron en la misma, así como, en algunos casos, los salarios en metálico, quitaciones, y en especie, raciones, que correspondían al puesto desempeñado de forma genérica, o los que cobró de forma efectiva cada servidor (tabla 2). Se trata de casi 700 nombres de "familiares" del heredero que a lo largo de sus 19 años de vida estuvieron a su servicio. Hay que aclarar que en realidad fueron algunos menos, pues alguno de ellos trabajó en más de un puesto durante ese período.

El gráfico 5 nos muestra que las áreas de la casa con mayor número de servidores fueron, como resulta lógico, la Casa Exterior y la Casa Interior, 
y, a gran distancia, la Corte, cuyo Consejo estuvo encargado del gobierno de los territorios patrimoniales del príncipe, aunque apenas tuvo cometidos, por tratarse de un heredero que murió al poco de su emancipación y no de un monarca en activo. También se ha desgajado en un área diferenciada la Administración de la Hacienda, con una única sección, la despensa, que situamos a medio camino entre la Corte y la Casa, con 20 servidores a lo largo del período.

Dentro de la Casa Exterior, u oficios que, dentro de la Casa servían de puertas afuera o en el ámbito más público de la misma, lo que también se puede entender como la sala, los más de 400 oficiales que sirvieron al príncipe a lo largo de su existencia se dedicaron a atender sobre todo la sección de aparato (209), o sala propiamente dicha (reposteros de estrados, de plata, trinchantes...); le siguieron en importancia las secciones de seguridad (101), caballerizas (52) y caza (34). Dentro del área de la Casa Interior, o estancias en torno a la cámara, con más de 200 servidores, destacan las secciones de la propia cámara (109), la capilla (77) y la educación (23). Las lagunas existentes en la documentación no nos permiten concretar más, y analizar la evolución de las áreas y secciones a lo largo del tiempo, pero no debió de diferir mucho de la distribución aquí esbozada. Aunque es cierto que el mayor número de servidores en un área o sección a lo largo de todo el período de la vida del heredero se puede deber a dos causas, que prestasen efectivamente servicio en las mismas mayor cantidad de oficiales, o bien que se diese en ellas una mayor rotación de éstos, o lo que es lo mismo, que dichos oficiales sirviesen por poco tiempo siendo sustituidos por otros.

De esta forma, la distribución porcentual de los oficiales del heredero por áreas de su casa contemplada en el gráfico 6 es simplemente aproximada. En el cual, en buena medida, el mayor peso de la Casa Exterior se debe al alto número de pajes que sirvieron a don Juan. Algo natural en la casa de un niñoadolescente, al que se quería preparar para sus futuras funciones políticas rodeándolo de los hijos de los personajes más poderosos del reino, e incluso de las cortes vecinas, a modo de pajes. Los cuales, por tanto, generalmente estuvieron presentes en la corte sólo puntual y circunstancialmente, de ahí el elevado número de ellos que pasó por la misma.

Por lo que respecta a la valoración de los salarios, éstos nos pueden indicar el nivel de consideración en el que se encontraba cada oficio, a mayor remuneración, en principio, habría que atribuirle mayor importancia. En términos generales, como antes he indicado, los servidores que desempeñaron un mismo puesto percibieron la misma retribución, aunque con matizaciones. La quitación solía ser la misma, aunque se puede ver a algunos sirvientes percibirla crecida por haber gozado del favoritismo de la familia real o por haber prestado servicios extraordinarios. Que más bien se retribuyeron mediante las raciones, que podían ser más variables que las quitaciones, en función de dichos servicios extraordinarios o de la temporalidad de los ordinarios. Otra forma de retribución extraordinaria con la que premiar las labores especiales fueron las ayudas de costa o los pagos en especie, que no estudiaremos, lo que hizo que no fuese imprescindible romper la unidad del 
salario para una misma categoría de servidores cuando se quería premiar a uno de ellos.

El mayor de todos los oficios fue el de ayo del príncipe, el más importante en retribución, que hay que situarlo, por tanto, a la cabeza de los funcionarios, con una ración y quitación anuales de $200.000 \mathrm{mrs}$; que en algunas anualidades fueron aumentados con otros 100.000 extra en forma de ayuda de costa, como hemos visto. En total 300.000mrs. anuales en un solo salario, que venían a ser equivalentes a los gastos de la caballeriza, de la cerería o de la acemilería del año 1491, o a la sexta parte de todos los salarios de los oficiales que vimos se desembolsaron en la nómina de 1495, que no incluía sin embargo a estos funcionarios de primera fila. He aquí el valor que los Reyes otorgaron a la formación de la persona de su hijo. De los restantes grandes funcionarios no conocemos sus emolumentos en todos los casos, pero se puede apuntar que tras el ayo, situado claramente a la cabeza de los mismos por su salario, había luego un primer nivel ocupado por aquéllos más importantes que percibieron en torno a los $100.000 \mathrm{mrs}$., la mitad que el ayo; tales fueron el ama de cría, el contador mayor, el maestro, el maestresala y posiblemente el mayordomo mayor. Un segundo nivel de importancia, por recibir un salario que era la mitad que el de los anteriores, lo ocuparon otros oficios mayores retribuidos sobre los 50.000mrs., como los secretarios del Consejo o el camarero mayor. Por último, dentro de los grandes funcionarios, por sueldo estaban los que percibieron entre los 20.000-30.000mrs., caso del cazador mayor o del maestro de capilla. Si el poder adquisitivo del ayo venía a ser equivalente al gasto de importantes áreas de la casa de don Juan como la caballeriza o la acemilería, los $100.000 \mathrm{mrs}$. del primer nivel de funcionarios les permitían apenas adquirir, por ejemplo, la quinta parte de las telas compradas por el príncipe en 1495 para su vestuario personal, sin contar los textiles empleados en otros fines, que ascendieron a más de medio millón de maravedís. Con un salario de $50.000 \mathrm{mrs}$., como el de los funcionarios de segundo rango se podían adquirir algunas de las chaperías menos caras que se encontraban entre las joyas del heredero (pues otras llegaron a costar $80.000 \mathrm{mrs}$.), un sayo de brocado como el que se le hizo en 1494 (por más de $52.000 \mathrm{mrs}$.) o un caparazón para una silla de montar, como el confeccionado en 1494 en brocado (que costó más de 56.000). Los funcionarios peor pagados apenas podían aspirar a adquirir una loba como la que se le cosió a don Juan en 1495, con unas 11,5 varas de velludo bellotado (por casi $30.000 \mathrm{mrs}$.), las mantelerías y cuberterías que anualmente compraba el copero para el servicio de mesa (25.000mrs.), o un caballo, como el comprado al heredero en 1493 (por 20.000).

Tras los funcionarios, los oficiales mejor pagados lo fueron con unos 18.000-15.000mrs. Dentro de esta primera categoría se encontraron los reposteros de plata, oficio de tal importancia, similar en salario a la última categoría de los funcionarios, que contó incluso con un teniente para su desarrollo efectivo; así como los cocineros mayores, que también recibieron la ayuda de numerosos cocineros secundarios; en este nivel se sitúan también el camarero de la tapicería y algunos cazadores menores, mientras que otros, 
en función de su habilidad, cobrarían por debajo de los 10.000mrs. En un segundo nivel de oficiales se encontraban aquéllos que percibieron sobre los $10.000 \mathrm{mrs}$. anuales, caso del copero, los reposteros de camas, los pajes, los ballesteros de maza, los monteros de Espinosa y los mozos de cámara. En un tercero, los hubo que recibieron en torno a los 6.000 o menos, caso de los reposteros de estrados, los porteros y los escuderos de pie. Los oficiales mejor pagados podían comprarse con su sueldo anual las sábanas destinadas a la cámara del heredero, que en 1494 costaron unos 14.000mrs., o una guarnición de mula, que en 1495 costó más de 17.000 . Con $10.000 \mathrm{mrs}$. de sueldo anual, un oficial de segunda fila podía adquirir, por ejemplo, una guarnición de oro con destino a la ropa, como la que se hizo al príncipe con 19 castellanos de oro $(9.215 \mathrm{mrs}$.). Por último, con unos $6.000 \mathrm{mrs}$. apenas se podía adquirir una cama de sargas de colores, como la comprada al príncipe en 1485 (por $6.219 \mathrm{mrs}$.).

Por lo que respecta a los asalariados, los mejor remunerados gozaron de sueldos alrededor de los $9.000 \mathrm{mrs}$., como los catarriberas y el platero, o los 8.000, como el panadero; todavía por encima de esas cantidades estuvieron el barbero, el zapatero y el bordador. En un segundo nivel se encontraron otros que percibieron en torno a los $4.000 \mathrm{mrs}$. o menos. Por salario y consideración, los oficios inferiores de la casa; caso de los mozos de espuela y ballesta, los de capilla, el albéitar o herrador, el brasero y los barrenderos. Con estos $4.000 \mathrm{mrs}$., que más o menos recibieron los sirvientes peor pagados, apenas se podían costear las libreas que algunos de ellos recibieron para servir al heredero, y en algún caso ni siquiera podrían haber aspirado a pagar las golosinas que éste consumía en un año, en forma de azúcar rosada, en la que en más de una anualidad se gastaron por encima de los citados $4.000 \mathrm{mrs}$.

Si éstos son los salarios de algunos de los trabajadores mejor remunerados del reino, que apenas pudieron aspirar con sus emolumentos a la enésima parte del gasto hecho para la sola persona del heredero, mucho peor lo tuvieron los restantes trabajadores del país. Así, por ejemplo, hacia 1478, año de nacimiento del príncipe Juan, un maestro albañil en Murcia ${ }^{14}$ cobraba un jornal de $35 \mathrm{mrs}$. diarios, con un horario laboral desde el amanecer (campana de prima) hasta la noche (tras el avemaría), lo que multiplicado por 365 hace un total de $12.775 \mathrm{mrs}$. anuales; si a éstos descontamos aproximadamente un tercio, los días del año no trabajados por ser festivos, quedan unos $8.500 \mathrm{mrs}$., lo que lo sitúa a la altura de los asalariados cortesanos mejor remunerados, y en torno al doble de los peor, pero, a diferencia de estos últimos, el albañil murciano no contaba con raciones, ayudas de costa ocasionales ni alojamiento, como los cortesanos, y su oficio era de mayor complejidad técnica y exigencia física que el de éstos.

${ }^{14}$ J.D. GONZÁLEZ ARCE, Gremios, producción artesanal y mercado. Murcia, siglos XIV y XV, Murcia, 2000, p. 162. 


\section{CONCLUSIONES}

A lo largo de las páginas precedentes hemos podido ver cómo al personal que trabajó para el príncipe Juan, en su Corte y Casa, lo podemos dividir en tres grandes categorías: "funcionarios", altos cargos más bien representativos o simbólicos desempeñados por personajes de familias de la alta nobleza o de alto rango; "oficiales", o puestos de carácter organizativo ejercidos generalmente por componentes de familias de la baja nobleza; y, finalmente, "asalariados", el personal que realizó un trabajo manual directo, cuyo origen social fue modesto. Mientras que otra división, aparte de por la naturaleza del sirviente y del tipo genérico de actividad desempeñada, la podemos establecer en función de la clase de actividad concreta según el área de la Corte y Casa principescas donde fue desempeñada: Corte, o área administrativa y de gobierno de las tierras y posesiones del heredero; Administración, o área de gestión de los recursos financieros; Casa externa, donde se desarrollaron las actividades públicas y protocolarias del mismo; y, la Casa interna, donde tuvieron lugar las cotidianas y privadas.

Aparte de esta división cualitativa de los servidores, asimismo se ha realizado, en la medida de lo posible, una estimación cuantitativa de los mismos por áreas de actividad, así como general, para todo el período de existencia de la Casa del príncipe, y su evolución a lo largo del tiempo. Para ello se ha recogido nominalmente la práctica totalidad de los empleados en la misma a lo largo de los años, así como los márgenes superiores e inferiores de los salarios genéricos percibidos. También aparecen en el estudio algunas nóminas con los salarios anuales concretos de buena parte de los mismos, igualmente por áreas de actividad.

De esta forma, el objeto central de análisis sobre dichos empleados ha versado sobre la naturaleza y forma de pago de las retribuciones ordinarias, en concreto las quitaciones y raciones. Para ello han sido establecidos niveles de servidores según la cuantía de sus ingresos, ofreciendo estimaciones cuantitativas al respecto y una breve comparación con el nivel de vida, considerando al personal de la casa del príncipe un ejemplo de los trabajadores mejor pagados de la Castilla de fines del XV, además de por sus salarios ordinarios, también por otras retribuciones extraordinarias en forma de dinero o de bienes materiales, conocidas como ayudas de costa.

Fecha de recepción del artículo: marzo de 2009.

Fecha de aceptación y versión final: julio 2009. 


\begin{tabular}{|c|c|c|c|c|c|c|c|c|c|}
\hline $\mid \begin{array}{l}\overrightarrow{\hat{q}} \\
\hat{\vec{z}}\end{array}$ & 1 & i & : & 1 & $\begin{array}{l}\hat{\vec{N}} \\
\text { in }\end{array}$ & 1 & 1 & 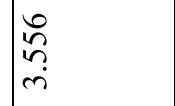 & $1:$ \\
\hline $\mid$ & 1 & 1 & 1 & 1 & $\mid \begin{array}{l}\mathscr{D} \\
\substack{0 \\
i}\end{array}$ & 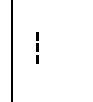 & 1 & 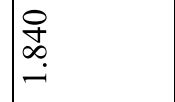 & $1: 1$ \\
\hline$\vec{t}$ & 1 & i & : & : & 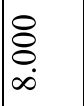 & 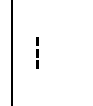 & $!$ & 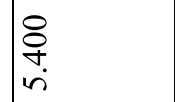 & $1:$ \\
\hline$\frac{\pi}{\tilde{\pi}}$ & 1 & i & i & 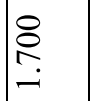 & $\overbrace{\substack{0 \\
\infty \\
\infty}}$ & 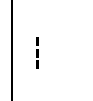 & 1 & 辛 & $1: 1$ \\
\hline 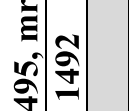 & i & i & : & ! & 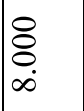 & 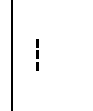 & I & $\begin{array}{l}8 \\
\text { ơ } \\
\text { in }\end{array}$ & $1:$ \\
\hline 离 & $i$ & : & ! & 1 & 1 & $\begin{array}{l}8 \\
0 \\
i \\
i n \\
n\end{array}$ & ! & $\begin{array}{l}8 \\
\vdots \\
\text { in } \\
\end{array}$ & 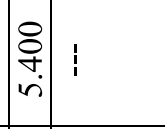 \\
\hline 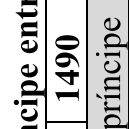 & 1 & i & : & 1 & 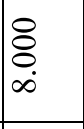 & $\begin{array}{l}8 \\
8 \\
i \\
\text { n. }\end{array}$ & i & : & 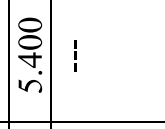 \\
\hline 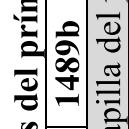 & 1 & 1 & 1 & i & 侅 & 冓 & 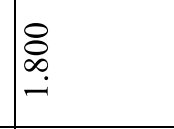 & 1 & 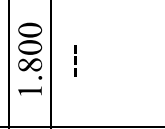 \\
\hline : & i & i & 1 & 1 & $\begin{array}{l}8 \\
\vdots \\
\infty \\
\infty\end{array}$ & 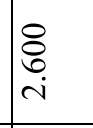 & 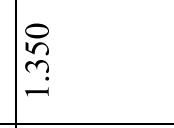 & 总 & 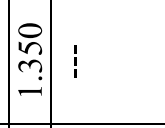 \\
\hline 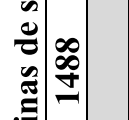 & : & ! & : & 1 & 务 & $\begin{array}{l}8 \\
\vdots \\
i \\
\text { in }\end{array}$ & 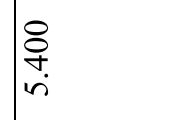 & 栄 & 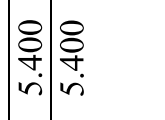 \\
\hline 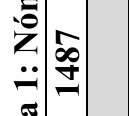 & $\mid \begin{array}{l}0 \\
0 \\
\infty \\
\infty\end{array}$ & $\begin{array}{l}8 \\
0 \\
\infty\end{array}$ & $\mid \begin{array}{l}8 \\
\vdots \\
\infty \\
\infty\end{array}$ & 1 & $\mid \begin{array}{l}8 \\
\vdots \\
\infty \\
\infty\end{array}$ & $\begin{array}{l}8 \\
\vdots \\
\vdots \\
\text { in }\end{array}$ & 辛 & 字 & 11 \\
\hline 总 & 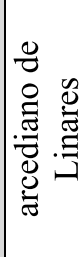 & 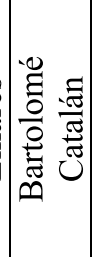 & 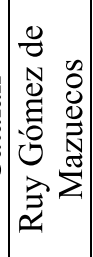 & 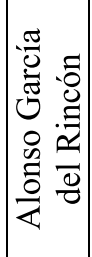 & 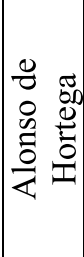 & 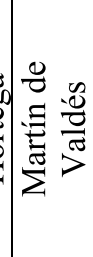 & 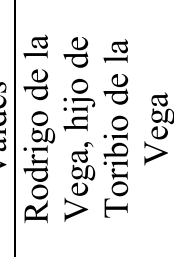 & 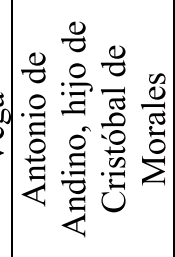 & 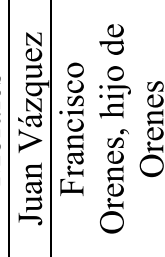 \\
\hline 昜 & 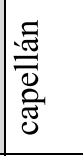 & & & & 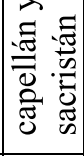 & 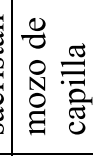 & & & \\
\hline
\end{tabular}




\begin{tabular}{|c|c|c|c|c|c|c|c|c|c|c|c|}
\hline 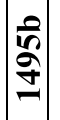 & 1 & $: \frac{8}{m}$ & 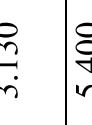 & $\mid \begin{array}{l}8 \\
\vdots \\
\vdots \\
n\end{array}$ & 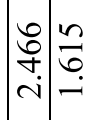 & 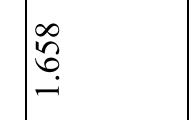 & ¿ & 各离 & 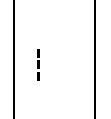 & : & : \\
\hline 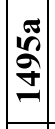 & 1 & 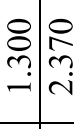 & in & 1 & 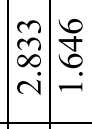 & 㐫 & 1 & $\mid$ & 1 & & 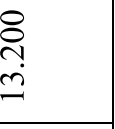 \\
\hline 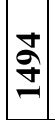 & i & 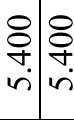 & 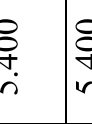 & $\begin{array}{l}8 \\
\vdots \\
\text { in }\end{array}$ & $1: 1$ & 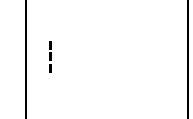 & 1 & $\mid$ & స్త్రి & & 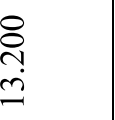 \\
\hline$\hat{\tilde{g}}$ & 1 & 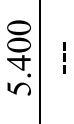 & i & 1 & $1: 1$ & 1 & 1 & 离象 & 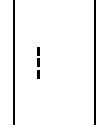 & & ته \\
\hline$\tilde{z}$ & 1 & 㝵|: & : & 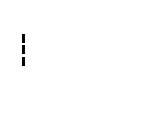 & $1: 1$ & ! & 1 & (: & 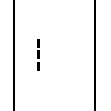 & & હે \\
\hline$\overline{\mathrm{g}}$ & 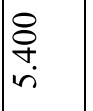 & 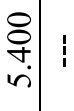 & : & 1 & $\begin{array}{l:l}1 & 1\end{array}$ & 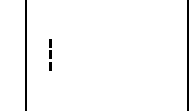 & 1 & $1: 1$ & 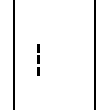 & & 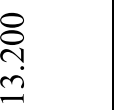 \\
\hline $\begin{array}{l}8 \\
\hat{q} \\
\end{array}$ & $\begin{array}{l}8 \\
\vdots \\
\vdots \\
n \\
n\end{array}$ & $1:$ & ! & 1 & $1:$ & 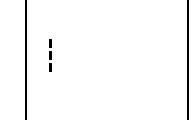 & 1 & i: 1 & 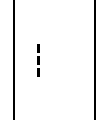 & & 空 \\
\hline $\mid$ & 1 & $::$ & ; & 1 & $1:$ & 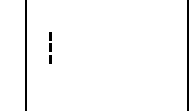 & : & i: & 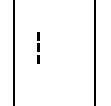 & & : \\
\hline 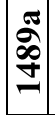 & 1 & 1 & i & 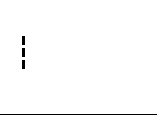 & $1: 1$ & 1 & 1 & $1: 1$ & 1 & & 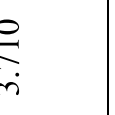 \\
\hline 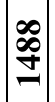 & 1 & $:$ & ; & 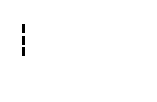 & $1:$ & 1 & 1 & $1: 1$ & 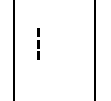 & & 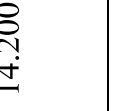 \\
\hline 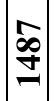 & 1 & $1:$ & ! & 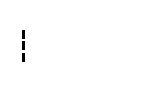 & $: 1$ & 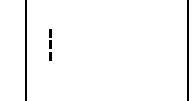 & 1 & $1: 1$ & ! & $\mid \begin{array}{l}\mid \\
\vdots \\
\vdots\end{array}$ & : \\
\hline & 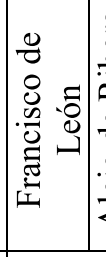 & 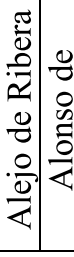 & 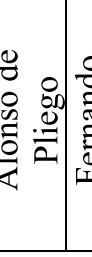 & 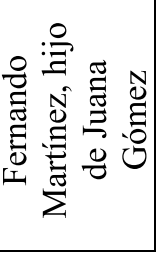 & 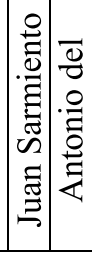 & 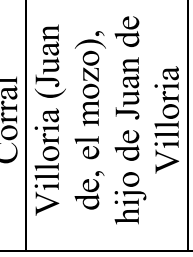 & 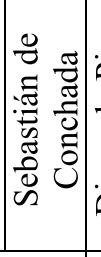 & 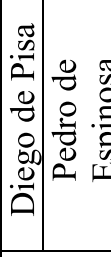 & : & 匙 & 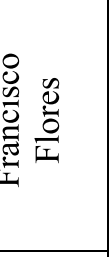 \\
\hline : & & & & & & & & 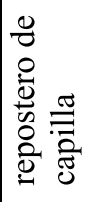 & & & 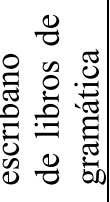 \\
\hline
\end{tabular}




\begin{tabular}{|c|c|c|c|c|c|c|c|c|c|c|c|c|c|}
\hline$\frac{6}{2}$ & & ! & 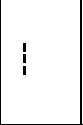 & 1 & 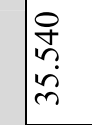 & 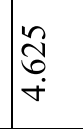 & $\left|\begin{array}{c}\frac{f}{d i n} \\
\vec{n}\end{array}\right|$ & 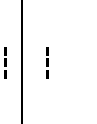 & & 1 & \begin{tabular}{|l|l} 
\\
$i n$
\end{tabular} & : & $\underset{\vec{f}}{\dot{f}}$ \\
\hline త్ర & & | & $!$ & m̂n & $\begin{array}{l}8 \\
0 \\
\vdots \\
\\
-1\end{array}$ & 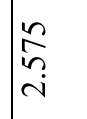 & $\left|\begin{array}{l}: \\
\stackrel{0}{0} \\
\dot{i}\end{array}\right|$ & 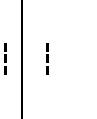 & & 1 & \begin{tabular}{|l}
0 \\
$\dot{D}$ \\
$i$
\end{tabular} & $\mid \begin{array}{l}8 \\
\infty \\
m \\
m\end{array}$ & $\stackrel{\nexists}{\stackrel{i}{i}}$ \\
\hline 守 & & 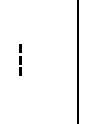 & 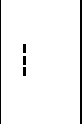 & ! & $\begin{array}{l}8 \\
\vdots \\
\dot{\sim}\end{array}$ & : & 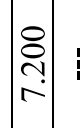 & : & & 1 & 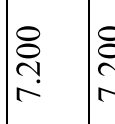 & ণ্ণి & : \\
\hline$\hat{g}$ & & $\begin{array}{l}8 \\
\text { in } \\
\text { in }\end{array}$ & 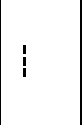 & 1 & $\begin{array}{l}8 \\
\vdots \\
\grave{\sim} \\
\dot{\sim}\end{array}$ & : & 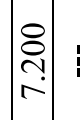 & : & & 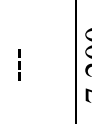 & 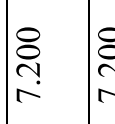 & : & ì \\
\hline 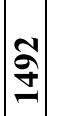 & & ! & : & ! & 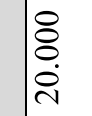 & ঙ্ণি & 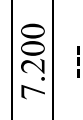 & : & & 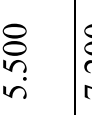 & 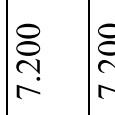 & | & ( \\
\hline$\overline{\mathrm{g}}$ & & 1 & $\begin{array}{l}8 \\
\vdots \\
i\end{array}$ & 1 & 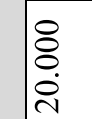 & 啇 & 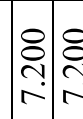 & : & & $\begin{array}{l}8 \\
\text { bn } \\
n\end{array}$ & ! & $1:$ & 1 \\
\hline 馬 & & 1 & $\begin{array}{l}8 \\
\vdots \\
\text { in }\end{array}$ & ! & $\begin{array}{ll}0 \\
0 \\
0\end{array}$ & ঐ̊̀ & : & : & & 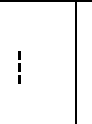 & ! & 1 & $i$ \\
\hline $\mid$ & & | & $!$ & 1 & 赵| & 1 & $\left|\begin{array}{c|}\hat{b} \\
\infty \\
\dot{\sim}\end{array}\right|$ & 1 & & 1 & 1 & 1 & 1 \\
\hline | & & ! & 1 & 1 & |c| & 1 & 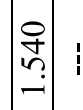 & 1 & & I & 1 & 1 & $\mathrm{i}$ \\
\hline 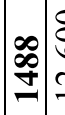 & $\begin{array}{l}\stackrel{8}{0} \\
\text { i }\end{array}$ & 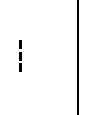 & 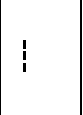 & | & $\begin{array}{l}8 \\
8 \\
\dot{4}\end{array}$ & 点 & 11 & 1 & & 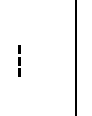 & ! & ! & i \\
\hline $\mid$ & & ! & 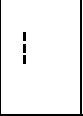 & ! & \begin{tabular}{|} 
ठे \\
ì
\end{tabular} & فํ. & $1:$ & : & & 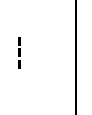 & 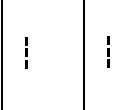 & 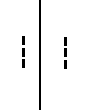 & 证 \\
\hline & 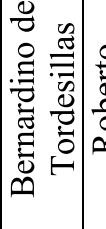 & 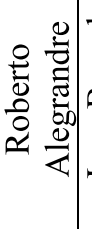 & 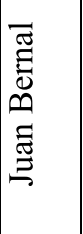 & 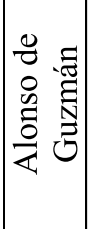 & 告 & 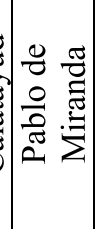 & 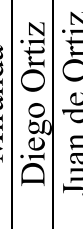 & 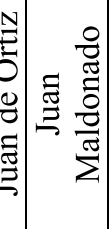 & 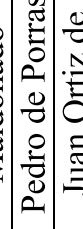 & 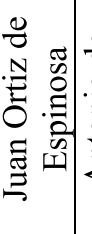 & 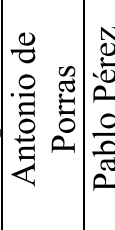 & 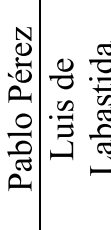 & 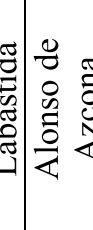 \\
\hline & 17 & & 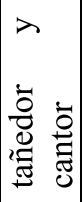 & 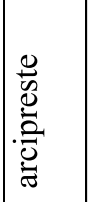 & 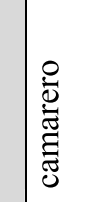 & 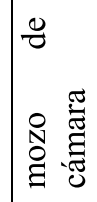 & & & & & & & \\
\hline
\end{tabular}




\begin{tabular}{|c|c|c|c|c|c|c|c|c|c|c|}
\hline 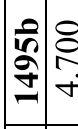 & $\frac{9}{i n}$ & $\frac{d}{i n}$ & $\underset{9}{9}$ & $\begin{array}{l}8 \\
\infty \\
\infty \\
\infty \\
0\end{array}$ & 1 & 1 & 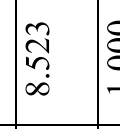 & \begin{tabular}{l|l}
8 \\
\hdashline \\
\hdashline
\end{tabular} & ฉૂ & : \\
\hline 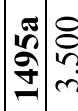 & 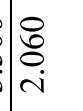 & 足 & 柋 & 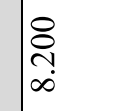 & 1 & 1 & 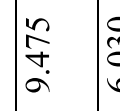 & 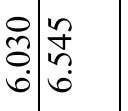 & 1 & 1 \\
\hline 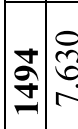 & 1 & i & 1 & $\begin{array}{l} \\
\varnothing \\
\infty \\
\infty\end{array}$ & $\begin{array}{l}8 \\
\vdots \\
i \\
1\end{array}$ & 1 & 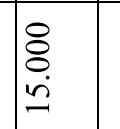 & : & 1 & 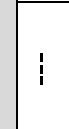 \\
\hline$\hat{\sigma}$ & 1 & ! & 1 & \begin{tabular}{l}
8 \\
\hdashline \\
$\infty$ \\
\hdashline
\end{tabular} & 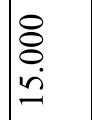 & : & 1 & $\mid \begin{array}{l}8 \\
0 \\
0\end{array}$ & 1 & 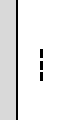 \\
\hline$\tilde{\Xi}$ & ! & i & i & \begin{tabular}{l}
8 \\
\hdashline \\
$\infty$ \\
\hdashline
\end{tabular} & $\begin{array}{l}8 \\
\vdots \\
i\end{array}$ & 1 & 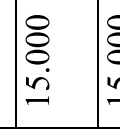 & \begin{tabular}{c|c}
8 \\
$\vdots$ \\
ப.
\end{tabular} & $i$ & ; \\
\hline $\bar{a}$ & 1 & ! & 1 & $\begin{array}{l}8 \\
\varnothing \\
\infty \\
\infty\end{array}$ & $\begin{array}{l}8 \\
\stackrel{8}{0} \\
\dot{0}\end{array}$ & 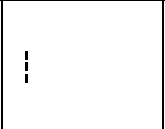 & 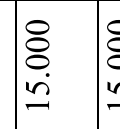 & \begin{tabular}{l|l}
8 \\
$\vdots$ \\
ज.
\end{tabular} & 1 & 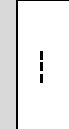 \\
\hline â & 1 & ! & 1 & {$\left[\begin{array}{l}0 \\
0 \\
0\end{array}\right.$} & $\begin{array}{l}8 \\
\vdots \\
\text { in }\end{array}$ & 1 & 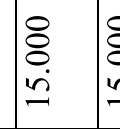 & 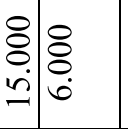 & & 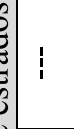 \\
\hline 它 & 1 & 1 & 1 & 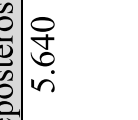 & $\begin{array}{l}8 \\
\dot{8} \\
\text { in }\end{array}$ & 1 & 1 & $\mid \begin{array}{l}\infty \\
\infty \\
\stackrel{\infty}{\mid}\end{array}$ & 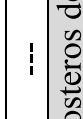 & | \\
\hline 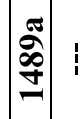 & 1 & 1 & 1 & 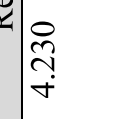 & $\begin{array}{l}8 \\
\stackrel{0}{m}\end{array}$ & 1 & 1 & $\mid \begin{array}{l}\infty \\
\stackrel{\infty}{n} \\
\end{array}$ & $1:$ & 4 \\
\hline \begin{tabular}{l}
$\infty$ \\
$\infty$ \\
$\infty$ \\
\multirow{2}{*}{}
\end{tabular} & 1 & 1 & 1 & \begin{tabular}{l}
8 \\
\hdashline \\
$\infty$ \\
$\infty$ \\
-1
\end{tabular} & $\begin{array}{l}8 \\
\vdots \\
i \\
\end{array}$ & ف & 1 & $\mid \begin{array}{l}8 \\
0 \\
0 \\
0\end{array}$ & 1 & ర్రీ \\
\hline 我 & ! & i & 1 & $\begin{array}{l}8 \\
\varnothing \\
\infty \\
\infty\end{array}$ & $\begin{array}{l}8 \\
8 \\
i \\
\end{array}$ & : & 1 & 11 & 1 & 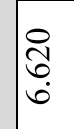 \\
\hline 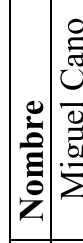 & 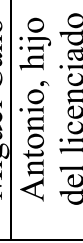 & 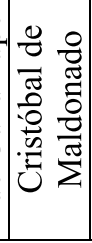 & 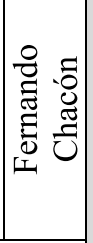 & 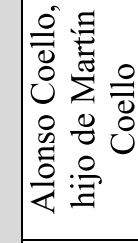 & $\frac{8}{0}$ & 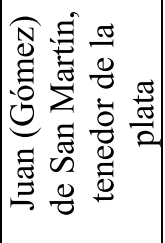 & 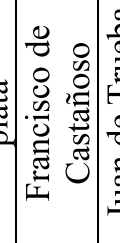 & 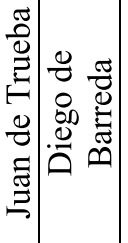 & & శี \\
\hline 8 & & & & 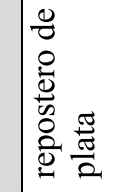 & & & & 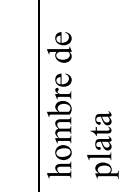 & & \\
\hline
\end{tabular}




\begin{tabular}{|c|c|c|c|c|c|c|c|c|c|c|c|c|}
\hline 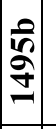 & & i & 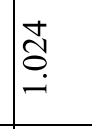 & 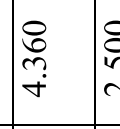 & 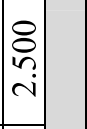 & i: & 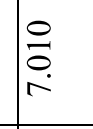 & 1 & 1 & 旁 & 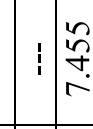 & : \\
\hline & & 1 & $\begin{array}{l}\stackrel{0}{2} \\
\text { in }\end{array}$ & 象 & $i$ & 11 & $\begin{array}{l}\stackrel{0}{\infty} \\
\infty \\
i \\
i\end{array}$ & 1 & 1 & $\begin{array}{l}\stackrel{0}{\infty} \\
\stackrel{i}{i} \\
i\end{array}$ & & $\begin{array}{l}0 \\
0 \\
0 \\
0\end{array}$ \\
\hline aे & & 1 & i & స్లి & 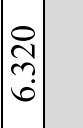 & $\mid$\begin{tabular}{l}
8 \\
\hdashline \\
0 \\
0
\end{tabular} & 文 & 1 & 1 & 文 & & 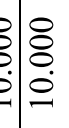 \\
\hline$\frac{8}{\square}$ & & స్ & స్ల్ర & స్ల్రి & 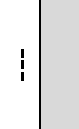 & $\begin{array}{ll}1 & 1\end{array}$ & : & : & 1 & $\begin{array}{l}8 \\
0 \\
0\end{array}$ & 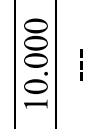 & : \\
\hline$\tilde{a}$ & & స్ & స్తి & त్ & $i$ & $\begin{array}{ll}1 & 1\end{array}$ & 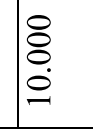 & 1 & 1 & \begin{tabular}{l}
8 \\
$\vdots$ \\
\hdashline
\end{tabular} & & : \\
\hline 5 & & 1 & $\begin{array}{l}\text { స్ } \\
\text { రై }\end{array}$ & 1 & 1 & $\mid$\begin{tabular}{l}
8 \\
\hdashline \\
0 \\
0
\end{tabular} & $\begin{array}{l}8 \\
0 \\
0 \\
0\end{array}$ & : & 1 & 文 & & 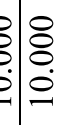 \\
\hline 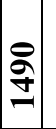 & & స్తి & 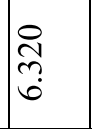 & 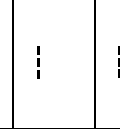 & 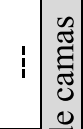 & $\mid$\begin{tabular}{l}
8 \\
$:$ \\
$\dot{0}$ \\
\hdashline
\end{tabular} & ! & : & 1 & : & $\mid \begin{array}{l}: \\
: \\
:\end{array}$ & : \\
\hline | & & 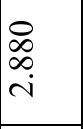 & 1 & 1 & 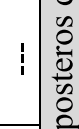 & 11 & ! & $\overbrace{\tilde{m}}^{\stackrel{m}{m}}$ & ई & ભল & ले: & $1:$ \\
\hline ه్ల & & 1 & 1 & 1 & $\approx$ & $\begin{array}{lll}11 & 1\end{array}$ & 1 & $\begin{array}{l}8 \\
\text { h్ } \\
i\end{array}$ & 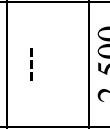 & 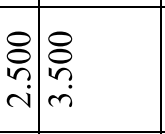 & 离 & $\hat{h}$ \\
\hline 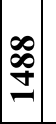 & & $\begin{array}{l}\text { ते } \\
\text { రु }\end{array}$ & तु & 1 & 1 & i: & 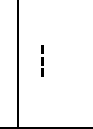 & $\begin{array}{l}\stackrel{8}{0} \\
\dot{0}\end{array}$ & 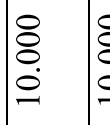 & 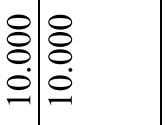 & $: 1$ & $:$ \\
\hline 命 & & 1 & ! & : & ! & $\begin{array}{l}0 \\
\vdots \\
\vdots \\
0\end{array}$ & 官 & 1 & : & 1 & 11 & i: \\
\hline 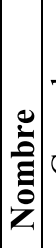 & 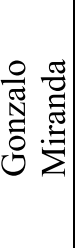 & $\begin{array}{ll}0 \\
0\end{array}$ & 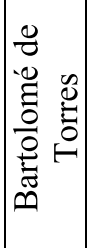 & 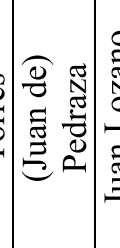 & 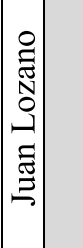 & 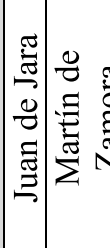 & 总 & 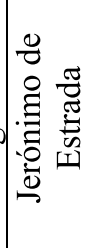 & 童 & 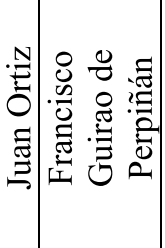 & 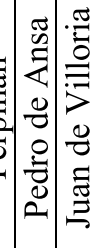 & 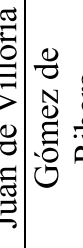 \\
\hline & & & & & & 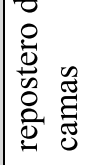 & & & & & & \\
\hline
\end{tabular}




\begin{tabular}{|c|c|c|c|c|c|c|c|c|c|c|}
\hline \begin{tabular}{|c|} 
\\
$\hat{q}$ \\
$\hat{g}$ \\
\end{tabular} & & $\stackrel{0}{0}$ & $\stackrel{0}{\stackrel{0}{c}}$ & 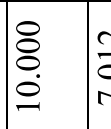 & 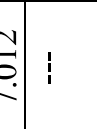 & 1 & $\frac{\circ}{\infty}$ & 1 & $\begin{array}{l}8 \\
\vdots \\
a \\
\alpha\end{array}$ & 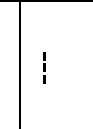 \\
\hline | & & 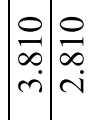 & 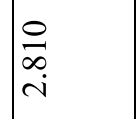 & 1 & 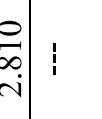 & 1 & $\begin{array}{l}0 \\
0 \\
0 \\
0 \\
0\end{array}$ & 放 & 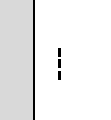 & 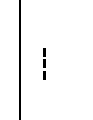 \\
\hline 竎 & & \begin{tabular}{l}
8 \\
$\vdots$ \\
\hdashline \\
\hdashline \\
\hdashline
\end{tabular} & \begin{tabular}{l} 
\\
\\
\hdashline \\
\hdashline
\end{tabular} & \begin{tabular}{|l|}
8 \\
0 \\
0 \\
\end{tabular} & : : & 1 & i & : & 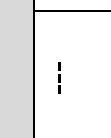 & ! \\
\hline$\stackrel{2}{\mathfrak{g}}$ & & \begin{tabular}{l}
8 \\
$\vdots$ \\
\hdashline \\
\hdashline
\end{tabular} & \begin{tabular}{l}
8 \\
\hdashline \\
\hdashline
\end{tabular} & \begin{tabular}{|l|} 
\\
\\
0 \\
0
\end{tabular} & $\mid \begin{array}{l}8 \\
0 \\
0\end{array}$ & \begin{tabular}{l}
8 \\
\hdashline \\
0 \\
\hdashline
\end{tabular} & 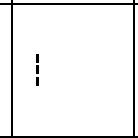 & 1 & $\begin{array}{l} \\
\\
\vdots \\
\alpha \\
\end{array}$ & 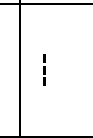 \\
\hline 令 & & \begin{tabular}{l}
8 \\
$\vdots$ \\
\hdashline \\
\hdashline
\end{tabular} & \begin{tabular}{l}
8 \\
\hdashline \\
\hdashline \\
\hdashline
\end{tabular} & \begin{tabular}{|l|}
8 \\
\\
0 \\
0
\end{tabular} & \begin{tabular}{ll|l}
8 & 1 \\
& 1 \\
\end{tabular} & 1 & i & : & $\begin{array}{l}8 \\
\vdots \\
\vdots \\
\sigma \\
\end{array}$ & 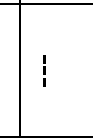 \\
\hline$\overline{\mathbf{g}}$ & & \begin{tabular}{l}
8 \\
$\vdots$ \\
0 \\
\hdashline
\end{tabular} & 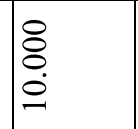 & $\begin{array}{ll}8 \\
0 \\
0 \\
0\end{array}$ & $8:$ & 1 & i & 1 & 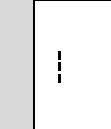 & ! \\
\hline 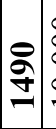 & $\begin{array}{l}0 \\
\vdots \\
0 \\
0 \\
\end{array}$ & $1:$ & ! & 1 & i: & 1 & ! & 1 & $\stackrel{0}{\circ}$ & ; \\
\hline 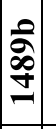 & & $1: 1$ & 1 & 1 & $1:$ & 1 & ! & 1 & 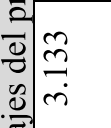 & 1 \\
\hline 趈 & & $1: 1$ & 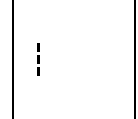 & i & 11 & 1 & 1 & 1 & 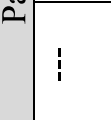 & ! \\
\hline | & & $1: 1$ & 1 & 1 & 11 & i & ! & : & \begin{tabular}{l}
8 \\
\multirow{+}{*}{} \\
a
\end{tabular} & 辛 \\
\hline | & 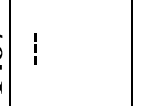 & $1: 1$ & 1 & ! & 1: & 1 & ! & 1 & $\begin{array}{l}\text { ò } \\
\text { a }\end{array}$ & 辛 \\
\hline 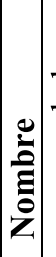 & 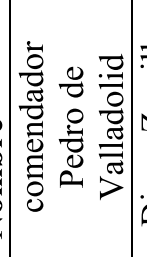 & 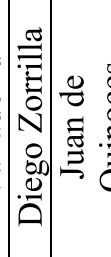 & 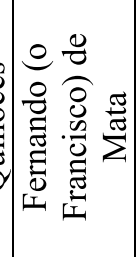 & 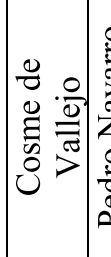 & 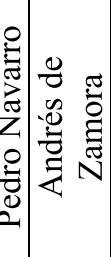 & 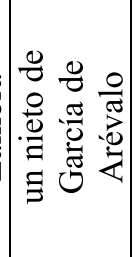 & 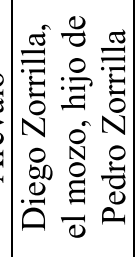 & 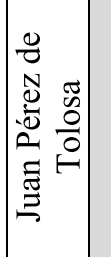 & 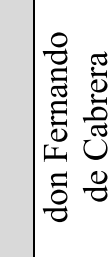 & 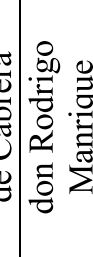 \\
\hline & & & & & & & & & 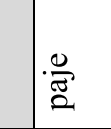 & \\
\hline
\end{tabular}




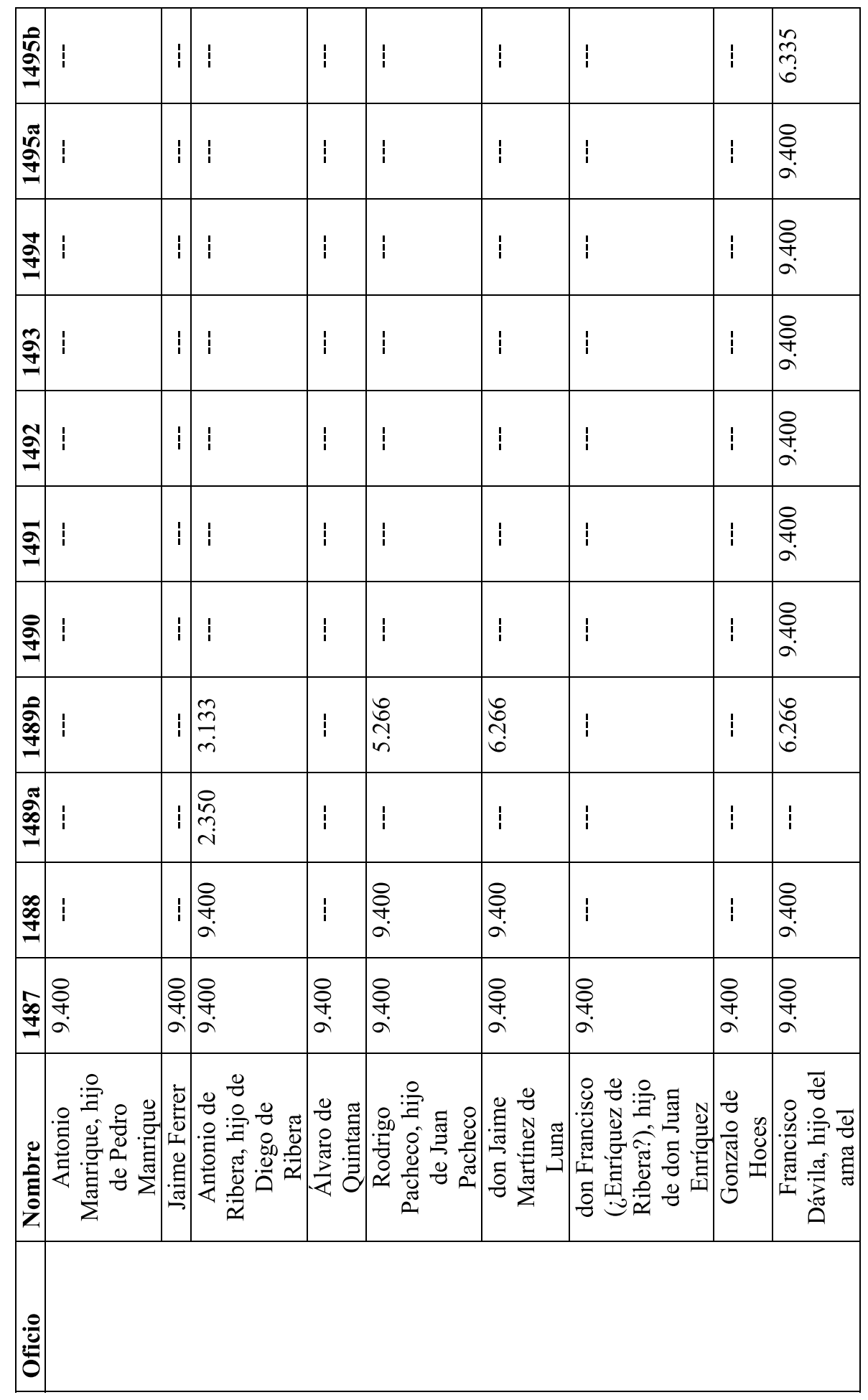




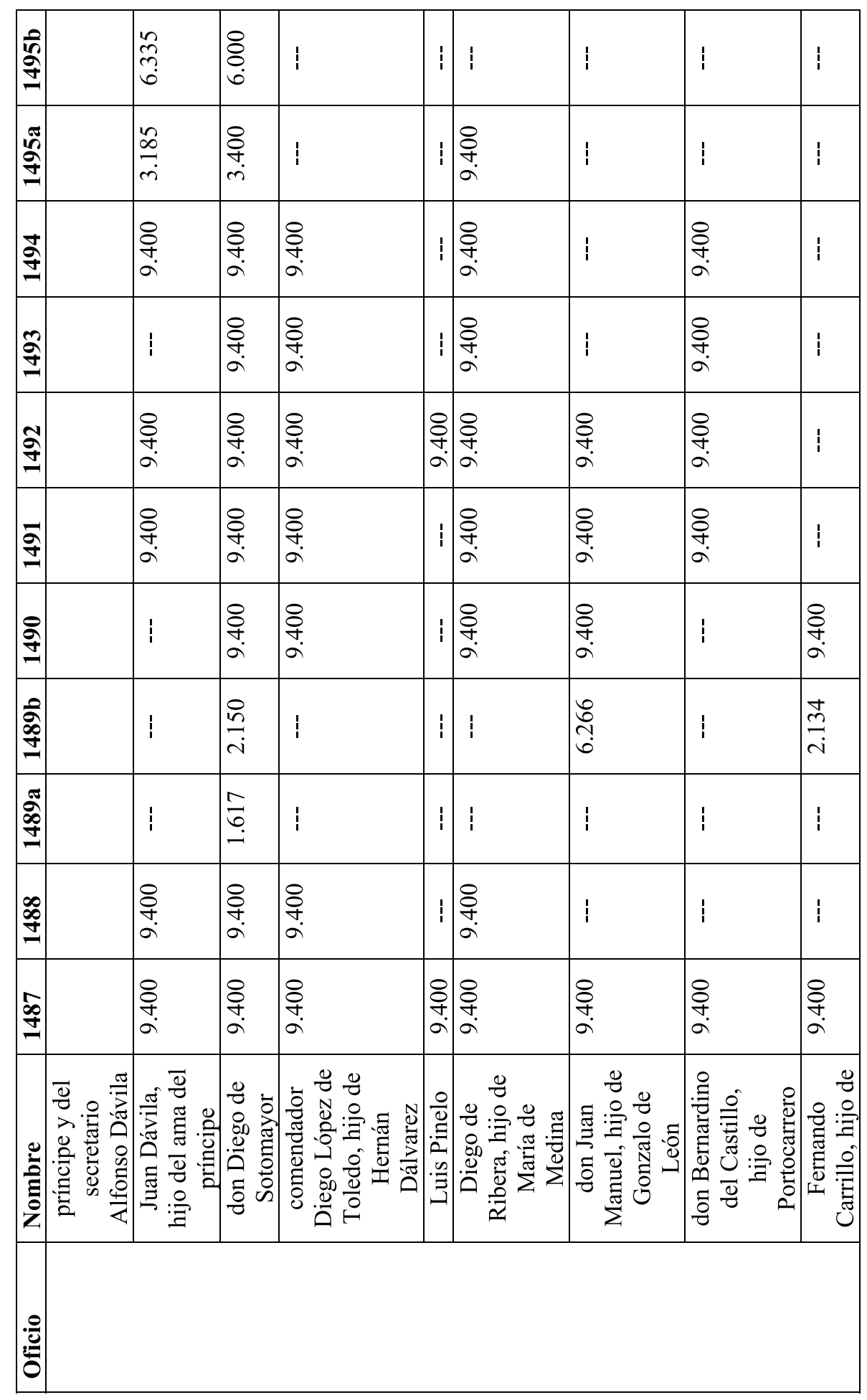




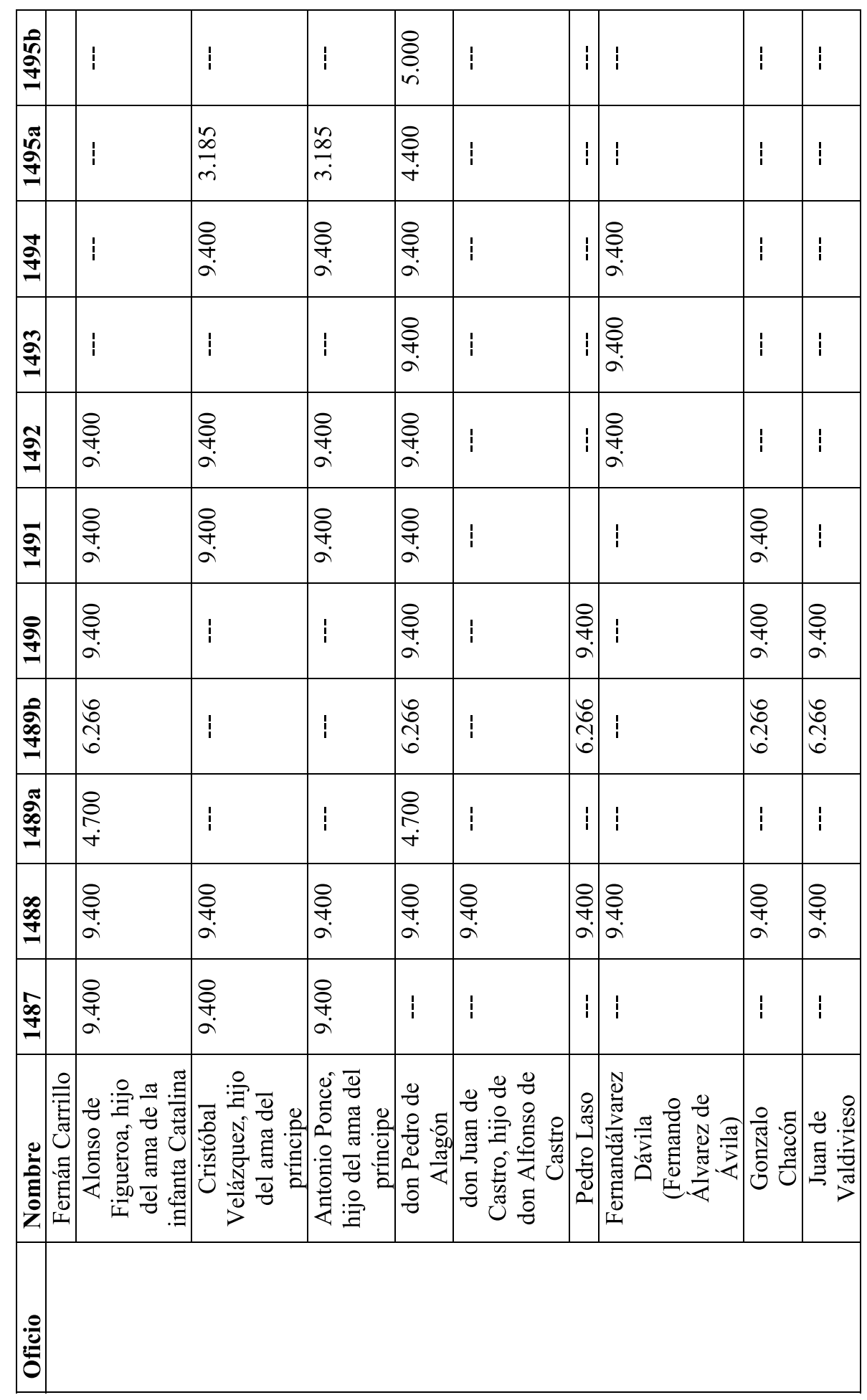




\begin{tabular}{|c|c|c|c|c|c|c|c|c|c|c|}
\hline $\begin{array}{l}\overrightarrow{0} \\
\hat{\sigma}\end{array}$ & & i & : & 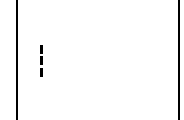 & 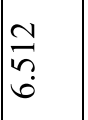 & |aे & 1 & $\begin{array}{lll}1 & 1\end{array}$ & 1 & 1 \\
\hline | & & ! & ! & ! & $\begin{array}{l}\infty \\
\substack{\infty \\
i \\
i}\end{array}$ & 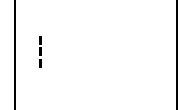 & 1 & $\begin{array}{lll}1 & 1 \\
\end{array}$ & 1 & 1 \\
\hline 竎 & & i & : & 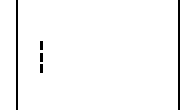 & 怼 & 1 & 吕 & 11 & 1 & 1 \\
\hline$\hat{\mathfrak{q}}$ & & : & : & 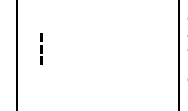 & 条 & 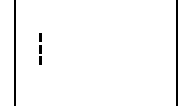 & 文 & $1: 1$ & 1 & 1 \\
\hline$\tilde{z}$ & & i & : & 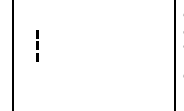 & 界 & 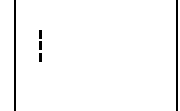 & 多 & $1: 1$ & i & 离 \\
\hline$\overline{\hat{q}}$ & & i & i & 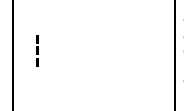 & 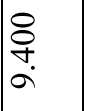 & 余 & 章 & $: 1:$ & 1 & $\begin{array}{l}8 \\
\vdots \\
\alpha \\
\alpha\end{array}$ \\
\hline d) & $\mid \begin{array}{l}0 \\
\vdots \\
0 \\
0\end{array}$ & : & : & 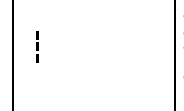 & 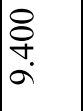 & 产 & 1 & $: 1:$ & 1 & 亲 \\
\hline 离 & ن] & $\underset{m}{m}$ & 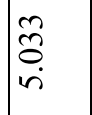 & லْ & $\stackrel{m}{m}$ & $\begin{array}{l}\infty \\
\overparen{7} \\
\text { in }\end{array}$ & : & 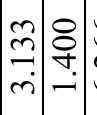 & 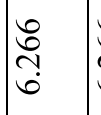 & 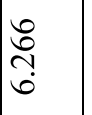 \\
\hline 离 & & 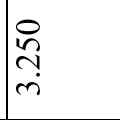 & 字 & 菂. & 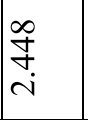 & $\overrightarrow{\widehat{\sigma}}$ & \begin{tabular}{|l|}
$\stackrel{8}{Q}$ \\
$\stackrel{+}{+}$ \\
\end{tabular} & $: 1:$ & 1 & 1 \\
\hline $\mid$\begin{tabular}{l}
$\infty$ \\
$\dot{\alpha}$ \\
\hdashline
\end{tabular} & 兮 & 安 & 字 & 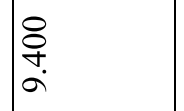 & 1 & 1 & i & $: \vdots:$ & 1 & 1 \\
\hline 离 & 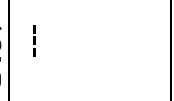 & i & 1 & 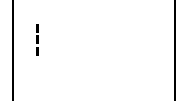 & 1 & 1 & : & $1: 1$ & 1 & 1 \\
\hline | & 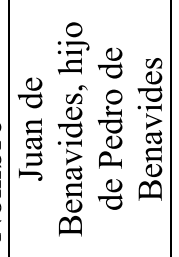 & 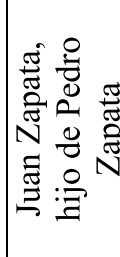 & 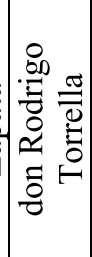 & 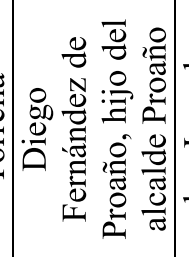 & 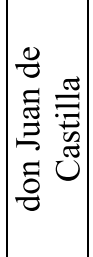 & 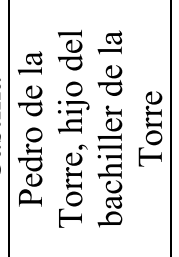 & 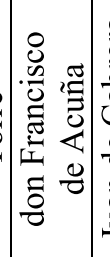 & 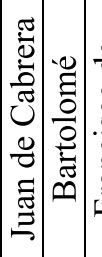 & 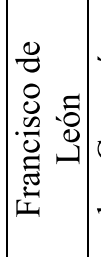 & 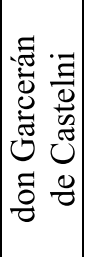 \\
\hline 1 & & & & & & & & & & \\
\hline
\end{tabular}




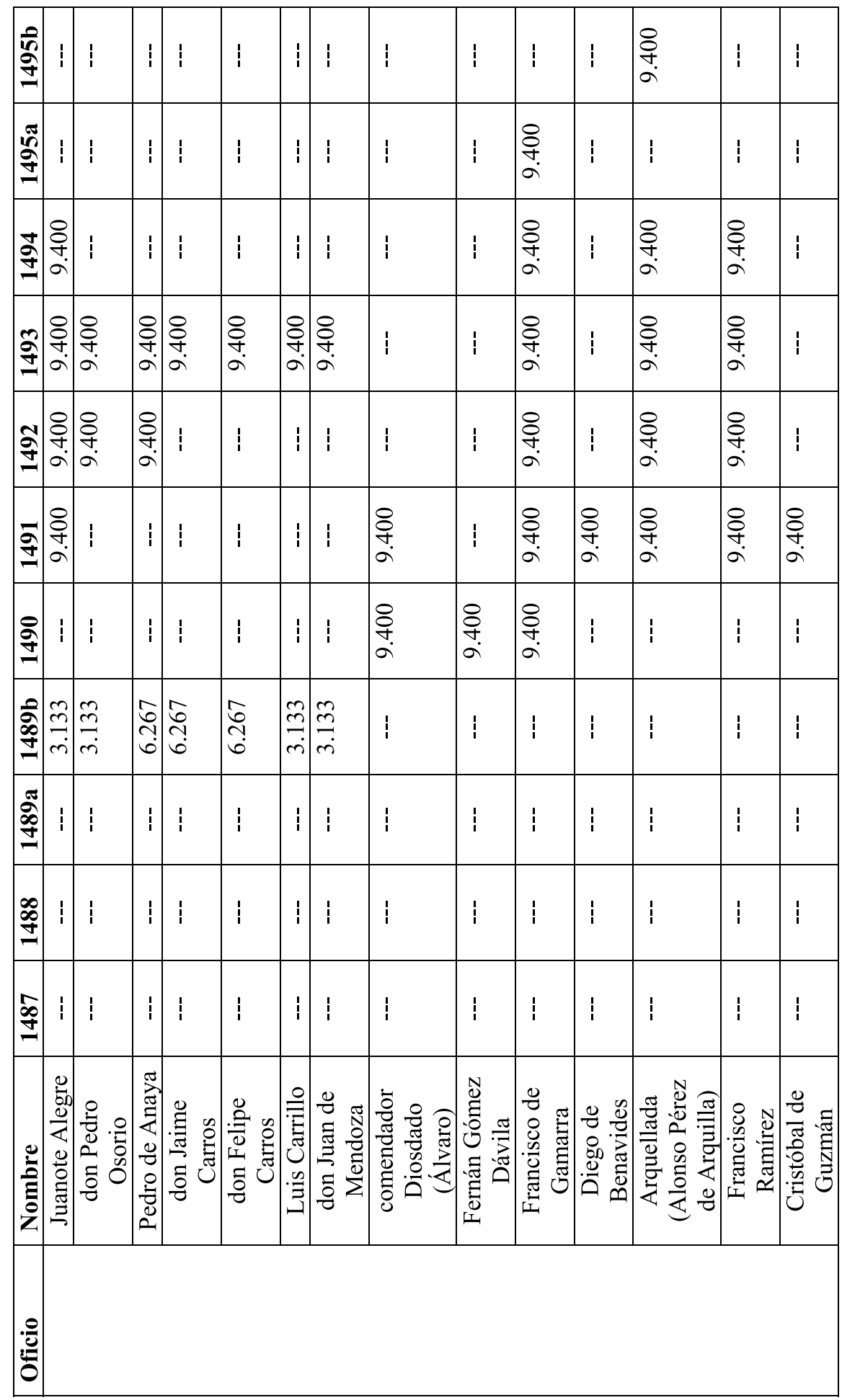




\begin{tabular}{|c|c|c|c|c|c|c|c|c|c|c|c|}
\hline $\begin{array}{l}\text { जी } \\
\hat{\sigma}\end{array}$ & $\mid$ & $\dot{1}$ & $i$ & 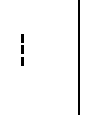 & $i$ & $\underset{8}{8}$ & $\begin{array}{l}8 \\
8 \\
0 \\
0\end{array}$ & $\mid$ & $\mid$ & $\vdots$ & $i$ \\
\hline ֶ̆ & 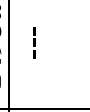 & $\mathrm{i}$ & 1 & $\mid$ & $\mid$ & $\mid$ & ! & 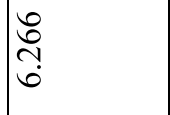 & $\mid$ & $\mid$ & $i$ \\
\hline$\stackrel{\Xi}{\vec{z}}$ & 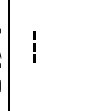 & $i$ & $i$ & $!$ & $\mid$ & \&̊ & 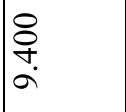 & ò & ஓ̊. & 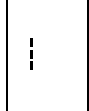 & $i$ \\
\hline 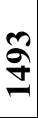 & 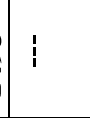 & i & 1 & $\mid$ & $!$ & ஓ̊. & $\begin{array}{l}8 \\
\stackrel{8}{+} \\
\text { à }\end{array}$ & 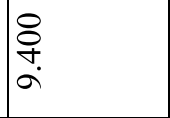 & 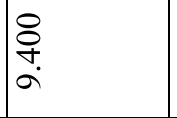 & $\begin{array}{l}\text { ஓ } \\
\vdots \\
\text { à }\end{array}$ & $\begin{array}{c}8 \\
0 \\
\vdots \\
\vdots \\
.\end{array}$ \\
\hline$\tilde{a}$ & 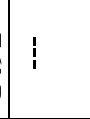 & $\left|\begin{array}{c}8 \\
⿱ 亠 \\
\vdots \\
\sigma\end{array}\right|$ & $\begin{array}{c}8 \\
8 \\
\vdots \\
\alpha\end{array}$ & 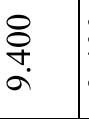 & ஓ̊. & ஓ̊. & 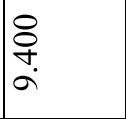 & 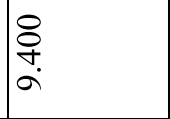 & ஓ & $\begin{array}{l}\text { ஓ } \\
\vdots \\
\vdots\end{array}$ & $\begin{array}{c}8 \\
\delta \\
\vdots \\
\sigma \\
.\end{array}$ \\
\hline $\bar{a}$ & 辛 & i & $i$ & $\mid$ & $\mid$ & $!$ & 1 & $\vdots$ & $\mid$ & 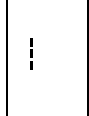 & $i$ \\
\hline$\stackrel{a}{\square}$ & 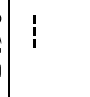 & 1 & $i$ & $\vdots$ & $i$ & $i$ & 1 & 1 & $i$ & $\vdots$ & $i$ \\
\hline $\begin{array}{l}\stackrel{0}{\widehat{\infty}} \\
\stackrel{+}{ \pm}\end{array}$ & $\mid$ & $i$ & $i$ & 1 & 1 & 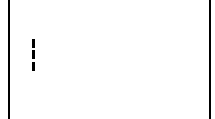 & ! & 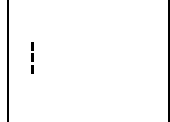 & $\mid$ & $\mid$ & $i$ \\
\hline $\begin{array}{l}\text { వే } \\
\stackrel{\infty}{ \pm} \\
-\end{array}$ & $\mid$ & 1 & $i$ & 1 & I & $\mid$ & 1 & $!$ & $\mid$ & 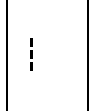 & $i$ \\
\hline $\begin{array}{l}\infty \\
\stackrel{\infty}{ \pm} \\
\end{array}$ & 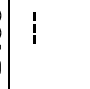 & i & $i$ & 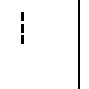 & $!$ & $!$ & 1 & $!$ & 1 & 1 & $i$ \\
\hline$\stackrel{-\infty}{\square}$ & $\vdots$ & $i$ & $i$ & $\mid$ & 1 & $\vdots$ & ! & $\vdots$ & 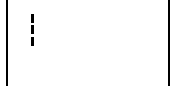 & 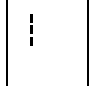 & $i$ \\
\hline $\begin{array}{l}\text { D. } \\
\text { है } \\
\text { Z }\end{array}$ & 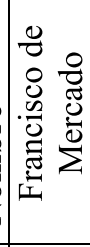 & 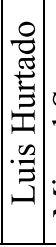 & 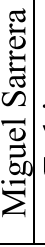 & : & 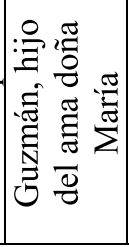 & 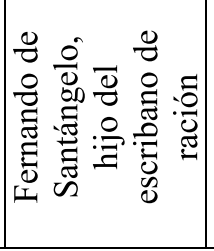 & 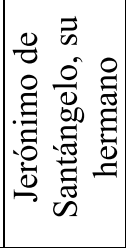 & 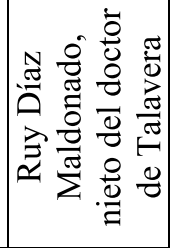 & 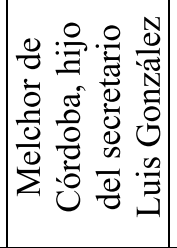 & 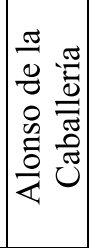 & 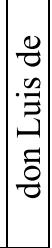 \\
\hline .5 & & & & & & & & & & & \\
\hline
\end{tabular}




\begin{tabular}{|c|c|c|c|c|c|c|c|}
\hline $\mid \begin{array}{l}\overrightarrow{\hat{o}} \\
\hat{\mathrm{g}}\end{array}$ & $\frac{m}{m}$ & 高 & i & 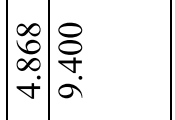 & 1 & | & $1:$ \\
\hline 胳 & 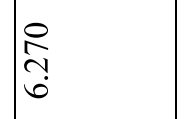 & 1 & : & 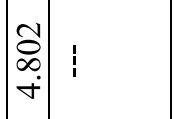 & 1 & $\frac{t}{\partial}$ & 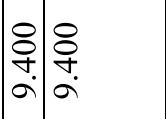 \\
\hline ta & 高 & 辛 & 1 & 字京 & 条 & 辛 & $\left|\begin{array}{l}0 \\
⿱ 亠 乂 \\
\hdashline \\
:\end{array}\right|$ \\
\hline$\hat{\mathfrak{q}}$ & 字. & 字. & 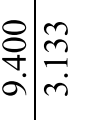 & 11 & 1 & 1 & $1:$ \\
\hline$\tilde{\hat{z}}$ & 条 & 1 & $1:$ & $1:$ & 1 & 1 & $1:$ \\
\hline$\overline{\hat{a}}$ & 1 & 1 & : & $1:$ & i & 1 & $1:$ \\
\hline $\begin{array}{l}0 \\
\hat{q} \\
\end{array}$ & 1 & 1 & : & $1:$ & 1 & 1 & $1:$ \\
\hline $\mid$ & i & 1 & 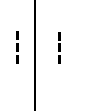 & :1: & 1 & 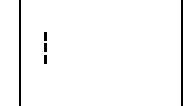 & 11 \\
\hline 离 & 1 & 1 & 1 & $1: 1$ & 1 & i & 11 \\
\hline 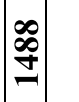 & i & 1 & i: & 11 & 1 & 1 & $1:$ \\
\hline 离 & 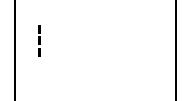 & 1 & : : & $1:$ & 1 & 1 & $1:$ \\
\hline 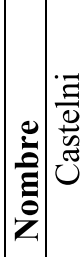 & 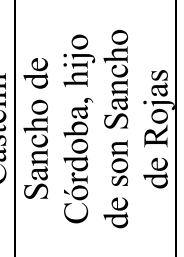 & 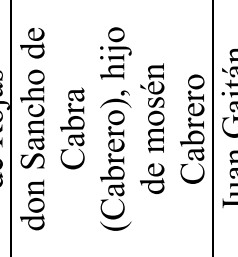 & 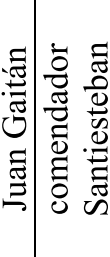 & 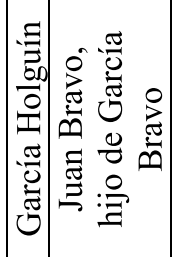 & 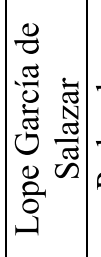 & 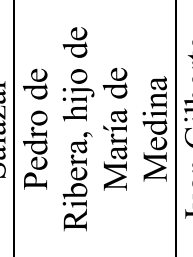 & 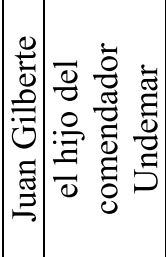 \\
\hline $\mid$ & & & & & & & \\
\hline
\end{tabular}




\begin{tabular}{|c|c|c|c|c|c|c|c|c|c|c|}
\hline 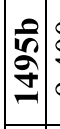 & $\begin{array}{l}8 \\
\vdots \\
\vdots \\
2\end{array}$ & ; & i & i & 1 & 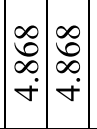 & & i & 1 & 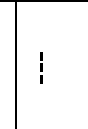 \\
\hline & $\begin{array}{l}8 \\
\vdots \\
\vdots \\
0\end{array}$ & 字 & 字 & ه্র & $\begin{array}{l}8 \\
\vdots \\
\vdots \\
a\end{array}$ & 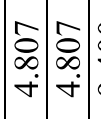 & 客 & 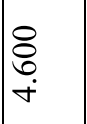 & $\begin{array}{l}\hat{D} \\
\infty \\
\dot{q} \\
\dot{0}\end{array}$ & প্র \\
\hline ta & & : & : & 1 & 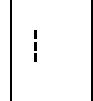 & $1: 1$ & 1 & 1 & : & 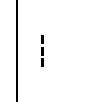 \\
\hline q & 1 & 1 & 1 & 1 & 1 & $1: 1$ & 1 & 1 & 1 & : \\
\hline$\tilde{z}$ & & i & : & $i$ & i & $: \vdots$ & $i$ & i & : & : \\
\hline $\bar{q}$ & & i & 1 & 1 & 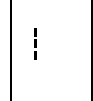 & $1: 1$ & 1 & : & 1 & : \\
\hline to & 1 & 1 & : & i & 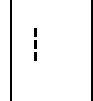 & $: 1$ & 1 & i & 1 & : \\
\hline 拿 & 1 & i & 1 & 1 & 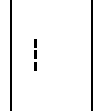 & $1: 1$ & 1 & 1 & 1 & : \\
\hline 离 & 1 & i & 1 & 1 & 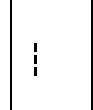 & $\begin{array}{lll}1 & 1 \\
\end{array}$ & 1 & 1 & 1 & i \\
\hline 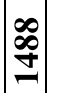 & 1 & i & 1 & ! & 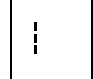 & $\begin{array}{lll}1 & 1 \\
\end{array}$ & 1 & i & 1 & ; \\
\hline 点 & 1 & i & : & ! & ! & $1: 1$ & 1 & i & 1 & 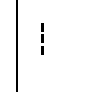 \\
\hline 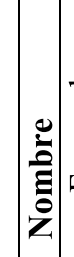 & 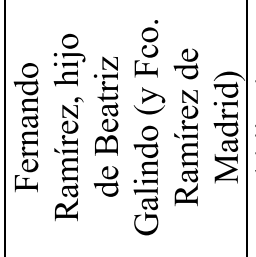 & 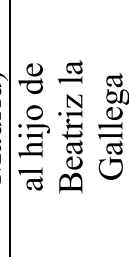 & 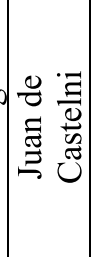 & 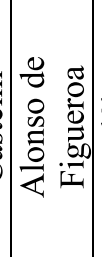 & 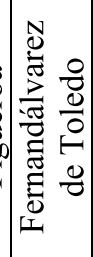 & 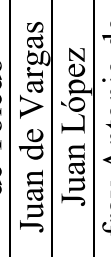 & 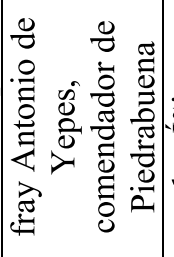 & 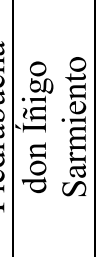 & 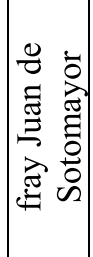 & 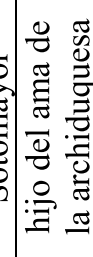 \\
\hline
\end{tabular}




\begin{tabular}{|c|c|c|c|c|c|c|c|c|c|}
\hline 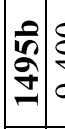 & $\begin{array}{l}\infty \\
\infty \\
\infty \\
\infty \\
\dot{\sim}\end{array}$ & $\begin{array}{l}0 \\
0 \\
0 \\
0\end{array}$ & $\begin{array}{l}\infty \\
\stackrel{\infty}{+} \\
\dot{\sigma}\end{array}$ & : : & : & : & 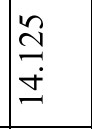 & $\begin{array}{l}0 \\
\stackrel{m}{m} \\
\stackrel{m}{2}\end{array}$ & $\begin{array}{l}0 \\
0 \\
0 \\
n \\
\end{array}$ \\
\hline 吕 & 1 & 1 & 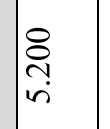 & $1:$ & 1 & 1 & 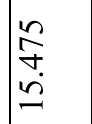 & 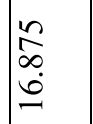 & 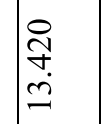 \\
\hline 齐 & 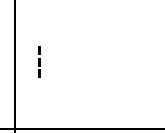 & 1 & 商 & $1:$ & 1 & : & $\begin{array}{l}8 \\
8 \\
\ddot{0} \\
\end{array}$ & $\begin{array}{l}8 \\
8 \\
0 \\
\dot{m}\end{array}$ & $\mid \begin{array}{l}8 \\
\text { ¿ें } \\
\text { त. }\end{array}$ \\
\hline âd & 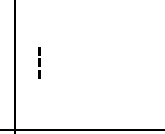 & 1 & \begin{tabular}{|l|}
\multirow{2}{0}{} \\
$\varrho$ \\
$\varrho$
\end{tabular} & $\begin{array}{l:l}8 \\
: & 1 \\
: & 1\end{array}$ & 1 & : & $\begin{array}{l}8 \\
8 \\
\\
\end{array}$ & $\begin{array}{l}8 \\
0 \\
0 \\
\dot{m}\end{array}$ & | \\
\hline$\tilde{z}$ & 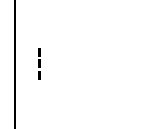 & | & ঐి & $1:$ & : & i & $\begin{array}{l}8 \\
8 \\
\\
\end{array}$ & $\begin{array}{l}\text { \& } \\
0 \\
0 \\
\dot{m}\end{array}$ & ; \\
\hline$\overline{\mathrm{a}}$ & 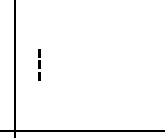 & ! & 옹 & $1:$ & 1 & : & $\begin{array}{l}8 \\
8 \\
0 \\
\\
-\end{array}$ & 1 & i \\
\hline 匇 & 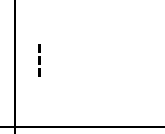 & 1 & : & $1:$ & : & : & $\begin{array}{l}8 \\
0 \\
\text { in } \\
\end{array}$ & 1 & ! \\
\hline 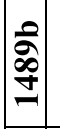 & 1 & 1 & $\stackrel{m}{m}$ & $1:$ & 1 & 1 & 1 & 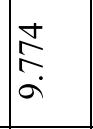 & : \\
\hline 竎 & 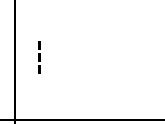 & 1 & 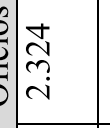 & $1:$ & 1 & 1 & 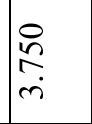 & 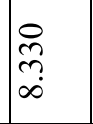 & i \\
\hline 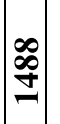 & 1 & : & @o & : 1 & $\mid \begin{array}{l}8 \\
0 \\
\\
\end{array}$ & $\begin{array}{l}8 \\
0 \\
0 \\
0 \\
\text {. }\end{array}$ & 1 & $\mid$ & 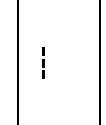 \\
\hline 占 & 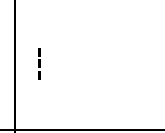 & | & ¿̊. & $\mid \begin{array}{l}8 \\
0 \\
\dot{m} \\
i\end{array}$ & 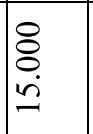 & 1 & : & : & ! \\
\hline 0 & 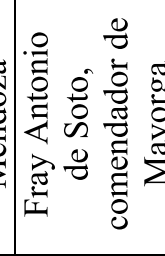 & 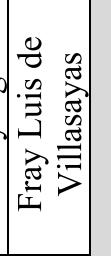 & 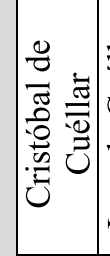 & 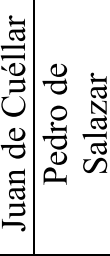 & 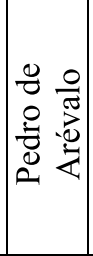 & 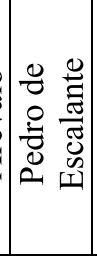 & 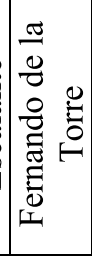 & $\begin{array}{l}\frac{\pi}{0} \\
0 \\
0 \\
0 \\
0 \\
0 \\
0 \\
0 \\
0 \\
0 \\
0\end{array}$ & on \\
\hline 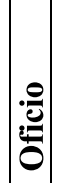 & & & 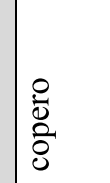 & 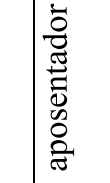 & & & & & \\
\hline
\end{tabular}




\begin{tabular}{|c|c|c|c|c|c|c|c|c|c|c|c|c|c|c|}
\hline & त̂ & $i$ & 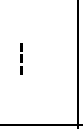 & 1 & 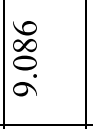 & & 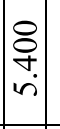 & & i & ; & : & : & i & $i$ \\
\hline & & 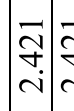 & $\underset{\mathrm{J}}{\overrightarrow{\mathrm{N}}}$ & 1 & $\stackrel{\ominus}{\underset{\sigma}{F}}$ & $: 1$ & 1 & ర్ & 1 & $1:$ & : & 命 & 1 & 命 \\
\hline & & 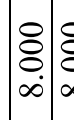 & 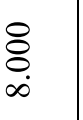 & $\begin{array}{l}8 \\
\vdots \\
\infty \\
\infty\end{array}$ & 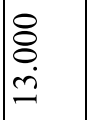 & & & 离 & i & . & : & 辛 & 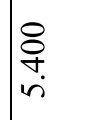 & $\mid \begin{array}{c}8 \\
\vdots \\
\vdots \\
i\end{array}$ \\
\hline & & $\left|\begin{array}{c}\S \\
\vdots \\
\infty \\
\infty\end{array}\right|$ & $\begin{array}{l}8 \\
\vdots \\
\infty \\
\infty\end{array}$ & 1 & 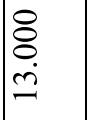 & & $\left|\begin{array}{l}8 \\
\vdots \\
\dot{n}\end{array}\right|$ & 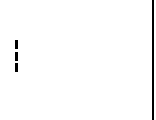 & $\begin{array}{l}8 \\
\vdots \\
\text { in }\end{array}$ & 1 & : & 吕 & 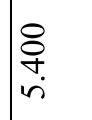 & 1 \\
\hline & & $\mid \begin{array}{c}8 \\
\vdots \\
\infty\end{array}$ & 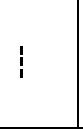 & i & 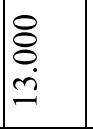 & & & & : & $1:$ & 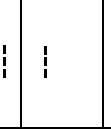 & 条 & $\begin{array}{l}8 \\
\text { a } \\
\text { in }\end{array}$ & $i$ \\
\hline & & $\mid$\begin{tabular}{l}
8 \\
\hdashline \\
$\infty$
\end{tabular} & 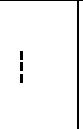 & 1: & $\begin{array}{l}\stackrel{8}{0} \\
\ddot{\ddot{m}}\end{array}$ & $: 1$ & $\mid \begin{array}{c}8 \\
\vdots \\
\text { r. }\end{array}$ & 安 & ! & 1 & i: & 变 & $\begin{array}{l}8 \\
\text { o } \\
\text { in }\end{array}$ & 1 \\
\hline & & $\mid$\begin{tabular}{c}
8 \\
\hdashline \\
$\infty$
\end{tabular} & 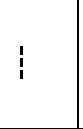 & 1 & $\begin{array}{l}8 \\
\vdots \\
\text { in }\end{array}$ & $:$ & 务 & 㝘 & i & $\left|\begin{array}{c|c}0 \\
⿱ 亠 乂 \\
\infty \\
\infty\end{array}\right|$ & $!$ & $\begin{array}{l}8 \\
\text { a } \\
\text { in }\end{array}$ & 度 & 1 \\
\hline & & $\mid \begin{array}{c}0 \\
: \\
i \\
ن\end{array}$ & 1 & 1 & $\begin{array}{l}\stackrel{8}{0} \\
\stackrel{0}{+}\end{array}$ & $: 1$ & : & ֻٕ & 1 & 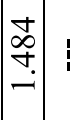 & $!$ & 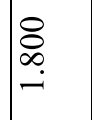 & 1 & 1 \\
\hline & & 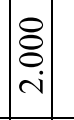 & 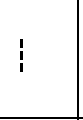 & 1 & $\begin{array}{l}\tilde{N} \\
\tilde{n} \\
\tilde{m}\end{array}$ & $1: 1$ & 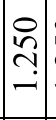 & तે & i & $\left(\begin{array}{c}\stackrel{n}{2} \\
\hdashline \\
\hdashline\end{array} \mid\right.$ & : & $\stackrel{\substack{n \\
\hdashline \\
\rightarrow}}{-1}$ & 1 & 1 \\
\hline & & $\mid \begin{array}{c}8 \\
\vdots \\
\infty\end{array}$ & 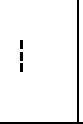 & : & 1 & $\left.\mid \begin{array}{l|l}0 \\
\vdots \\
\vdots \\
\vdots\end{array}\right)$ & 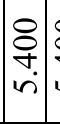 & 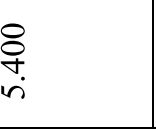 & 1 & 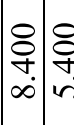 & 它 & 1 & 1 & 1 \\
\hline & & $\mid$\begin{tabular}{c}
8 \\
\hdashline \\
$\infty$
\end{tabular} & & | & $\begin{array}{l}\text { ¿े } \\
\text { త্ } \\
\end{array}$ & $: 1:$ & $\begin{array}{l}0 \\
\vdots \\
\dot{v}\end{array}$ & 8 & ! & $1:$ & 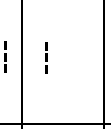 & 1 & 1 & 1 \\
\hline$\Xi$ & 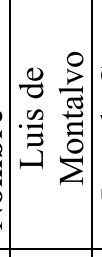 & 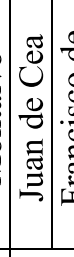 & 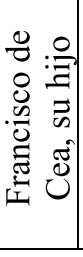 & 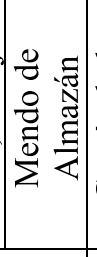 & 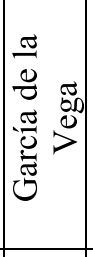 & 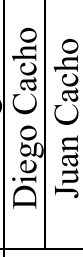 & 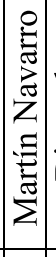 & 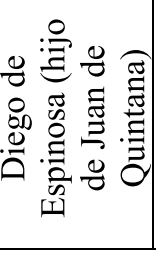 & 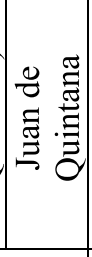 & 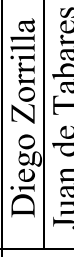 & 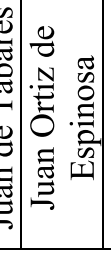 & 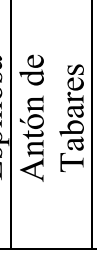 & 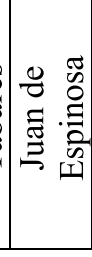 & 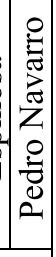 \\
\hline & & 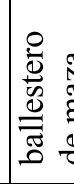 & 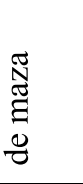 & & 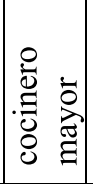 & & & 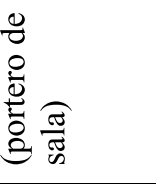 & & & & & & \\
\hline
\end{tabular}




\begin{tabular}{|c|c|c|c|c|c|c|c|c|c|c|}
\hline $\mid$ & 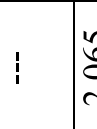 & 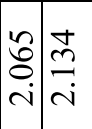 & : & & 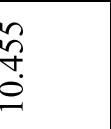 & 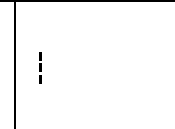 & 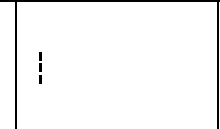 & 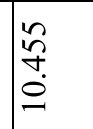 & i & $\begin{array}{l}n \\
\hat{y} \\
\stackrel{n}{9}\end{array}$ \\
\hline $\mid$ & & 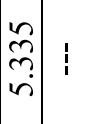 & ! & & : & $\begin{array}{l}\infty \\
\substack{\infty \\
i \\
i}\end{array}$ & 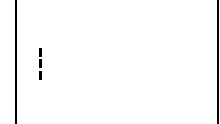 & 苂 & 1 & బ్ \\
\hline$\hat{a}$ & & 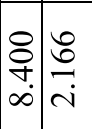 & ! & & i. & 离 & 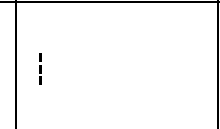 & 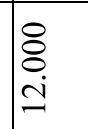 & : & 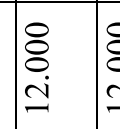 \\
\hline $\mathscr{g}$ & & 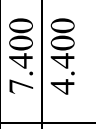 & : & & $\begin{array}{l}8 \\
\text { ì } \\
\end{array}$ & 곡 & 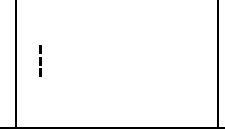 & 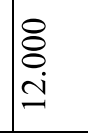 & : & 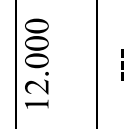 \\
\hline$\tilde{\tilde{g}}$ & & ণ্ণ் & : & & ¿ & 곡 & 1 & 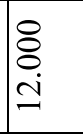 & : & $\begin{array}{l}\text { ه্ } \\
\text { İ }\end{array}$ \\
\hline$\overline{\vec{g}}$ & & 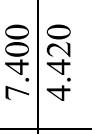 & : & & 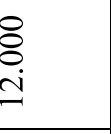 & 공 & i & 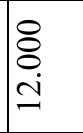 & $\begin{array}{l}\stackrel{8}{0} \\
\text { î } \\
\end{array}$ & 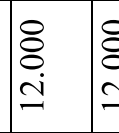 \\
\hline すิ & & $\begin{array}{c}8 \\
\stackrel{8}{+}: 1\end{array}$ & : & & : & 恿 & : & 1 & | & 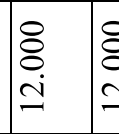 \\
\hline 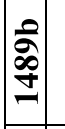 & & i: & | & & $\underset{+}{8}$ & 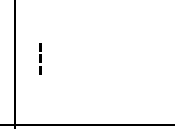 & 1 & 1 & 1 & $\begin{array}{l}\stackrel{8}{8} \\
\dot{+} \\
\end{array}$ \\
\hline 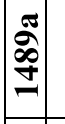 & & i & | & & 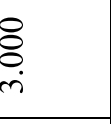 & 1 & 1 & : & I & 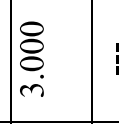 \\
\hline $\mid$\begin{tabular}{c}
$\infty$ \\
$\infty$ \\
\hdashline \\
\hdashline
\end{tabular} & & | & 월 & & 동 & 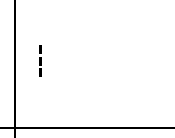 & 1 & : & : & 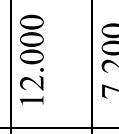 \\
\hline$\stackrel{\infty}{\mathfrak{\infty}}$ & & : & 올 & & त्. & ঙำ & 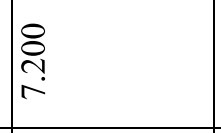 & : & 1 & 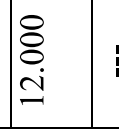 \\
\hline \begin{tabular}{l|l} 
\\
$\vdots$ \\
$\vdots$
\end{tabular} & 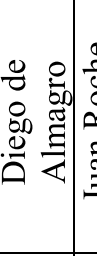 & 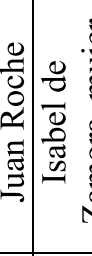 & ส․ & & 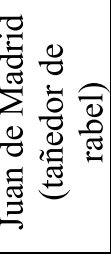 & 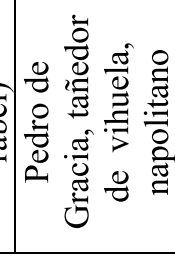 & 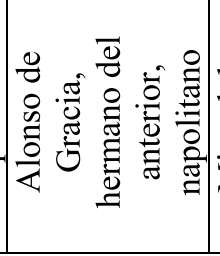 & 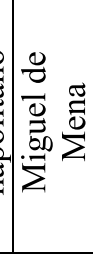 & 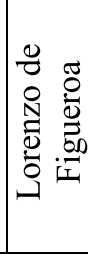 & 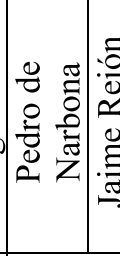 \\
\hline & 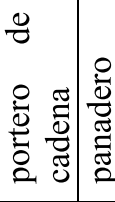 & 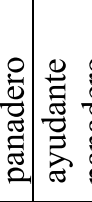 & 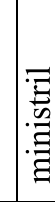 & & & & & & & 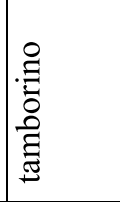 \\
\hline
\end{tabular}




\begin{tabular}{|c|c|c|c|c|c|c|c|c|c|c|c|c|c|}
\hline 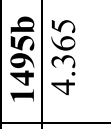 & 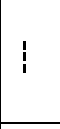 & 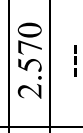 & : & 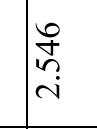 & i & : & 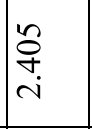 & 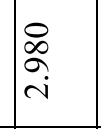 & 足 & & i & 1 & $i$ \\
\hline 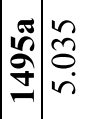 & 1 & : & 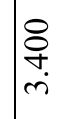 & 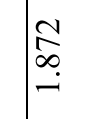 & 1 & 1 & ণ્ণ & $\underset{\mathfrak{d}}{\stackrel{f}{\mathfrak{g}}}$ & 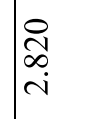 & $\begin{array}{l}\vec{b} \\
\dot{b} \\
i \\
\text { in }\end{array}$ & 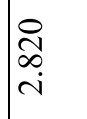 & 䓌 & 1 \\
\hline 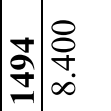 & 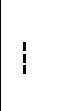 & $\mid$ & 总 & 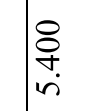 & i & : & 总 & $\begin{array}{l}\stackrel{1}{\tilde{N}} \\
\stackrel{+}{+}\end{array}$ & 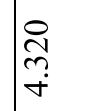 & \begin{tabular}{l}
8 \\
0 \\
0 \\
0 \\
\hdashline
\end{tabular} & 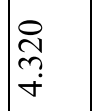 & \begin{tabular}{l}
8 \\
$\vdots$ \\
0 \\
\\
\hdashline
\end{tabular} & 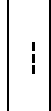 \\
\hline 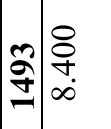 & 1 & : & $\mid \begin{array}{l}0 \\
\vdots \\
0 \\
0\end{array}$ & 栄 & 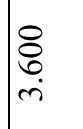 & $\begin{array}{l}8 \\
\vdots \\
\dot{ \pm}\end{array}$ & 1 & 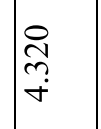 & 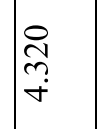 & 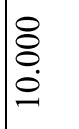 & 离 & 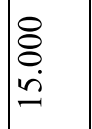 & 1 \\
\hline 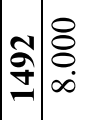 & 1 & 1 : & : & $\begin{array}{l}8 \\
\vdots \\
\vdots \\
\text { in }\end{array}$ & : & $\begin{array}{l}\stackrel{8}{0} \\
\dot{+}\end{array}$ & i & $\begin{array}{l}\stackrel{\mathrm{J}}{2} \\
\stackrel{+}{*}\end{array}$ & i & 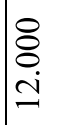 & $\begin{array}{l}\text { స్ } \\
\stackrel{్}{+}\end{array}$ & 离 & $i$ \\
\hline 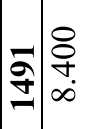 & i & 1 & $\mid \begin{array}{l}0 \\
0 \\
0 \\
0\end{array}$ & 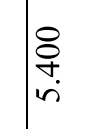 & : & $\begin{array}{l}8 \\
0 \\
\dot{I}\end{array}$ & : & 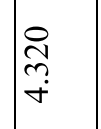 & 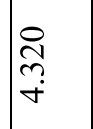 & $\begin{array}{l}8 \\
\stackrel{0}{0} \\
\dot{0}\end{array}$ & $\begin{array}{l}\text { D } \\
\text { ñ } \\
\text { in }\end{array}$ & $\begin{array}{l}8 \\
\vdots \\
0 \\
\end{array}$ & \begin{tabular}{l}
8 \\
\hdashline \\
\hdashline
\end{tabular} \\
\hline 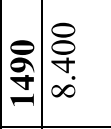 & i & : & 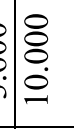 & $\begin{array}{l}8 \\
\vdots \\
\text { in } \\
\text { n. }\end{array}$ & 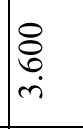 & $\begin{array}{l}8 \\
\vdots \\
\pm \\
\end{array}$ & 1 & $\begin{array}{l}\stackrel{8}{2} \\
\stackrel{2}{+}\end{array}$ & : & $\begin{array}{l}8 \\
\substack{n \\
\\
i \\
i}\end{array}$ & 总 & 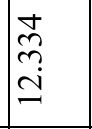 & $\begin{array}{l}0 \\
8 \\
\dot{1} \\
\end{array}$ \\
\hline 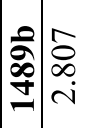 & i & 11 & $\stackrel{m}{m}$ & 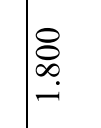 & $\mid$ & $\begin{array}{l}\stackrel{\rho}{o} \\
\underline{m} \\
0 \\
0\end{array}$ & : & 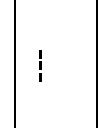 & 1 & 1 & 1 & 1 & $i$ \\
\hline 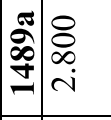 & & 11 & 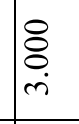 & 号 & \&ু & i & 1 & 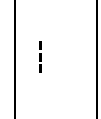 & 1 & 这 & 1 & 1 & 1 \\
\hline 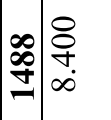 & 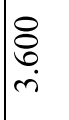 & 1 & 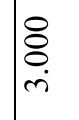 & 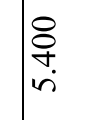 & 兽 & : & : & 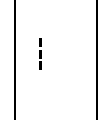 & 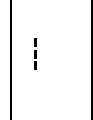 & $\begin{array}{l}0 \\
\stackrel{0}{0} \\
0 \\
0\end{array}$ & i & : & 1 \\
\hline 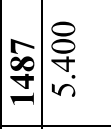 & $\begin{array}{l}\text { : } \\
\text { in }\end{array}$ & 11 & 号 & $\begin{array}{l}8 \\
\dot{a} \\
\text { in }\end{array}$ & : & ! & $\begin{array}{l}8 \\
0 \\
\dot{m} \\
\text {. }\end{array}$ & 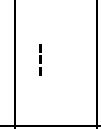 & 1 & : & 1 & 1 & $i$ \\
\hline |c & 荧 & 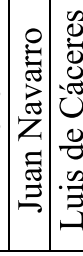 & 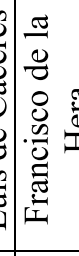 & 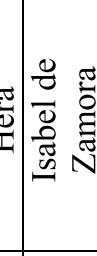 & : & 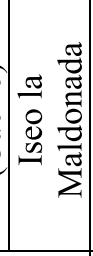 & 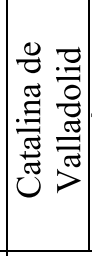 & 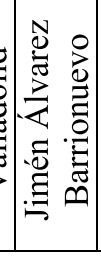 & 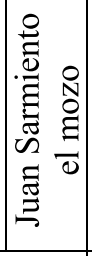 & 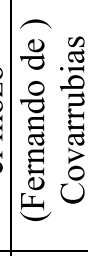 & 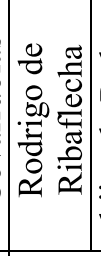 & 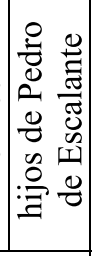 & 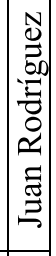 \\
\hline 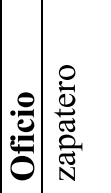 & 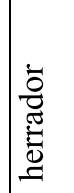 & & 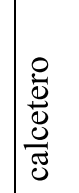 & 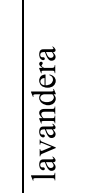 & & & $\mid$ & & & $\mid$ & 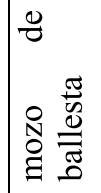 & & \\
\hline
\end{tabular}




\begin{tabular}{|c|c|c|c|c|c|c|c|c|c|c|c|c|c|c|c|}
\hline 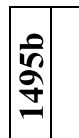 & 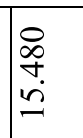 & 各 & 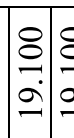 & $\begin{array}{l}8 \\
\stackrel{8}{9} \\
\stackrel{9}{9}\end{array}$ & \begin{tabular}{|l|} 
\\
$\stackrel{0}{0}$ \\
2 \\
\end{tabular} & \begin{tabular}{l}
$\stackrel{8}{0}$ \\
\hdashline
\end{tabular} & & 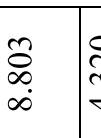 & $\begin{array}{l}\stackrel{乛}{\tilde{\sigma}} \\
\stackrel{+}{+}\end{array}$ & 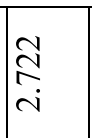 & 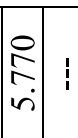 & ; & 1 & i & ! \\
\hline 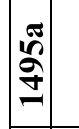 & 1 & 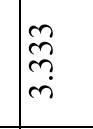 & 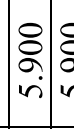 & $\begin{array}{l}8 \\
\text { a } \\
\text { in }\end{array}$ & $\begin{array}{l}8 \\
\text { ¿. } \\
\text { in } \\
\end{array}$ & $\begin{array}{l}8 \\
\text { ¿ } \\
\text { in }\end{array}$ & & 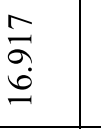 & 1 & $\begin{array}{l}\infty \\
\vdots \\
0 \\
i \\
\end{array}$ & 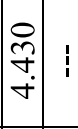 & : & $\mid \begin{array}{l}\stackrel{8}{a} \\
\dot{m}\end{array}$ & 1 & i \\
\hline $\begin{array}{l}\vec{z} \\
\dot{q} \\
\end{array}$ & 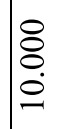 & $\begin{array}{l}8 \\
\stackrel{8}{0} \\
0 \\
0\end{array}$ & $\left|\begin{array}{l}8 \\
\vdots \\
\hdashline \\
ن\end{array}\right|$ & $\begin{array}{l}8 \\
\text { ¿े } \\
\text { in }\end{array}$ & 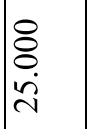 & $\begin{array}{l}8 \\
8 \\
\text { ì }\end{array}$ & & 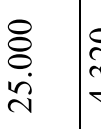 & $\begin{array}{l}\text { ָे } \\
\text { r } \\
+\end{array}$ & 1 & ف: & & 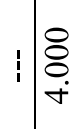 & 1 & 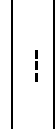 \\
\hline$\hat{\tilde{q}}$ & 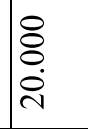 & $\begin{array}{l}8 \\
\vdots \\
0 \\
0\end{array}$ & $\left|\begin{array}{l}\vdots \\
\vdots \\
\vdots \\
\vdots\end{array}\right|$ & $\begin{array}{l}8 \\
8 \\
\text { ते }\end{array}$ & $\mid \begin{array}{l}8 \\
\vdots \\
\dot{i} \\
\end{array}$ & $\begin{array}{l}8 \\
8 \\
\text { ì }\end{array}$ & & 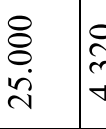 & ले & 章 & 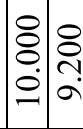 & 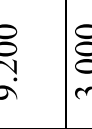 & : & $\begin{array}{l}8 \\
\text { O } \\
\text { İ }\end{array}$ & $\begin{array}{l}8 \\
0 \\
0 \\
0\end{array}$ \\
\hline$\hat{\tilde{g}}$ & 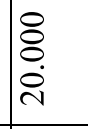 & $\begin{array}{l}8 \\
8 \\
0 \\
0\end{array}$ & 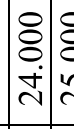 & $\begin{array}{l}8 \\
\text { ¿े } \\
\text { i. } \\
\end{array}$ & i & : & : & 1 & $\begin{array}{l}\stackrel{\tilde{N}}{+} \\
\stackrel{+}{+}\end{array}$ & $\begin{array}{l}8 \\
\vdots \\
i \\
\end{array}$ & & : & 1 & 1 & 1 \\
\hline$\overline{\bar{g}}$ & 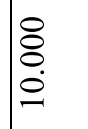 & 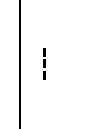 & : & 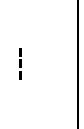 & 1 & i & $1:$ & 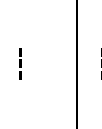 & 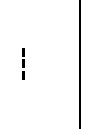 & 1 & & : & : & 1 & 1 \\
\hline $\mid$ & 1 & 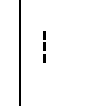 & & 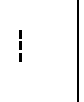 & 1 & ! & & 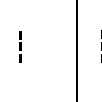 & 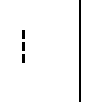 & 1 & & ; & : & : & 1 \\
\hline $\mid$\begin{tabular}{|}
$\overline{\mathbf{\alpha}}$ \\
$\bar{a}$ \\
\end{tabular} & 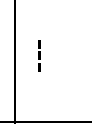 & 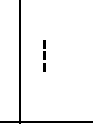 & & 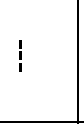 & 1 & 1 & $1: 1$ & 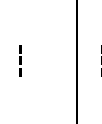 & 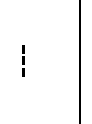 & 1 & & ! & 1 & 1 & : \\
\hline 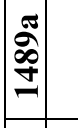 & 1 & 1 & & 1 & 1 & 1 & 11 & 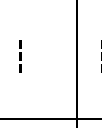 & 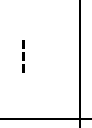 & 1 & & ; & 1 & 1 & 1 \\
\hline 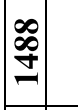 & 1 & 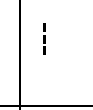 & 1 & 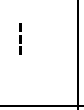 & 1 & 1 & 1 & 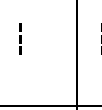 & 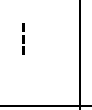 & 1 & & ; & $:$ & i & $:$ \\
\hline $\begin{array}{l}\tilde{\infty} \\
\stackrel{\infty}{=}\end{array}$ & 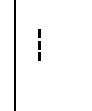 & 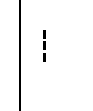 & & 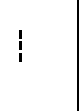 & 1 & ! & & : & 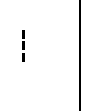 & 1 & & ; & 1 & 1 & 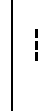 \\
\hline 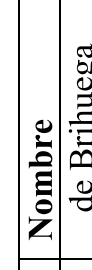 & 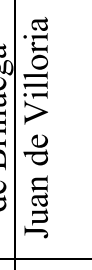 & 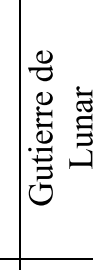 & 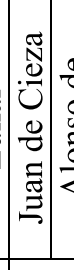 & 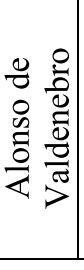 & 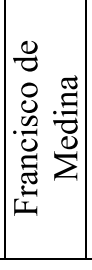 & 列 & 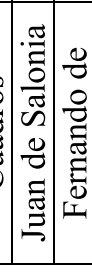 & 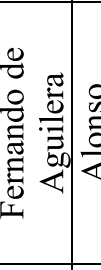 & 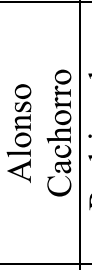 & 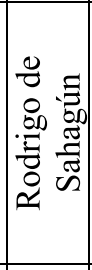 & 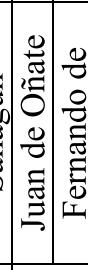 & 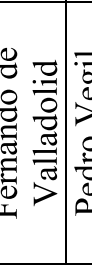 & 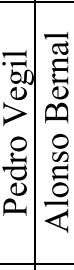 & 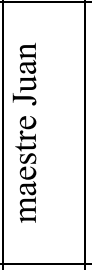 & 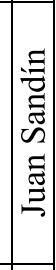 \\
\hline $\mid$ & 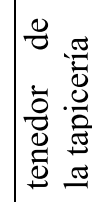 & 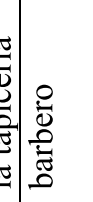 & 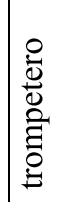 & & & & & & 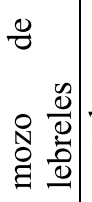 & 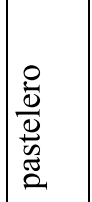 & 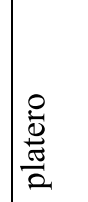 & & & 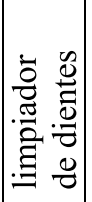 & \\
\hline
\end{tabular}




\begin{tabular}{|c|c|c|c|c|c|c|c|c|c|c|c|c|c|}
\hline 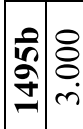 & & & 哭 & 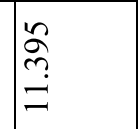 & $\mid \begin{array}{l}9 \\
\dot{q} \\
\infty \\
\dot{+}\end{array}$ & $\begin{array}{l}\infty \\
\infty \\
\infty \\
n \\
m \\
m\end{array}$ & $\begin{array}{l}8 \\
\vdots \\
\dot{m} \\
\text { in }\end{array}$ & \begin{tabular}{|c|} 
\\
$\vdots$ \\
$ن$ \\
\end{tabular} & 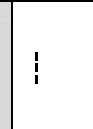 & 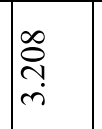 & શి: & 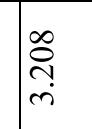 & $\vdots$ \\
\hline 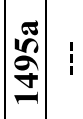 & & ! & 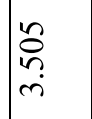 & $\begin{array}{l}n \\
\tilde{n} \\
n \\
n \\
n\end{array}$ & 辨 & $\begin{array}{l}\stackrel{7}{7} \\
\dot{I}\end{array}$ & 1 & 1 & 1 & $\cong$ & 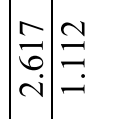 & 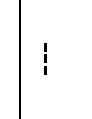 & 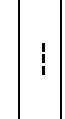 \\
\hline बे & & i & $\begin{array}{l}8 \\
\text { in } \\
i\end{array}$ & $\begin{array}{l}8 \\
0 \\
0 \\
1\end{array}$ & . & | & : & $i$ & 1 & 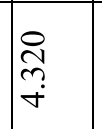 & 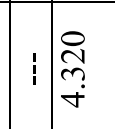 & 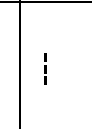 & $i$ \\
\hline$\hat{z}$ & $i$ & 1 & 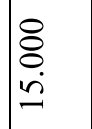 & 辛 & 1 & ： & 1 & $i$ & 1 & $\begin{array}{l}\text { ले } \\
\text { }\end{array}$ & 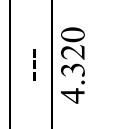 & $!$ & 1 \\
\hline$\tilde{\tilde{\Xi}}$ & 1 & 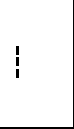 & 1 & 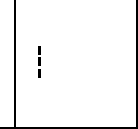 & : & i & : & 1 & 1 & 商 & il & 原 & $\begin{array}{l}\stackrel{2}{\sim} \\
\stackrel{\sim}{*}\end{array}$ \\
\hline $\mid \bar{q}$ & 1 & 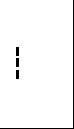 & 1 & 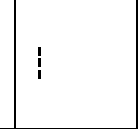 & : & i & : & 1 & 1 & $\begin{array}{l}\stackrel{\text { In }}{2} \\
\stackrel{\sim}{+}\end{array}$ & 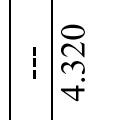 & 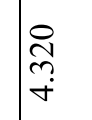 & $\begin{array}{l}\stackrel{\overbrace{}}{2} \\
\stackrel{\sim}{r}\end{array}$ \\
\hline ब̊ & $i$ & $!$ & 1 & 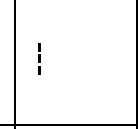 & 1 & ： & : & $1 \frac{\pi}{0}$ & 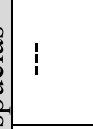 & 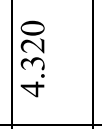 & : & 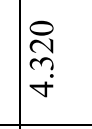 & 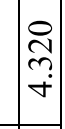 \\
\hline 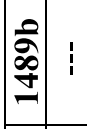 & 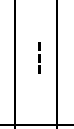 & 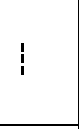 & 1 & 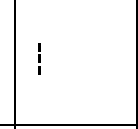 & : & | & | & $: \begin{array}{l}0 \\
1 \\
0 \\
0 \\
s\end{array}$ & 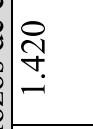 & 胥 & 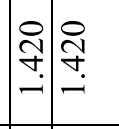 & 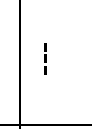 & 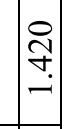 \\
\hline क् & $i$ & 1 & 1 & 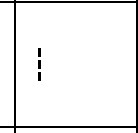 & 1 & i & : & $1^{\Sigma}$ & 年 & 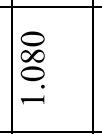 & 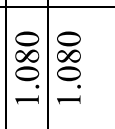 & 1 & $\mid$ \\
\hline 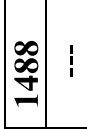 & $i$ & 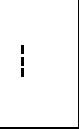 & 1 & 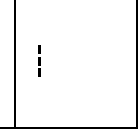 & 1 & : & : & 1 & 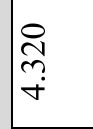 & 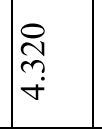 & 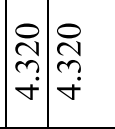 & 离 & $\mid \begin{array}{l}\mid \\
\text { ते } \\
\dot{+}\end{array}$ \\
\hline$\stackrel{\infty}{\substack{\infty \\
g}}$ & & $!$ & 1 & ! & : & : & | & 1 & $\begin{array}{l}\stackrel{1}{1} \\
\stackrel{\sim}{*} \\
+\end{array}$ & 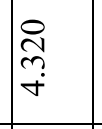 & 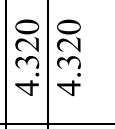 & $\mid \begin{array}{l}\overrightarrow{\tilde{N}} \\
\stackrel{\varpi}{+}\end{array}$ & 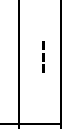 \\
\hline 总 & : & 递 & 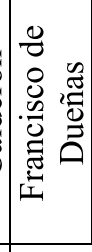 & 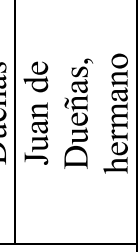 & 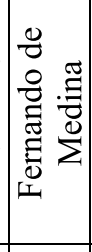 & 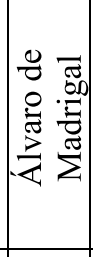 & 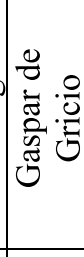 & 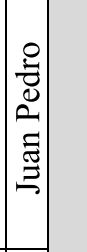 & 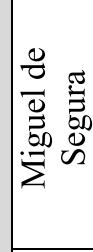 & 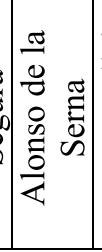 & 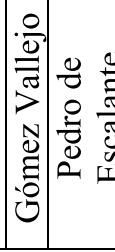 & 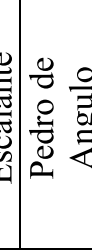 & 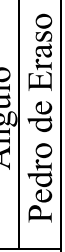 \\
\hline 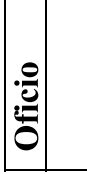 & & & 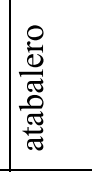 & & 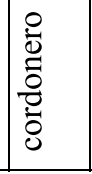 & \begin{tabular}{|l} 
童 \\
㟧 \\
\end{tabular} & 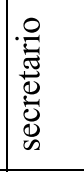 & 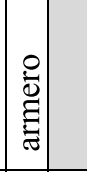 & $\begin{array}{l}0 \\
0 \\
0 \\
0 \\
0 \\
0 \\
0 \\
0 \\
0\end{array}$ & & & & \\
\hline
\end{tabular}




\begin{tabular}{|c|c|c|c|c|c|c|c|c|c|c|c|c|c|}
\hline $\begin{array}{l}\hat{0} \\
\hat{\sigma} \\
\bar{g}\end{array}$ & : & 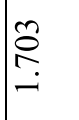 & 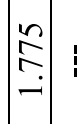 & $\stackrel{\substack{2 \\
i}}{i}$ & 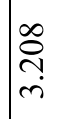 & 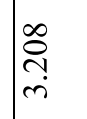 & $\stackrel{\Re}{\stackrel{R}{R}}$ & :ִ: & $\stackrel{2}{\stackrel{2}{\imath}}$ & 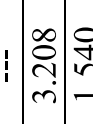 & 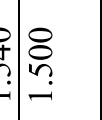 & . & \\
\hline 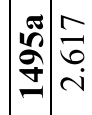 & 1 & 1 & $\mid \begin{array}{l}0 \\
\substack{0 \\
\\
i}\end{array}$ & $: \begin{array}{l}\overline{0} \\
i\end{array}$ & $\cong$ & $\cong$ & $\begin{array}{l}\tilde{N} \\
\overrightarrow{0} \\
i\end{array}$ & 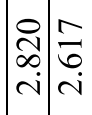 & 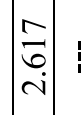 & $:=$ & : & ! & \\
\hline \begin{tabular}{l|l}
$\vec{g}$ & $\stackrel{\sim}{\sim}$ \\
$\stackrel{\sim}{+}$
\end{tabular} & 1 & 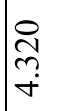 & 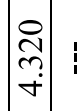 & : & 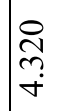 & $\begin{array}{l}\stackrel{\text { }}{\sim} \\
\stackrel{+}{\sigma}\end{array}$ & 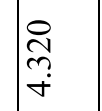 & il & 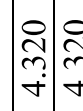 & 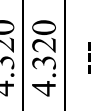 & ; & ! & \\
\hline 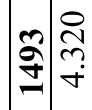 & 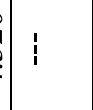 & $\begin{array}{l}\text { స్ } \\
\text { †े }\end{array}$ & 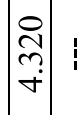 & : & 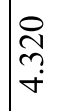 & 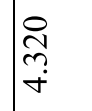 & 商 & 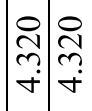 & 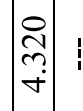 & 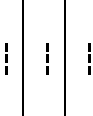 & : & 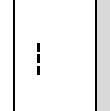 & \\
\hline$\tilde{\sigma}$ & i & $\begin{array}{l}\text { हे } \\
\text { के }\end{array}$ & 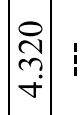 & : & 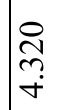 & ָे & ָे & స: & $1:$ & $\vdots:$ & : & 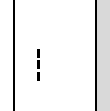 & \\
\hline$\exists$ & 1 & 1 & 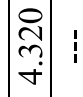 & 1: & 1 & 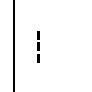 & 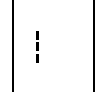 & 11 & $1:$ & $:$ & $:$ & ! & \\
\hline ఫ) & 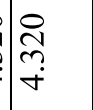 & $\begin{array}{l}\text { ते } \\
\text { के }\end{array}$ & 11 & 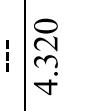 & : & 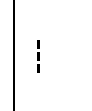 & 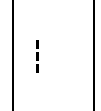 & $1: 1$ & 11 & $1:$ & : & 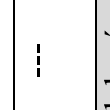 & \\
\hline 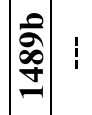 & $\stackrel{\text { จิ }}{-}$ & 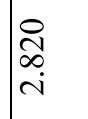 & 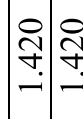 & : & 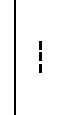 & 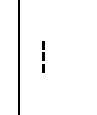 & 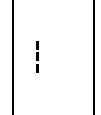 & $\begin{array}{llll}1 & 1\end{array}$ & $:$ & $\vdots$ & 1 & 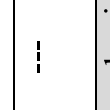 & \\
\hline 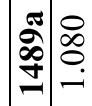 & 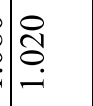 & $\frac{\stackrel{B}{i}}{i}$ & $\left(\begin{array}{l}: \\
\hdashline \\
\hdashline \\
\hdashline\end{array}\right.$ & 1 & 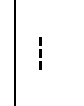 & 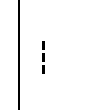 & 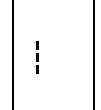 & $1: 1$ & $1:$ & 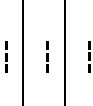 & $1:$ & 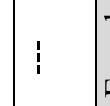 & 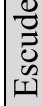 \\
\hline 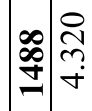 & 1 & 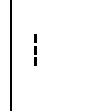 & $1:$ & i: & 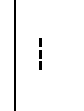 & 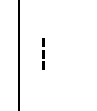 & 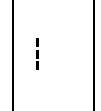 & $\begin{array}{l:l}1 & 1\end{array}$ & 1 & $\vdots$ & : & ! & \\
\hline 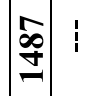 & 1 & : & $1:$ & ;: & i & 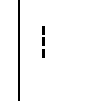 & $:$ & $1:$ & $: 1$ & $: 1$ & : & $\vdots$ & \\
\hline ב⿱ & 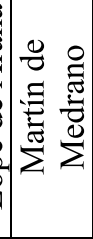 & $\begin{array}{l}0 \\
0 \\
0 \\
0 \\
0 \\
0 \\
0 \\
\frac{0}{2} \\
\frac{\pi}{4} \\
\end{array}$ & 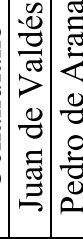 & 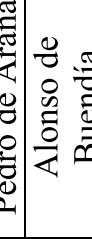 & 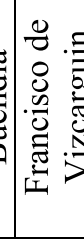 & 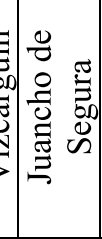 & 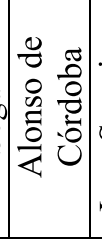 & 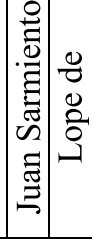 & 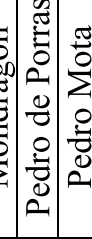 & 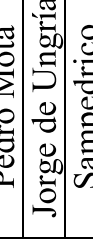 & $\begin{array}{l}: \\
:\end{array}$ & $\frac{2}{2}$ & \\
\hline 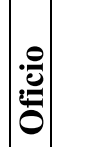 & & & & & & & & & & & & & \\
\hline
\end{tabular}




\begin{tabular}{|c|c|c|c|c|c|c|c|c|c|c|c|c|c|}
\hline 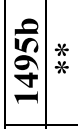 & $*$ & $*$ & $\begin{array}{ll}* & * \\
*\end{array}$ & $\stackrel{*}{*}$ & * & * & $\frac{*}{*} *$ & $*$ & 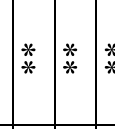 & * & \begin{tabular}{l|l}
$*$ & $*$ \\
$*$
\end{tabular} & \begin{tabular}{|l|l}
$* *$ & $*$ \\
$*$
\end{tabular} & ** $* *$ \\
\hline 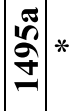 & * & * & * * & * & * & * & $* *$ & * & $* * *$ & * & $*$ & $* *$ & $* *$ \\
\hline 孛 & $\begin{array}{l}\stackrel{2}{2} \\
\stackrel{\infty}{+}\end{array}$ & 1 & $1: 1$ & 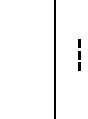 & : & 1 & $1:$ & : & $\begin{array}{lll}1 & 1\end{array}$ & $:$ & 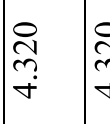 & 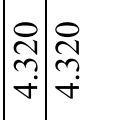 & 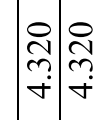 \\
\hline 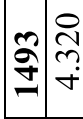 & 尽 & : & $1: 1$ & & : & 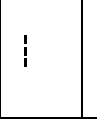 & $\begin{array}{l:l}1 & \vdots\end{array}$ & i & 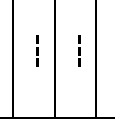 & 1 & 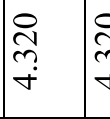 & 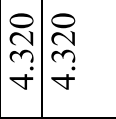 & 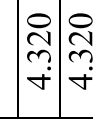 \\
\hline ปิ & 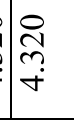 & 1 & $1:$ & & ; & 1 & $\begin{array}{l:l} & 1\end{array}$ & ! & $1:$ & 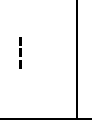 & : & 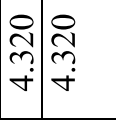 & 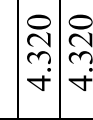 \\
\hline$\overline{\bar{g}}$ & i & 1 & $1: 1$ & 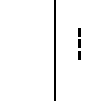 & ; & 1 & $::$ & : & $1: 1$ & 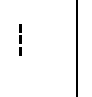 & : & $1:$ & $:$ \\
\hline 矛 & 离 & $\begin{array}{l}\text { त्र } \\
\text { +े } \\
\end{array}$ & $1: 1$ & 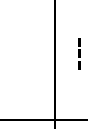 & : & 1 & $: 1$ & 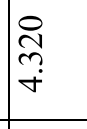 & 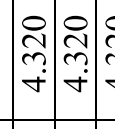 & ָे & 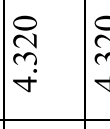 & 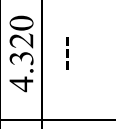 & 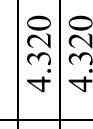 \\
\hline 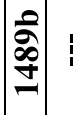 & 1 & 1 & $1: 1$ & ; & i & 1 & $\begin{array}{l:l} & 1\end{array}$ & 1 & $\begin{array}{l:l}1 & 1\end{array}$ & 1 & 1 & $: 1$ & $1: 1$ \\
\hline$\stackrel{\partial}{\stackrel{\partial}{d}}$ & 1 & 1 & $1: 1$ & : & : & ! & $\begin{array}{l:l}1 & 1\end{array}$ & 1 & $1: 1$ & 1 & 1 & :1: & $1:$ \\
\hline 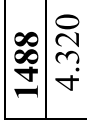 & $\begin{array}{l}\stackrel{2}{2} \\
\stackrel{\sigma}{+}\end{array}$ & $\begin{array}{l}\text { श्ञ } \\
\text { ซ }\end{array}$ & 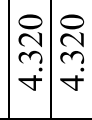 & 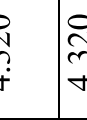 & 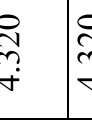 & 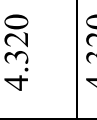 & 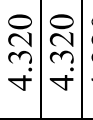 & 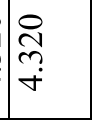 & 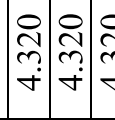 & 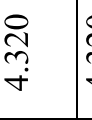 & 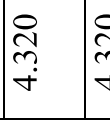 & 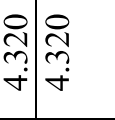 & 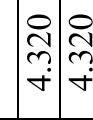 \\
\hline 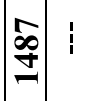 & i & i & $1: 1$ & 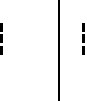 & ; & 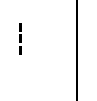 & $1: 1$ & 1 & $1: 1$ & 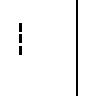 & : & $1:$ & 1 \\
\hline 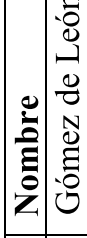 & $\mid \begin{array}{ll}0 \\
0 \\
0\end{array}$ & 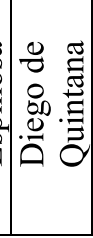 & 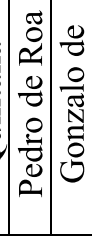 & \begin{tabular}{l|l}
0 \\
0
\end{tabular} & 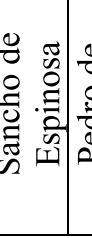 & 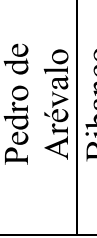 & 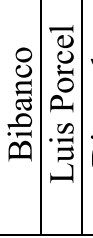 & 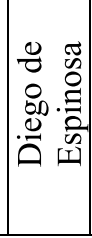 & 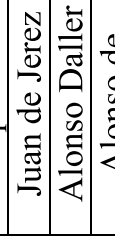 & 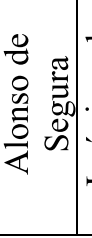 & 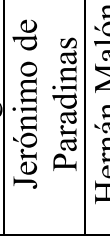 & 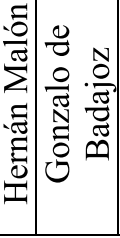 & 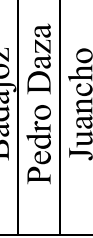 \\
\hline : & & & & & & & & & & & & & \\
\hline
\end{tabular}




\begin{tabular}{|c|c|c|c|c|c|c|c|c|c|c|c|c|c|c|c|}
\hline $\mid \begin{array}{l}\overrightarrow{\hat{a}} \\
\hat{\mathfrak{z}}\end{array}$ & 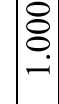 & $*$ & * & * & $*$ & $*$ & $\stackrel{*}{*}$ & $*$ & $\stackrel{*}{*}$ & $*$ & $\begin{array}{ll}* & * \\
* & *\end{array}$ & $: *$ & $*$ & $*$ & $*$ \\
\hline 恕 & $*$ & $*$ & $*$ & $*$ & * & $*$ & $*$ & $*$ & $*$ & $*$ & $* \quad *$ & $*$ & $*$ & $*$ & $*$ \\
\hline 竎 & 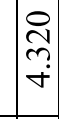 & $\begin{array}{l}\stackrel{\sim}{2} \\
\sim \\
\sim\end{array}$ & $\begin{array}{l}\stackrel{N}{1} \\
\text { } \\
\stackrel{+}{+}\end{array}$ & $i$ & $\begin{array}{l}\stackrel{\sim}{2} \\
\text { }\end{array}$ & $\begin{array}{l}\underset{N}{n} \\
\underset{\sim}{+}\end{array}$ & $\begin{array}{l}\stackrel{N}{2} \\
\text { } \\
+\end{array}$ & & 1 & 1 & 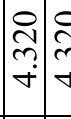 & 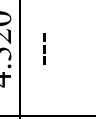 & 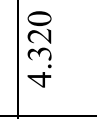 & $\begin{array}{l}\stackrel{\text { }}{2} \\
\stackrel{\sim}{+}\end{array}$ & 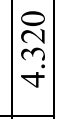 \\
\hline$\hat{\mathfrak{g}}$ & 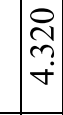 & 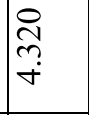 & 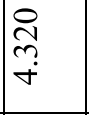 & & $\begin{array}{l}\stackrel{\text { }}{\sim} \\
\stackrel{+}{2}\end{array}$ & $\begin{array}{l}\stackrel{\sim}{N} \\
\underset{\sim}{+}\end{array}$ & $\begin{array}{l}\text { î } \\
\text { } \\
+\end{array}$ & $\mid \begin{array}{l}1 \\
1\end{array}$ & i & i & 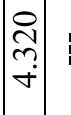 & $\mid \begin{array}{l}\stackrel{\sim}{N} \\
\sim \\
+\end{array}$ & i্ & $\begin{array}{l}\stackrel{\text { }}{ } \\
\stackrel{+}{+}\end{array}$ & 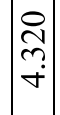 \\
\hline$\tilde{\sigma}$ & 尽 & 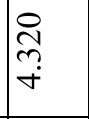 & $\begin{array}{r}\stackrel{N}{\sim} \\
\text { } \\
+ \\
\end{array}$ & & $\begin{array}{l}\stackrel{N}{\sim} \\
\stackrel{\sim}{+}\end{array}$ & $\begin{array}{l}\stackrel{\text { }}{2} \\
\stackrel{\sim}{+} \\
\end{array}$ & $\begin{array}{l}\stackrel{\text { }}{2} \\
\text { ஸे }\end{array}$ & $i$ & i & 尽 & 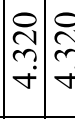 & 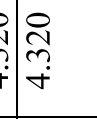 & $\mid \begin{array}{c}\stackrel{N}{m} \\
\underset{\sim}{+}\end{array}$ & $\begin{array}{l}\stackrel{\text { }}{\sim} \\
\stackrel{+}{*}\end{array}$ & 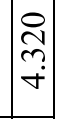 \\
\hline$\overline{\vec{z}}$ & 1 & $!$ & 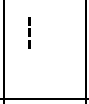 & i & ! & $!$ & ! & $\vdots$ & i & i & 1 & 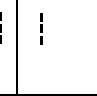 & $!$ & 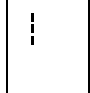 & $\dot{1}$ \\
\hline ఫे & 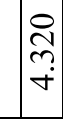 & 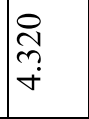 & 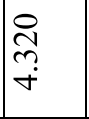 & 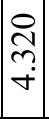 & $\begin{array}{l}\stackrel{一}{\sim} \\
\stackrel{+}{+}\end{array}$ & $\begin{array}{l}\stackrel{7}{2} \\
\stackrel{\sim}{+} \\
+\end{array}$ & 尽 & 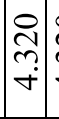 & 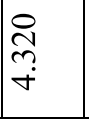 & $\vdots$ & 1 & 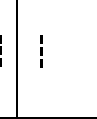 & 1 & $!$ & 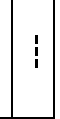 \\
\hline 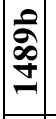 & i & 1 & 1 & i & I & 1 & I & $\mid \begin{array}{l}1 \\
i \\
1\end{array}$ & 1 & i & \begin{tabular}{ll|l}
1 & 1
\end{tabular} & ! & $!$ & $!$ & $\vdots$ \\
\hline 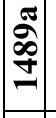 & i & 1 & 1 & 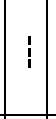 & 1 & 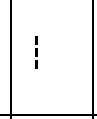 & 1 & $\mid \begin{array}{l}1 \\
1\end{array}$ & 1 & 1 & 11 & 1 & 1 & 1 & 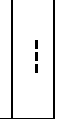 \\
\hline $\left.\mid \begin{array}{c}\infty \\
\infty \\
\vdots \\
-\end{array}\right]$ & 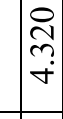 & 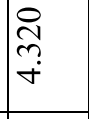 & ! & 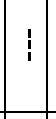 & 1 & 1 & I & $\mid$ & i & i & \begin{tabular}{ll|l}
1 & 1
\end{tabular} & 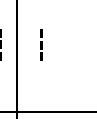 & 1 & 1 & 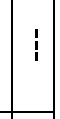 \\
\hline $\begin{array}{r}\infty \\
\dot{\infty} \\
\dot{=}\end{array}$ & $i$ & 1 & 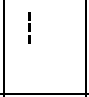 & 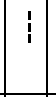 & 1 & 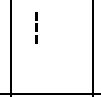 & ! & $\vdots$ & 1 & 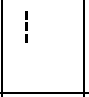 & $1:$ & 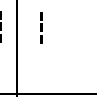 & 1 & 1 & 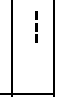 \\
\hline 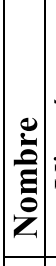 & 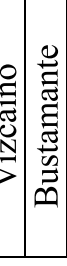 & 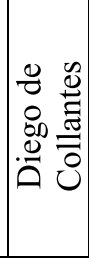 & 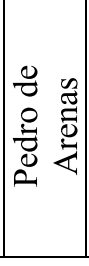 & 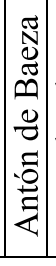 & 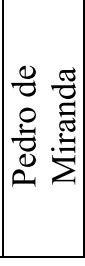 & 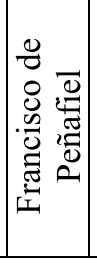 & 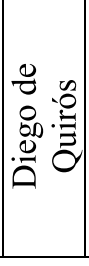 & 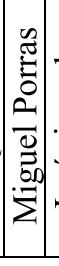 & 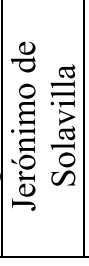 & 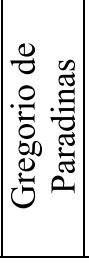 & 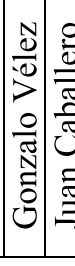 & 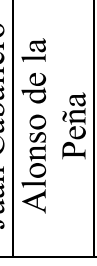 & $\begin{array}{cc}0 & 0 \\
0 & 0 \\
0 & 0 \\
0 & 0 \\
0 & 0 \\
0 & 0 \\
2 & 1 \\
0\end{array}$ & 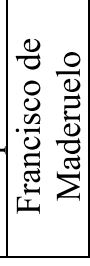 & 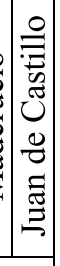 \\
\hline 量 & & & & & & & & & & & & & & & \\
\hline
\end{tabular}




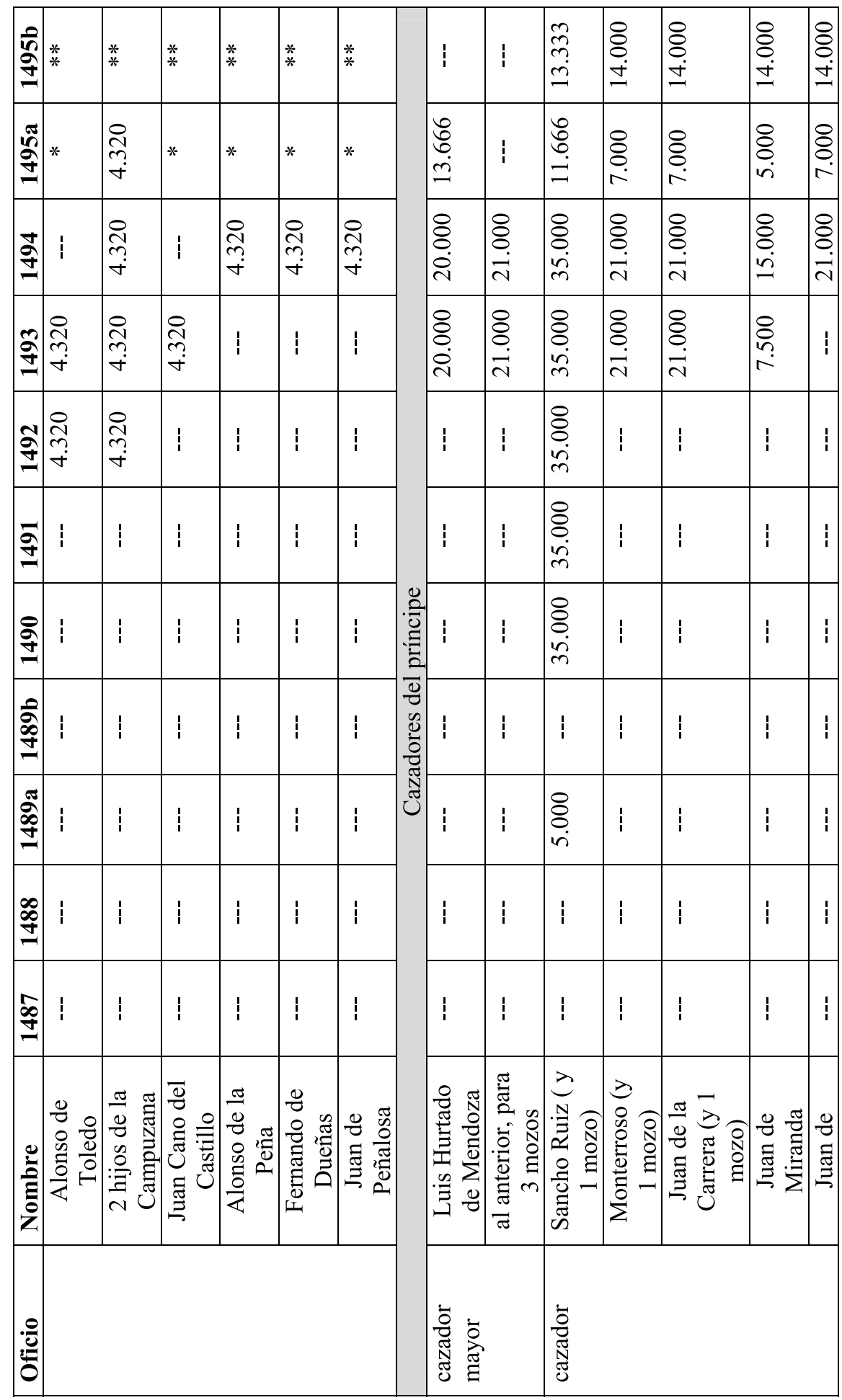




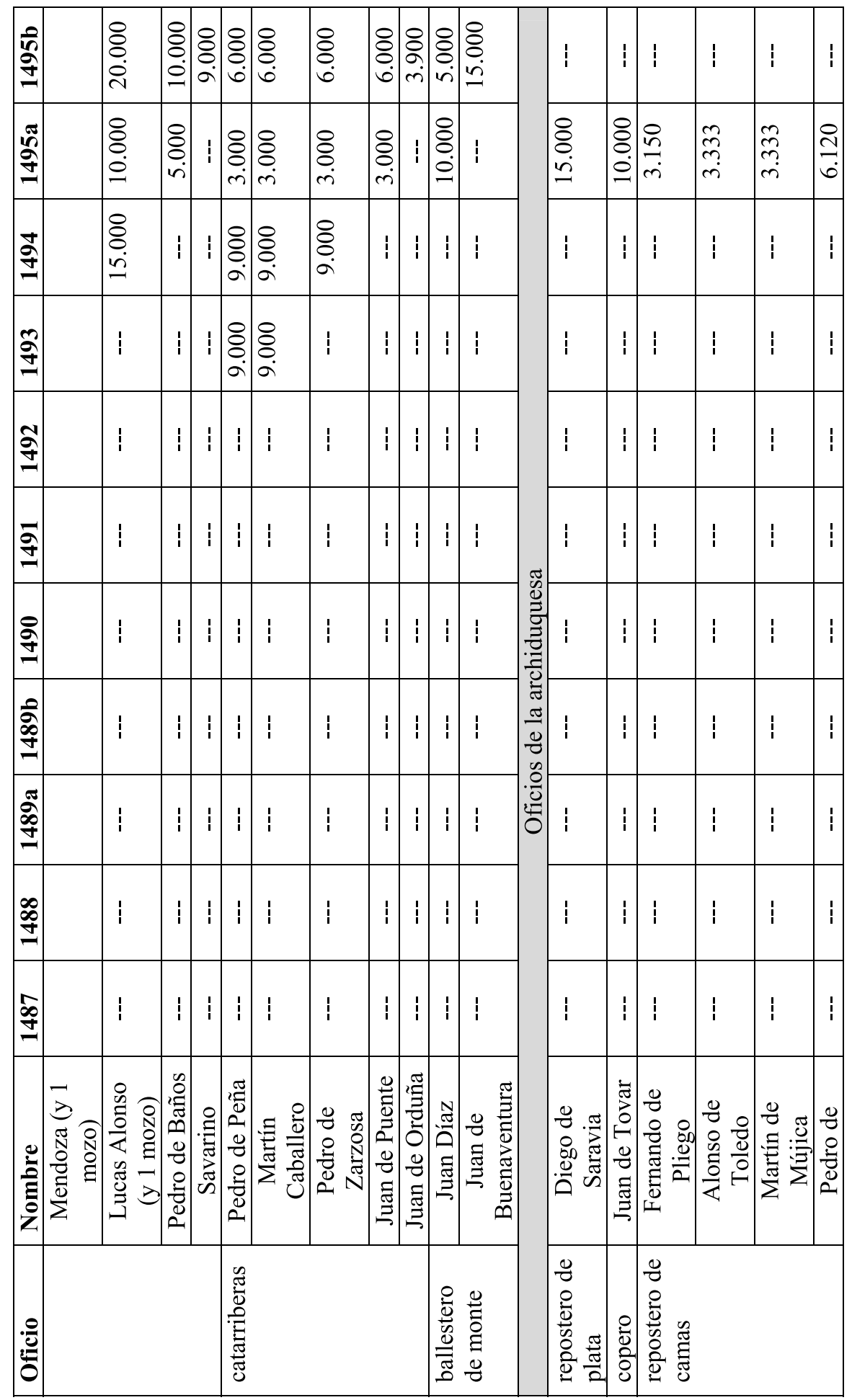




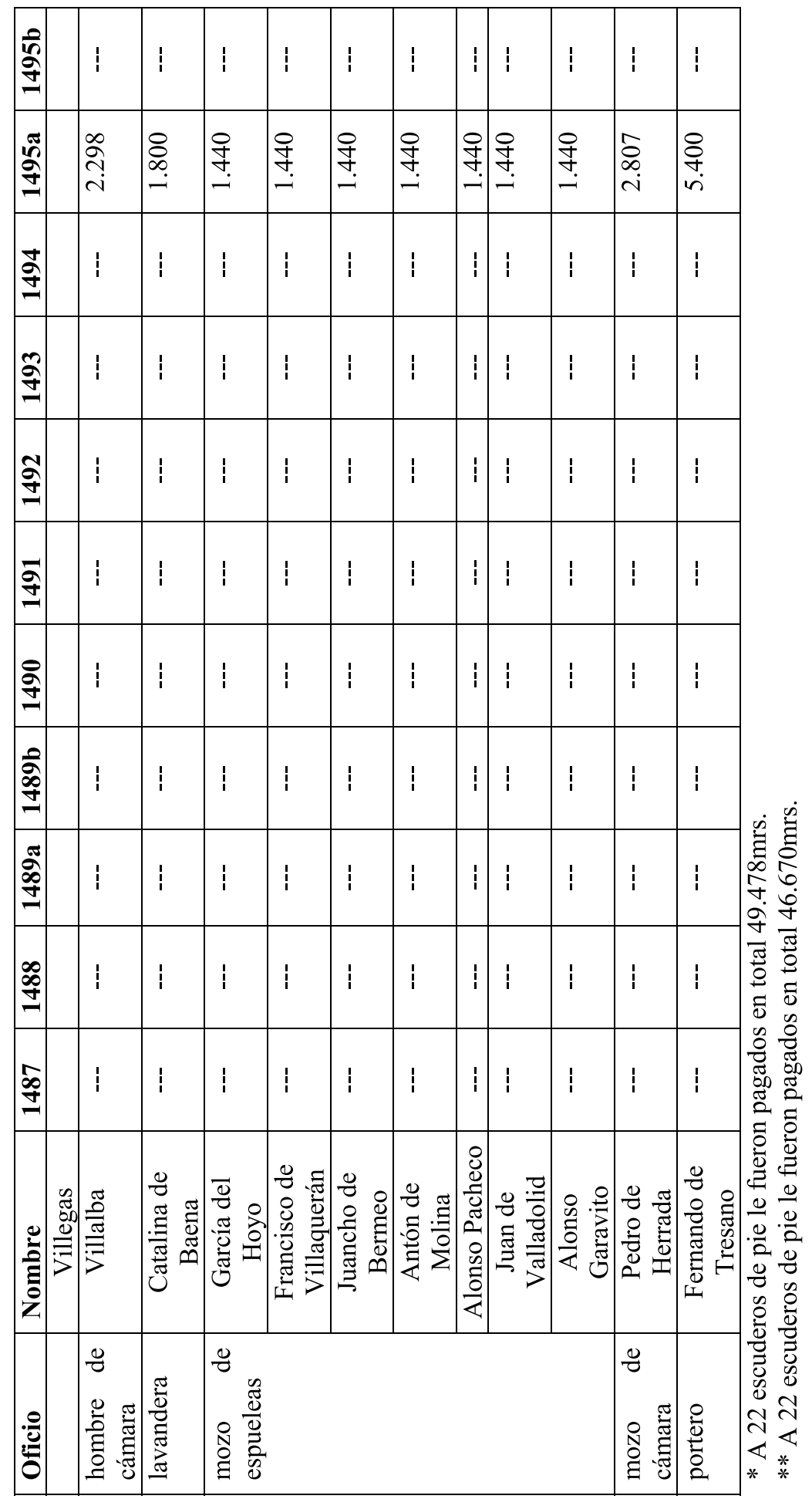


Tabla 2: Servidores de la Corte y Casa del Príncipe Juan, antes y después de su emancipación, por secciones y categorías* (Funcionarios, Oficiales y Asalariados), y sus quitaciones y raciones en maravedís

\begin{tabular}{|c|c|c|c|c|c|}
\hline Sección & Puesto & Nombre & $*$ & Quitación & Ración \\
\hline \multirow[t]{21}{*}{ Justicia } & $\begin{array}{l}\text { Presidente del } \\
\text { Consejo }\end{array}$ & Álvaro de Portugal & \multirow[t]{21}{*}{$\mathrm{F}$} & & \\
\hline & \multirow{3}{*}{$\begin{array}{l}\text { Secretarios del } \\
\text { Consejo }\end{array}$} & Gaspar de Grizio & & & \\
\hline & & Pedro de Torres & & & \\
\hline & & $\begin{array}{l}\text { Fernán de Álvarez } \\
\text { Zapata }\end{array}$ & & & \\
\hline & $\begin{array}{l}\text { Escribano del } \\
\text { Consejo }\end{array}$ & Gaspar de Grizio & & & \\
\hline & \multirow[t]{6}{*}{$\begin{array}{l}\text { Letrados del } \\
\text { Consejo }\end{array}$} & $\begin{array}{l}\text { Dr. Martín Fernández } \\
\text { de Angulo }\end{array}$ & & & \\
\hline & & licenciado Luis Zapata & & \multirow[t]{2}{*}{50.000} & \\
\hline & & licenciado Múgica & & & \\
\hline & & doctor Oropesa & & & \\
\hline & & $\begin{array}{l}\text { doctor Juan de } \\
\text { Talavera }\end{array}$ & & & \\
\hline & & Sancho de Castilla & & & \\
\hline & \multirow{6}{*}{$\begin{array}{l}\text { ¿Otros } \\
\text { miembros del } \\
\text { Consejo? }\end{array}$} & Fernán Duque & & & \\
\hline & & Belondo Guitar & & & \\
\hline & & $\begin{array}{l}\text { Gonzalo de Estrada o } \\
\text { de Sala }\end{array}$ & & & \\
\hline & & Francisco de Hocho & & & \\
\hline & & Juan Martínez & & & \\
\hline & & Alonso de la Puente & & & \\
\hline & Alcalde & $\begin{array}{l}\text { licenciado Luis de } \\
\text { Polanco }\end{array}$ & & & \\
\hline & \multirow[t]{3}{*}{ Alguaciles } & Bernal de Pisa & & & \\
\hline & & Vallejo & & & \\
\hline & & Herrán & & & \\
\hline \multirow[t]{2}{*}{ Guerra } & Guión & Gracián & $\mathrm{O}$ & & \\
\hline & Alférez & $\begin{array}{l}\text { Juan de Silva, conde de } \\
\text { Cifuentes }\end{array}$ & \multirow[t]{7}{*}{$\mathrm{F}$} & & \\
\hline \multirow[t]{4}{*}{ Hacienda } & \multirow[t]{4}{*}{ Contador mayor } & $\begin{array}{l}\text { Fernando Pérez } \\
\text { Coronel }\end{array}$ & & & \\
\hline & & $\begin{array}{l}\text { Juan Velázquez de } \\
\text { Cuéllar }\end{array}$ & & \multicolumn{2}{|c|}{132.000} \\
\hline & & $\begin{array}{l}\text { Pedro Núñez de } \\
\text { Guzmán }\end{array}$ & & & \\
\hline & & Íñigo López Coronel & & & \\
\hline \multirow[t]{2}{*}{$\begin{array}{l}\text { Despen- } \\
\text { sa }\end{array}$} & \multirow[t]{2}{*}{$\begin{array}{l}\text { Contador mayor } \\
\text { de la despensa }\end{array}$} & $\begin{array}{l}\text { Gonzalo Chacón el } \\
\text { Viejo }\end{array}$ & & & \multirow[t]{2}{*}{$\begin{array}{l}\text { cera y } \\
\text { comida }\end{array}$} \\
\hline & & Gonzalo Chacón el & & & \\
\hline
\end{tabular}




\begin{tabular}{|c|c|c|c|c|c|}
\hline Sección & Puesto & Nombre & $*$ & Quitación & Ración \\
\hline & & Joven & & & \\
\hline & $\begin{array}{l}\text { Teniente de } \\
\text { Contador mayor } \\
\text { de la despensa }\end{array}$ & $\begin{array}{l}\text { Juan de Torres de } \\
\text { Murcia }\end{array}$ & $\mathrm{O}$ & & \\
\hline & Despensero & Pedro de Arezo & $\mathrm{F}$ & & \\
\hline & mayor & Pedro de Medina & & & \\
\hline & & Juan de Codorniz & & & \\
\hline & & Juan de Ribasaltas & & & \\
\hline & & $\begin{array}{l}\text { Francisco Ramírez de } \\
\text { Madrid }\end{array}$ & & & \\
\hline & & Juan Ramírez & & & \\
\hline & Veedor & García de Badajoz & $\mathrm{O}$ & & \\
\hline & & Álvaro de Mercado & & & \\
\hline & & Fernando de Mercado & & & \\
\hline & & Pedro Patiño & & & \\
\hline & Secretario** & $\begin{array}{l}\text { Francisco Ramírez de } \\
\text { Madrid }\end{array}$ & $\mathrm{F}$ & & \\
\hline & & $\begin{array}{l}\text { comendador Luis } \\
\text { García }\end{array}$ & & & \\
\hline & & $\begin{array}{l}\text { Miguel Velázquez } \\
\text { Clemente }\end{array}$ & & & \\
\hline & & Juan de Soria & & \multirow{2}{*}{\multicolumn{2}{|c|}{30.000}} \\
\hline & & Gaspar López & & & \\
\hline & Tesorero & Gabriel Sánchez & & & \\
\hline & General** & Gonzalo de Baeza & & & \\
\hline & $\begin{array}{l}\text { Escribano } \\
\text { mayor de }\end{array}$ & $\begin{array}{l}\text { Hernán Jiménez de } \\
\text { Pidrola }\end{array}$ & & & \\
\hline & rentas $* *$ & conde de Benavente & & & \\
\hline & $\begin{array}{l}\text { Pregonero } \\
\text { mayor** }\end{array}$ & Alonso de Cárdenas & & & \\
\hline \multirow[t]{3}{*}{$\begin{array}{l}\text { Área } \\
\text { externa }\end{array}$} & $\begin{array}{l}\text { Mayordomo } \\
\text { mayor }\end{array}$ & Gutierre de Cárdenas & & & \multirow[t]{3}{*}{$\begin{array}{l}\text { cera y } \\
\text { comida }\end{array}$} \\
\hline & Teniente de & Alfonso Patiño & $\mathrm{O}$ & & \\
\hline & mayordomo & Pedro Patiño & & & \\
\hline \multirow[t]{9}{*}{ Aparato } & \multirow[t]{7}{*}{ Maestresala } & $\begin{array}{l}\text { Juan Velázquez de } \\
\text { Cuéllar }\end{array}$ & \multirow[t]{7}{*}{$\mathrm{F}$} & \multicolumn{2}{|c|}{150.000} \\
\hline & & Sancho de Castilla & & \multicolumn{2}{|c|}{50.000} \\
\hline & & Luis de Quintanilla & & & \\
\hline & & $\begin{array}{l}\text { Hernán, duque de } \\
\text { Estrada }\end{array}$ & & & \\
\hline & & mosén Jaime Sorell & & & \\
\hline & & Íñigo Manrique & & & \\
\hline & & Jaime de Luna & & & \\
\hline & \multirow[t]{2}{*}{ Trinchante } & Íñigo de Guevara & \multirow[t]{2}{*}{$\mathrm{O}$} & & \\
\hline & & mosén Jaime Ferrer & & & \\
\hline
\end{tabular}




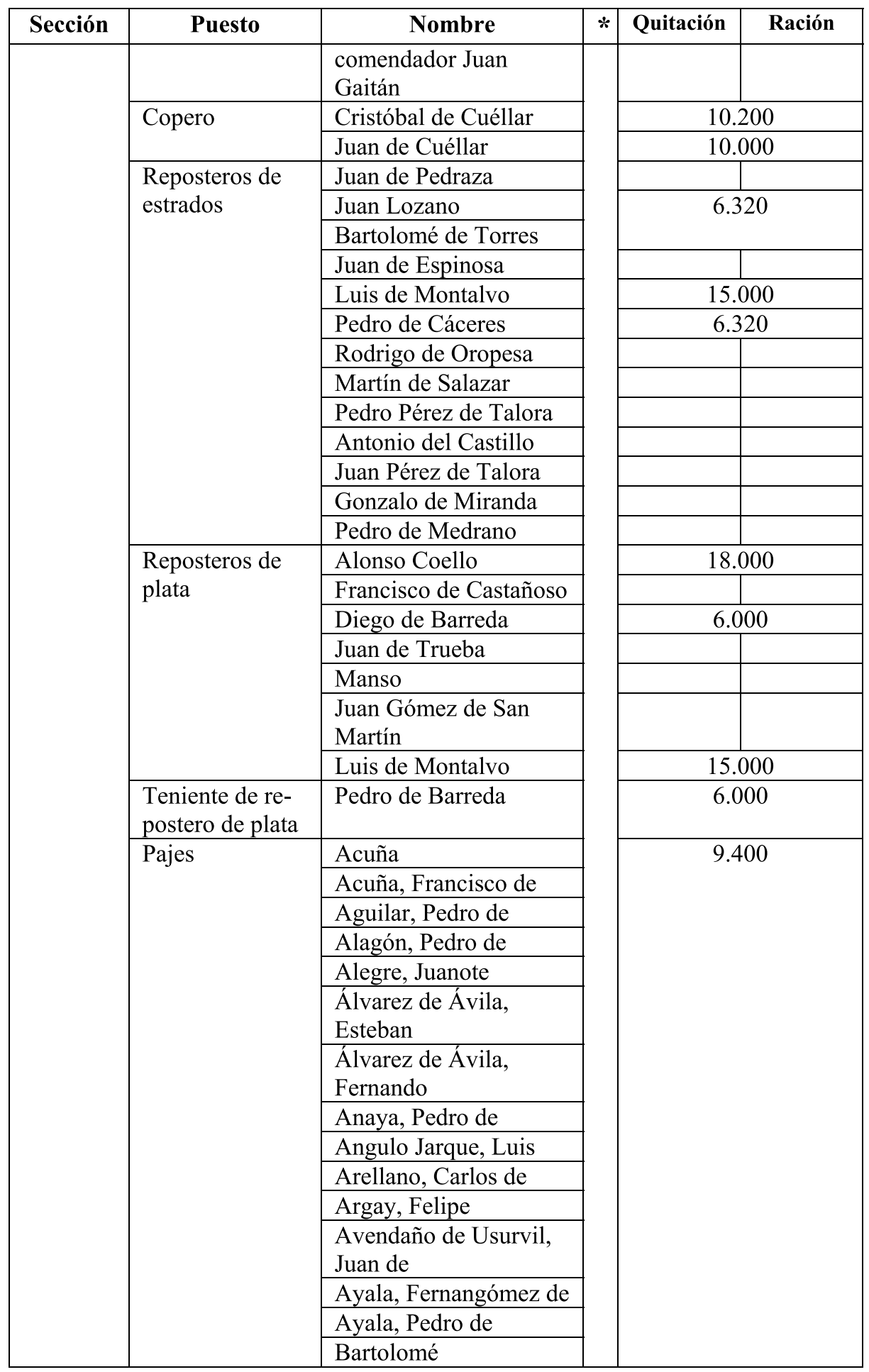




\begin{tabular}{|c|c|c|c|c|c|}
\hline Sección & Puesto & Nombre & $*$ & Quitación & Ración \\
\hline & & Bazán, Pedro de & & & \\
\hline & & Benavides, Diego de & & & \\
\hline & & Benavides, Juan de & & & \\
\hline & & Bernabé, Álvaro de & & & \\
\hline & & Bobadilla, Fernando de & & & \\
\hline & & Bon, Gaspar & & & \\
\hline & & $\begin{array}{l}\text { Bravo de Lagunas, } \\
\text { Juan }\end{array}$ & & & \\
\hline & & Bravo, Juan & & & \\
\hline & & $\begin{array}{l}\text { Caballería, Alonso de } \\
\text { la }\end{array}$ & & & \\
\hline & & $\begin{array}{l}\text { Cabra (Cabrero o } \\
\text { Cabrera), Sancho de }\end{array}$ & & & \\
\hline & & Cabrera, Fernando de & & & \\
\hline & & Cabrera, Gonzalo & & & \\
\hline & & Cabrera, Juan de & & & \\
\hline & & Calatayud, Juan de & & & \\
\hline & & Cárdenas, Alonso de & & & \\
\hline & & Cárdenas, Diego de & & & \\
\hline & & $\begin{array}{l}\text { Carrilero de Albornoz, } \\
\text { Luis }\end{array}$ & & & \\
\hline & & Carrillo, Fernando & & & \\
\hline & & Carros, Felipe & & & \\
\hline & & Carros, Jaime & & & \\
\hline & & Castelni, don Luis de & & & \\
\hline & & Castelni, Galcerán de & & & \\
\hline & & Castelni, García de & & & \\
\hline & & Castelni, Juan de & & & \\
\hline & & Castilla, Juan de & & & \\
\hline & & $\begin{array}{l}\text { Castillo, Bernardino } \\
\text { del }\end{array}$ & & & \\
\hline & & Castro, Juan de & & & \\
\hline & & Cerda, Luis de la & & & \\
\hline & & Colón, Diego & & & \\
\hline & & Colón, Fernando & & & \\
\hline & & Córdoba, Melchor de & & & \\
\hline & & Córdoba, Sancho de & & & \\
\hline & & Chacón, Gonzalo & & & \\
\hline & & $\begin{array}{l}\text { Dálvarez, Hernán, } \\
\text { comendador }\end{array}$ & & & \\
\hline & & Dávila, Fernandálvarez & & & \\
\hline & & Dávila, Francisco & & & \\
\hline & & Dávila, Juan & & & \\
\hline & & Díaz Maldonado, Ruy & & & \\
\hline & & Díaz, Fernán & & & \\
\hline
\end{tabular}




\begin{tabular}{|c|c|c|c|c|c|}
\hline Sección & Puesto & Nombre & $*$ & Quitación & Ración \\
\hline & & $\begin{array}{l}\text { Diosdado, Álvaro (o } \\
\text { Alonso) }\end{array}$ & & & \\
\hline & & $\begin{array}{l}\text { Enríquez de Ribera, } \\
\text { Fernando }\end{array}$ & & & \\
\hline & & $\begin{array}{l}\text { Enríquez de Ribera, } \\
\text { Francisco }\end{array}$ & & & \\
\hline & & Enríquez, Enrique & & & \\
\hline & & Enríquez, Fadrique & & & \\
\hline & & Enríquez, Fernando & & & \\
\hline & & Fajardo, Pedro & & & \\
\hline & & $\begin{array}{l}\text { Fernández de Córdoba, } \\
\text { Pedro }\end{array}$ & & & \\
\hline & & $\begin{array}{l}\text { Fernández de Proaño, } \\
\text { Diego }\end{array}$ & & & \\
\hline & & Ferrer Jaime, Francisco & & & \\
\hline & & Ferrer, Jaime & & & \\
\hline & & Figuero, Álvaro de & & & \\
\hline & & Figueroa, Alonso de & & & \\
\hline & & Figueroa, Gómez de & & & \\
\hline & & $\begin{array}{l}\text { Folch de Cardona, } \\
\text { Fernando }\end{array}$ & & & \\
\hline & & $\begin{array}{l}\text { Folch de Cardona, } \\
\text { Pedro }\end{array}$ & & & \\
\hline & & Folguín, García & & & \\
\hline & & Fonseca, Gutierre de & & & \\
\hline & & Gaitán, Juan & & & \\
\hline & & Gamarra, Francisco & & & \\
\hline & & $\begin{array}{l}\text { García de Salazar, } \\
\text { Lope }\end{array}$ & & & \\
\hline & & Gavarra, Francisco de & & & \\
\hline & & Gea de Salazar, Lope & & & \\
\hline & & Gilberte, Juan & & & \\
\hline & & Girón, Pedro & & & \\
\hline & & Gómez Dávila, Fernán & & & \\
\hline & & $\begin{array}{l}\text { González del Águila, } \\
\text { Gil }\end{array}$ & & & \\
\hline & & $\begin{array}{l}\text { González del Águila, } \\
\text { Nuño }\end{array}$ & & & \\
\hline & & González, Las & & & \\
\hline & & Gudiel, Diego & & & \\
\hline & & Guzmán & & & \\
\hline & & Guzmán, Cristóbal de & & & \\
\hline & & $\begin{array}{l}\text { Guzmán, fray } \\
\text { Hernando de }\end{array}$ & & & \\
\hline & & Guzmán, Juan de & & & \\
\hline
\end{tabular}




\begin{tabular}{|c|c|c|c|c|c|}
\hline Sección & Puesto & Nombre & $*$ & Quitación & Ración \\
\hline & & Híjar, Luis de & & & \\
\hline & & Hoces, Gonzalo de & & & \\
\hline & & $\begin{array}{l}\text { Holguin, Álvaro (o } \\
\text { Alonso) }\end{array}$ & & & \\
\hline & & Holguin, García & & & \\
\hline & & Hurtado, Luis & & & \\
\hline & & Jarque, Vicente & & & \\
\hline & & Jerez, fray Antonio de & & & \\
\hline & & Jiménez Cerdán, Juan & & & \\
\hline & & $\begin{array}{l}\text { Jiménez de Guerrea, } \\
\text { Miguel }\end{array}$ & & & \\
\hline & & Laso, Pedro & & & \\
\hline & & León, Francisco de & & & \\
\hline & & López de Garreta, Juan & & & \\
\hline & & López de Zúñiga, Íñigo & & & \\
\hline & & López Pacheco, Diego & & & \\
\hline & & López, Diego & & & \\
\hline & & López, Juan & & & \\
\hline & & Luisboo, Gaspar & & & \\
\hline & & Manrique, Antonio & & & \\
\hline & & Manrique, Fadrique & & & \\
\hline & & Manrique, García & & & \\
\hline & & Manrique, Pedro & & & \\
\hline & & Manrique, Rodrigo & & & \\
\hline & & Manuel, Juan & & & \\
\hline & & $\begin{array}{l}\text { Martínez de Luna, } \\
\text { Jaime }\end{array}$ & & & \\
\hline & & Mejía, Sancho & & & \\
\hline & & Mendoza, Juan de & & & \\
\hline & & Mendoza, Pedro de & & & \\
\hline & & Mendoza, Rodrigo de & & & \\
\hline & & Mercado, Francisco de & & & \\
\hline & & Mergarite, Luis & & & \\
\hline & & Miguel, Juan & & & \\
\hline & & Navarra, Juan & & & \\
\hline & & Navarro, Juan & & & \\
\hline & & Orozco, Rodrigo de & & & \\
\hline & & Osorio, Álvaro de & & & \\
\hline & & Osorio, Luis de & & & \\
\hline & & Osorio, Pedro & & & \\
\hline & & Pacheco, Fernando & & & \\
\hline & & Pacheco, Francisco & & & \\
\hline & & Pacheco, Rodrigo & & & \\
\hline & & $\begin{array}{l}\text { Pérez de Arquilla (o } \\
\text { Arquellada), Alonso }\end{array}$ & & & \\
\hline
\end{tabular}




\begin{tabular}{|c|c|c|c|c|c|}
\hline Sección & Puesto & Nombre & $*$ & Quitación & Ración \\
\hline & & Pérez de Luján, Fernán & & & \\
\hline & & Pérez Osorio, Álvar & & & \\
\hline & & $\begin{array}{l}\text { Piedrabuena, } \\
\text { comendador }\end{array}$ & & & \\
\hline & & Pinelo, Luis & & & \\
\hline & & Ponce, Antonio & & & \\
\hline & & Portugal, Jorge de & & & \\
\hline & & Quinoces, Antonio de & & & \\
\hline & & $\begin{array}{l}\text { Quintanilla (o de } \\
\text { Quintana), Álvaro de }\end{array}$ & & & \\
\hline & & Quinto, Nicolao & & & \\
\hline & & Ramírez, Fernando & & & \\
\hline & & Ramírez, Francisco & & & \\
\hline & & Ribera, Antonio de & & & \\
\hline & & Ribera, Diego de & & & \\
\hline & & Ribera, Pedro de & & & \\
\hline & & Ríos, Pedro de los & & & \\
\hline & & $\begin{array}{l}\text { Ruiz de Alarcón, } \\
\text { García }\end{array}$ & & & \\
\hline & & Sánchez Maño & & & \\
\hline & & $\begin{array}{l}\text { Santángelo, Fernando } \\
\text { de }\end{array}$ & & & \\
\hline & & $\begin{array}{l}\text { Santángelo, Jerónimo } \\
\text { de }\end{array}$ & & & \\
\hline & & $\begin{array}{l}\text { Santibáñez, } \\
\text { comendador }\end{array}$ & & & \\
\hline & & $\begin{array}{l}\text { Santiesteban, } \\
\text { comendador }\end{array}$ & & & \\
\hline & & Sarmiento, Íñigo & & & \\
\hline & & Sarrera, Miguel & & & \\
\hline & & Silva, Alonso de & & & \\
\hline & & Sorel, Baltasar & & & \\
\hline & & $\begin{array}{l}\text { Soto, fray Antonio de, } \\
\text { comendador de } \\
\text { Mayorga }\end{array}$ & & & \\
\hline & & Sotomayor, Alonso de & & & \\
\hline & & Sotomayor, Diego de & & & \\
\hline & & $\begin{array}{l}\text { Sotomayor, fray Juan } \\
\text { de }\end{array}$ & & & \\
\hline & & Stúñiga, Francisco de & & & \\
\hline & & $\begin{array}{l}\text { Toledo, Fernandálvarez } \\
\text { de }\end{array}$ & & & \\
\hline & & Toledo, García de & & & \\
\hline & & Torre, Pedro de la & & & \\
\hline & & Torrella, Rodrigo & & & \\
\hline
\end{tabular}




\begin{tabular}{|c|c|c|c|c|c|}
\hline Sección & Puesto & Nombre & * & Quitación & Ración \\
\hline & & Torres, Fernando de & & & \\
\hline & & Torres, Luis de & & & \\
\hline & & Ulloa, Juan de & & & \\
\hline & & Valdivieso, Juan de & & & \\
\hline & & Vargas, Francisco de & & & \\
\hline & & Vargas, Juan de & & & \\
\hline & & Velázquez, Cristóbal & & & \\
\hline & & Villahermosa, duque de & & & \\
\hline & & Villasayas, fray Luis de & & & \\
\hline & & Yepes, fray Antonio de & & & \\
\hline & & Zapata, Juan & & & \\
\hline & & Zapata, Pedro & & & \\
\hline \multirow{5}{*}{ Cerería } & \multirow{3}{*}{ Cerero mayor } & Fernando de Bobadilla & & & \\
\hline & & Francisco del Valle & & & \\
\hline & & $\begin{array}{l}\text { Leonor López de } \\
\text { Valladolid }\end{array}$ & & & \\
\hline & $\begin{array}{l}\text { Teniente de } \\
\text { cerero mayor }\end{array}$ & Medina & & & \\
\hline & $\begin{array}{l}\text { Ayudante de } \\
\text { cera }\end{array}$ & Antón de Montalbán & $\mathrm{A}$ & & \\
\hline \multirow{7}{*}{ Cocina } & \multirow{3}{*}{ Cocinero mayor } & Juan Cacho & \multirow[t]{3}{*}{$\mathrm{O}$} & 20.000 & \multirow{3}{*}{$\begin{array}{l}\text { menu- } \\
\text { dillos }\end{array}$} \\
\hline & & Diego Cacho & & & \\
\hline & & Juan García de la Vega & & $\begin{array}{l}13.000 / \\
15.000\end{array}$ & \\
\hline & Panadero & Juan Roche & & \multicolumn{2}{|c|}{$7.400 / 8.400$} \\
\hline & $\begin{array}{l}\text { Ayudante de } \\
\text { panadero }\end{array}$ & $\begin{array}{l}\text { Isabel Olevella, mujer } \\
\text { del anterior }\end{array}$ & & \multicolumn{2}{|c|}{4.420} \\
\hline & Pastelero & Rodrigo de Sahagún & & \multicolumn{2}{|c|}{5.400} \\
\hline & Gallinero & Pedro de Carvajal & & & \\
\hline \multirow[t]{12}{*}{$\begin{array}{l}\text { Caballe- } \\
\text { rizas }\end{array}$} & $\begin{array}{l}\text { Caballerizo } \\
\text { mayor }\end{array}$ & Diego de Castilla & & & $\begin{array}{c}\text { arneses y } \\
\text { palio }\end{array}$ \\
\hline & Caballerizo & Diego de Salas & & & \\
\hline & menor & comendador Villanta & & & \\
\hline & \multirow{9}{*}{$\begin{array}{l}\text { Mozos de } \\
\text { espuelas y } \\
\text { ballesta }\end{array}$} & Villaseca (ballesta) & \multirow[t]{9}{*}{$\mathrm{A}$} & & \\
\hline & & $\begin{array}{l}\text { Juan Sarmiento } \\
\text { (espuelas) }\end{array}$ & & & \\
\hline & & $\begin{array}{l}\text { Juan Sarmiento (hijo, } \\
\text { espuelas) }\end{array}$ & & & \\
\hline & & Campuzano & & & \\
\hline & & Serna & & & \\
\hline & & Garnica & & & \\
\hline & & $\begin{array}{l}\text { Pedro de Angulo } \\
\text { (espuelas) }\end{array}$ & & \multicolumn{2}{|c|}{4.320} \\
\hline & & Salcedo & & & \\
\hline & & Diego de Salazar & & & \\
\hline
\end{tabular}




\begin{tabular}{|c|c|c|c|c|c|}
\hline Sección & Puesto & Nombre & $*$ & Quitación & Ración \\
\hline & & San Pedrico (espuelas) & & & \\
\hline & & $\begin{array}{l}\text { Rodrigo de Ribaflecha } \\
\text { (ballesta) }\end{array}$ & & 5.530 & \\
\hline & & $\begin{array}{l}\text { Lope de Arana } \\
\text { (ballesta y espuelas) }\end{array}$ & & \multirow{27}{*}{\multicolumn{2}{|c|}{4.320}} \\
\hline & \multirow{26}{*}{$\begin{array}{l}\text { Mozos de } \\
\text { espuelas }\end{array}$} & Alonso de Buendía & & & \\
\hline & & Alonso de Córdoba & & & \\
\hline & & Lope de Mondragón & & & \\
\hline & & $\begin{array}{l}\text { Antonio de } \\
\text { Ochandiano }\end{array}$ & & & \\
\hline & & Juan de Valdés & & & \\
\hline & & Lope de Arana & & & \\
\hline & & $\begin{array}{l}\text { Francisco de } \\
\text { Vizcarguin }\end{array}$ & & & \\
\hline & & Pedro de Escalante & & & \\
\hline & & Alonso de la Serna & & & \\
\hline & & $\begin{array}{l}\text { Juancho (Juan ) de } \\
\text { Segura }\end{array}$ & & & \\
\hline & & Pedro de Maza & & & \\
\hline & & Rodrigo de Ribaflecha & & & \\
\hline & & Pedro de Vallejos & & & \\
\hline & & Jorge de Ungría & & & \\
\hline & & Pedro Bustamante & & & \\
\hline & & Pedro de Porras & & & \\
\hline & & Martín de Medrano & & & \\
\hline & & Pedro Catarribera & & & \\
\hline & & Gómez Vallejo & & & \\
\hline & & Miguel de Segura & & & \\
\hline & & Pedro de Eraso & & & \\
\hline & & $\begin{array}{l}\text { Pedro Mota (o de } \\
\text { Mata) }\end{array}$ & & & \\
\hline & & Pedro de Arana & & & \\
\hline & & Juan de Castilla & & & \\
\hline & & $\begin{array}{l}\text { Bernardino de } \\
\text { Salvadiós }\end{array}$ & & & \\
\hline & & Juan de Lano & & & \\
\hline & \multirow{3}{*}{$\begin{array}{l}\text { Albéitar y } \\
\text { herrador }\end{array}$} & Fernando de Palencia & \multirow{3}{*}{\multicolumn{3}{|c|}{3.600}} \\
\hline & & Luis de Cáceres & & & \\
\hline & & Juan Navarro & & & \\
\hline & \multirow[t]{2}{*}{ Guarnicionero } & Juan de Molina & & & \\
\hline & & Antonio Gómez & & & \\
\hline & \multirow[t]{2}{*}{ Cordonero } & $\begin{array}{l}\text { Fernando (o Francisco) } \\
\text { de Medina }\end{array}$ & & & \\
\hline & & Martín de Bernabé & & & \\
\hline & Armero & Juan Pedro de Milán & & & \\
\hline
\end{tabular}




\begin{tabular}{|c|c|c|c|c|c|}
\hline Sección & Puesto & Nombre & $*$ & Quitación & Ración \\
\hline & & (Pedro Milanés) & & & \\
\hline & & Velasco & & & \\
\hline & & Juan Alonso & & & \\
\hline & & Rojel & & & \\
\hline & Lancero & Gonzalo Fornos & & & \\
\hline & Sillero & Francisco de Madrid & & & \\
\hline & Frenero dorador & Juan de Burgos & & & \\
\hline \multirow{4}{*}{$\begin{array}{l}\text { Acemile- } \\
\text { ría }\end{array}$} & \multirow{3}{*}{$\begin{array}{l}\text { Acemilero } \\
\text { mayor }\end{array}$} & Hernando de Badajoz & \multirow[t]{4}{*}{$\mathrm{O}$} & & \\
\hline & & Diego Flores & & & \\
\hline & & García de Badajoz & & & \\
\hline & Sobreacemilero & Franciso de Villaharta & & & \\
\hline \multirow[t]{32}{*}{ Caza } & Cazador mayor & $\begin{array}{l}\text { Luis Hurtado de } \\
\text { Mendoza }\end{array}$ & $\mathrm{F}$ & \multicolumn{2}{|c|}{20.000} \\
\hline & \multirow{16}{*}{$\begin{array}{l}\text { Cazadores } \\
\text { menores }\end{array}$} & Sancho Ruiz & \multirow[t]{16}{*}{$\mathrm{O}$} & \multicolumn{2}{|c|}{35.000} \\
\hline & & Monterroso & & \multirow{3}{*}{\multicolumn{2}{|c|}{$\frac{7.000 / 21.000}{21.000}$}} \\
\hline & & Juan de Mendoza & & & \\
\hline & & Juan de la Carrera & & & \\
\hline & & Juan de Miranda & & \multirow{2}{*}{\multicolumn{2}{|c|}{$\begin{array}{c}7.500 / 15.000 \\
15.000\end{array}$}} \\
\hline & & Lucas Alonso & & & \\
\hline & & Pedro de Baños & & & \\
\hline & & Savarino & & & \\
\hline & & Alonso del Campo & & & \\
\hline & & Martín Caballero & & & \\
\hline & & Porico & & & \\
\hline & & Pedro de Herrera & & & \\
\hline & & Juan de Coslaga & & & \\
\hline & & Alonso Barbaza & & & \\
\hline & & Pedro de la Torre & & & \\
\hline & & Jerónimo Román & & & \\
\hline & Mozo de caza & Pedro Alonso & $\mathrm{A}$ & & \\
\hline & \multirow[t]{2}{*}{ Montero mayor } & $\begin{array}{l}\text { Diego Hurtado de } \\
\text { Mendoza }\end{array}$ & \multirow[t]{2}{*}{$\mathrm{F}$} & & \\
\hline & & Francisco Dávila & & & \\
\hline & \multirow[t]{4}{*}{ Monteros } & Diego de Bustamante & \multirow[t]{4}{*}{$\mathrm{O}$} & & \\
\hline & & Bartolomé del Tiemplo & & & \\
\hline & & Juan Sandín & & \multicolumn{2}{|c|}{6.000} \\
\hline & & Bartolomé de Tejeda & & & \\
\hline & \multirow[t]{7}{*}{ Catarriberas } & Pedro de Peña & \multirow[t]{8}{*}{$\mathrm{A}$} & \multirow{7}{*}{\multicolumn{2}{|c|}{9.000}} \\
\hline & & Pedro de Zarzosa & & & \\
\hline & & Martín Caballero & & & \\
\hline & & Juan de la Puente & & & \\
\hline & & Juan de Orduña & & & \\
\hline & & Gómez & & & \\
\hline & & Juan del Castillo & & & \\
\hline & Ballesteros de & Juan de Buenaventura & & & \\
\hline
\end{tabular}




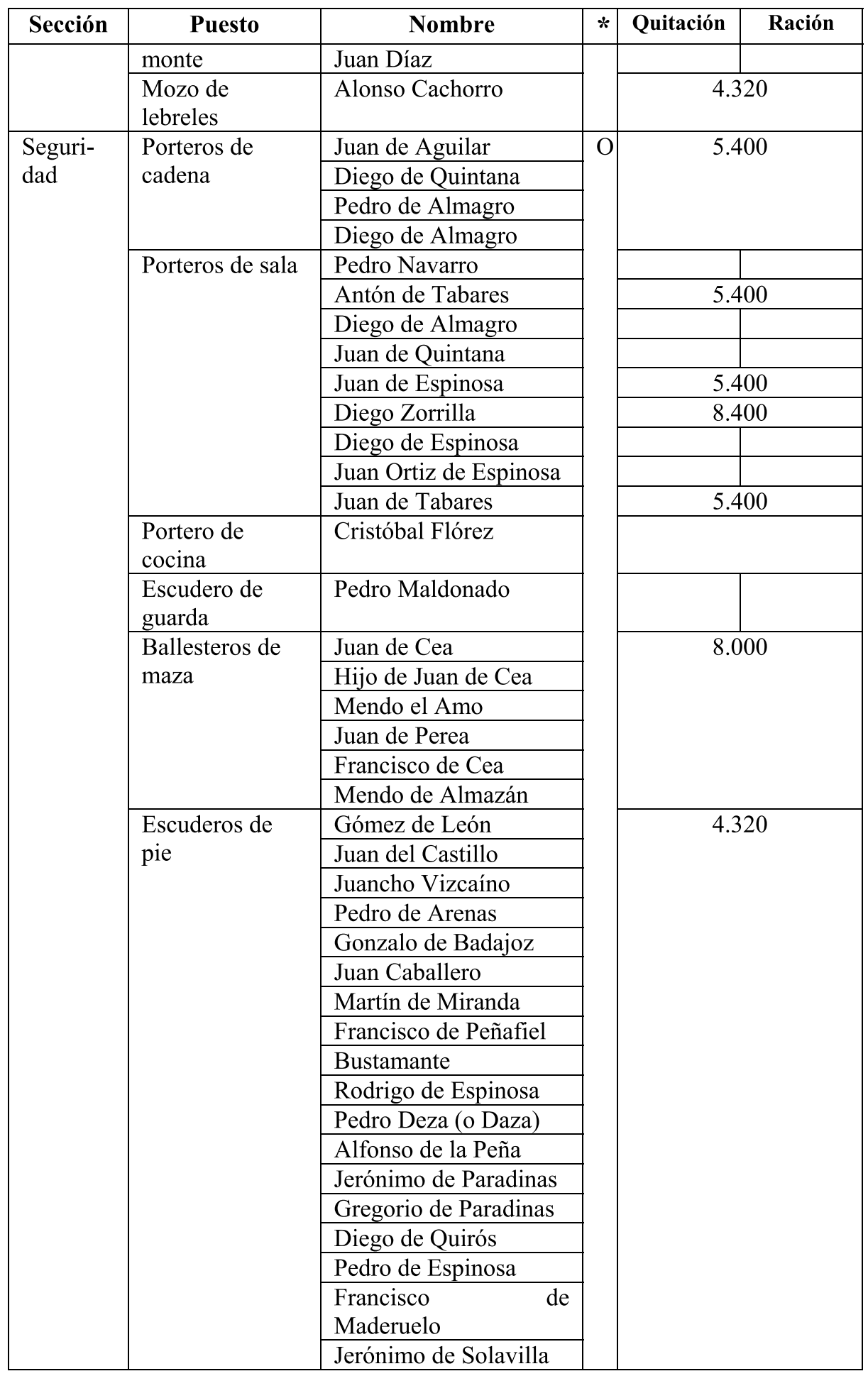




\begin{tabular}{|c|c|c|c|c|c|}
\hline Sección & Puesto & Nombre & $*$ & Quitación & Ración \\
\hline & & Fernando Malón & & & \\
\hline & & Gonzalo Vélez & & & \\
\hline & & Diego de Collantes & & & \\
\hline & & $\begin{array}{l}\text { Alfonso de Aller (o } \\
\text { Alonso Daller) }\end{array}$ & & & \\
\hline & & Juan Cacho & & & \\
\hline & & Jorge de Campuzano & & & \\
\hline & & Rodrigo de Campuzano & & & \\
\hline & & Diego de Espinosa & & & \\
\hline & & Juan de Jerez & & & \\
\hline & & Antón de Baeza & & & \\
\hline & & Pedro de Miranda & & & \\
\hline & & Diego de Quintana & & & \\
\hline & & Alonso Segura & & & \\
\hline & & Miguel Porras & & & \\
\hline & & Alonso de Toledo & & & \\
\hline & & Juan Cano del Castillo & & & \\
\hline & & Fernando de Dueñas & & & \\
\hline & & Juan de Peñalosa & & & \\
\hline & & Pedro de Roa & & & \\
\hline & & Gonzalo de Ochando & & & \\
\hline & & Sancho de Espinosa & & & \\
\hline & & Pedro de Arévalo & & & \\
\hline & & Bibanco & & & \\
\hline & & Luis Porcel & & & \\
\hline & \multirow{19}{*}{$\begin{array}{l}\text { Monteros de } \\
\text { Espinosa }\end{array}$} & abad Bibanco & \multirow{19}{*}{\multicolumn{3}{|c|}{7.320}} \\
\hline & & Gonzalo Gómez & & & \\
\hline & & Hernando de Mirones & & & \\
\hline & & Juan Ortiz & & & \\
\hline & & Fernando Ortiz & & & \\
\hline & & Gómez Calderón & & & \\
\hline & & García de Saravia & & & \\
\hline & & Pedro de Azcona & & & \\
\hline & & Pedro Similor & & & \\
\hline & & Fernando de Porras & & & \\
\hline & & Juan Zorrilla & & & \\
\hline & & Fernando Bruesa & & & \\
\hline & & Pedro de Escalera & & & \\
\hline & & Pedro Ortiz & & & \\
\hline & & $\begin{array}{l}\text { Fernando González } \\
\text { Fraile }\end{array}$ & & & \\
\hline & & García Canos & & & \\
\hline & & García Fernández & & & \\
\hline & & Martín Ochoa & & & \\
\hline & & Cristóbal Carral & & & \\
\hline
\end{tabular}




\begin{tabular}{|c|c|c|c|c|c|}
\hline Sección & Puesto & Nombre & $*$ & Quitación & Ración \\
\hline & & Juan de Trueba & & & \\
\hline & & Sebastián de Conchada & & & \\
\hline & & Pedro de Espinosa & & & \\
\hline & & $\begin{array}{l}\text { Gómez Martínez de } \\
\text { Erana }\end{array}$ & & & \\
\hline & & Gonzalo Hernández & & & \\
\hline & & García Gómez & & & \\
\hline & & Pedro de Porras & & & \\
\hline & & Juan Gómez del & & & \\
\hline & & Camino & & & \\
\hline & & Pedro Ortiz & & & \\
\hline & & Juan Brasa & & & \\
\hline & & Juan Ruiz de Azcona & & & \\
\hline & & Diego de la Peña & & & \\
\hline & & Rodrigo de los Cabales & & & \\
\hline & & Rodrigo de Erana & & & \\
\hline & & $\begin{array}{l}\text { Pedro González del } \\
\text { Camino }\end{array}$ & & & \\
\hline & & Diego Barba & & & \\
\hline & & Agustín Barba & & & \\
\hline & & Cristóbal Carral (otro) & & & \\
\hline & & Diego de Guevara & & & \\
\hline \multirow[t]{15}{*}{ Cámara } & $\begin{array}{l}\text { Camarero } \\
\text { mayor }\end{array}$ & $\begin{array}{l}\text { Juan de Calatayud (y } \\
\text { su mujer, Francisca } \\
\text { Juárez) }\end{array}$ & $\mathrm{F}$ & $\begin{array}{c}(20.000) \\
50.000\end{array}$ & $\begin{array}{c}\text { comida y } \\
\text { cera, } \\
\text { zapatos y } \\
\text { ropa }\end{array}$ \\
\hline & $\begin{array}{l}\text { Escribano de } \\
\text { cámara }\end{array}$ & Diego Cano & $\mathrm{O}$ & & \\
\hline & \multirow{3}{*}{$\begin{array}{l}\text { Camarero de } \\
\text { tapicería }\end{array}$} & Diego Cano & & 15.000 & \multirow{3}{*}{$\begin{array}{c}\text { comida y } \\
\text { cera }\end{array}$} \\
\hline & & Alonso de Burgos & & & \\
\hline & & $\begin{array}{l}\text { Juan de Villoria, el } \\
\text { mozo }\end{array}$ & & $\begin{array}{l}10.000 / \\
20.000\end{array}$ & \\
\hline & \multirow{10}{*}{$\begin{array}{l}\text { Mozos de } \\
\text { cámara }\end{array}$} & Pablo de Basurto & & \multirow{10}{*}{$\begin{array}{l}7.200 / \\
8.000\end{array}$} & \multirow[t]{10}{*}{12.000} \\
\hline & & $\begin{array}{l}\text { Hernando (Fernando) } \\
\text { Chacón }\end{array}$ & & & \\
\hline & & Antonio de Porras & & & \\
\hline & & $\begin{array}{l}\text { Juan de Sanromán o de } \\
\text { Sandoval }\end{array}$ & & & \\
\hline & & Antonio de Salazar & & & \\
\hline & & Antonio Fernández & & & \\
\hline & & Pedro de la Huerta & & & \\
\hline & & F. Carguizano & & & \\
\hline & & Miguel Cano & & & \\
\hline & & Cristóbal de & & & \\
\hline
\end{tabular}




\begin{tabular}{|c|c|c|c|c|c|}
\hline Sección & Puesto & Nombre & $*$ & Quitación & Ración \\
\hline & & Maldonado & & & \\
\hline & & Juan de Tavira & & & \\
\hline & & F. Bastidas & & & \\
\hline & & Miranda & & & \\
\hline & & Diego de Ortiz & & & \\
\hline & & Pablo Pérez & & & \\
\hline & & Pablo de Miranda & & & \\
\hline & & Luis de Labastida & & & \\
\hline & & Alonso de Azcona & & & \\
\hline & & Juan Ortiz de Espinosa & & & \\
\hline & & F. Valdés & & & \\
\hline & & Alonso de Zuazo & & & \\
\hline & & Juan Maldonado & & & \\
\hline & & $\begin{array}{l}\text { Antonio de Herrera (o } \\
\text { Herrero) }\end{array}$ & & & \\
\hline & & Antonio de Guadalupe & & & \\
\hline & & Pablo de Maqueda & & & \\
\hline & & Juan de la Cuadra & & & \\
\hline & & Pedro de Porras & & & \\
\hline & & Martín de Ochoa & & & \\
\hline & & Rodrigo de Oropesa & & & \\
\hline & & $\begin{array}{l}\text { Gonzalo Fernández de } \\
\text { Oviedo y Valdés }\end{array}$ & & & \\
\hline & Mozo de las & Diego de Ortiz & & & \\
\hline & llaves & $\begin{array}{l}\text { Gonzalo Fernández de } \\
\text { Oviedo y Valdés }\end{array}$ & & & \\
\hline & Mozo del retrete & Un hidalgo de Soria & & & \\
\hline & & Miranda & & & \\
\hline & Mozo del bacín & Barrionuevo & & & \\
\hline & Mozos de las & Martín de Ochoa & & & \\
\hline & armas & García López de Sese & & & \\
\hline & $\begin{array}{l}\text { Reposteros de } \\
\text { camas }\end{array}$ & $\begin{array}{l}\text { mosén Francisco } \\
\text { Guirao de Perpiñán }\end{array}$ & & 10. & \\
\hline & & Torres de Murcia & & & \\
\hline & & $\begin{array}{l}\text { Juan de Villoria, el } \\
\text { Viejo }\end{array}$ & & & \\
\hline & & Jerónimo de Agüero & & & \\
\hline & & Diego Zorrilla & & & \\
\hline & & Mata Quinoces & & & \\
\hline & & Juan de Otalora & & & \\
\hline & & Pedro Navarro & & & \\
\hline & & Cosme de Vallejo & & & \\
\hline & & $\begin{array}{l}\text { Francisco (o Fernando) } \\
\text { de Mata }\end{array}$ & & & \\
\hline & & Juan de Quincoces & & & \\
\hline
\end{tabular}




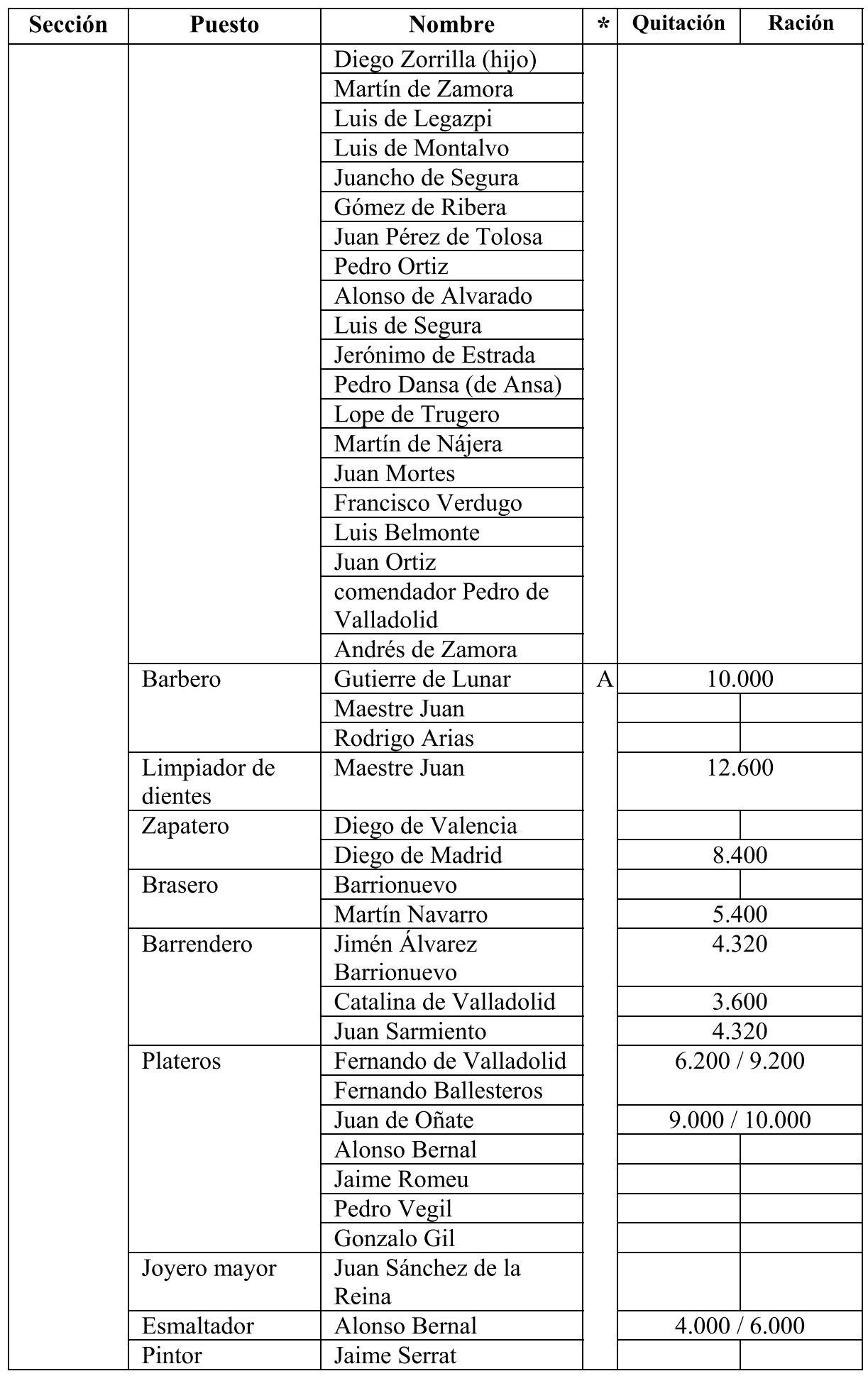




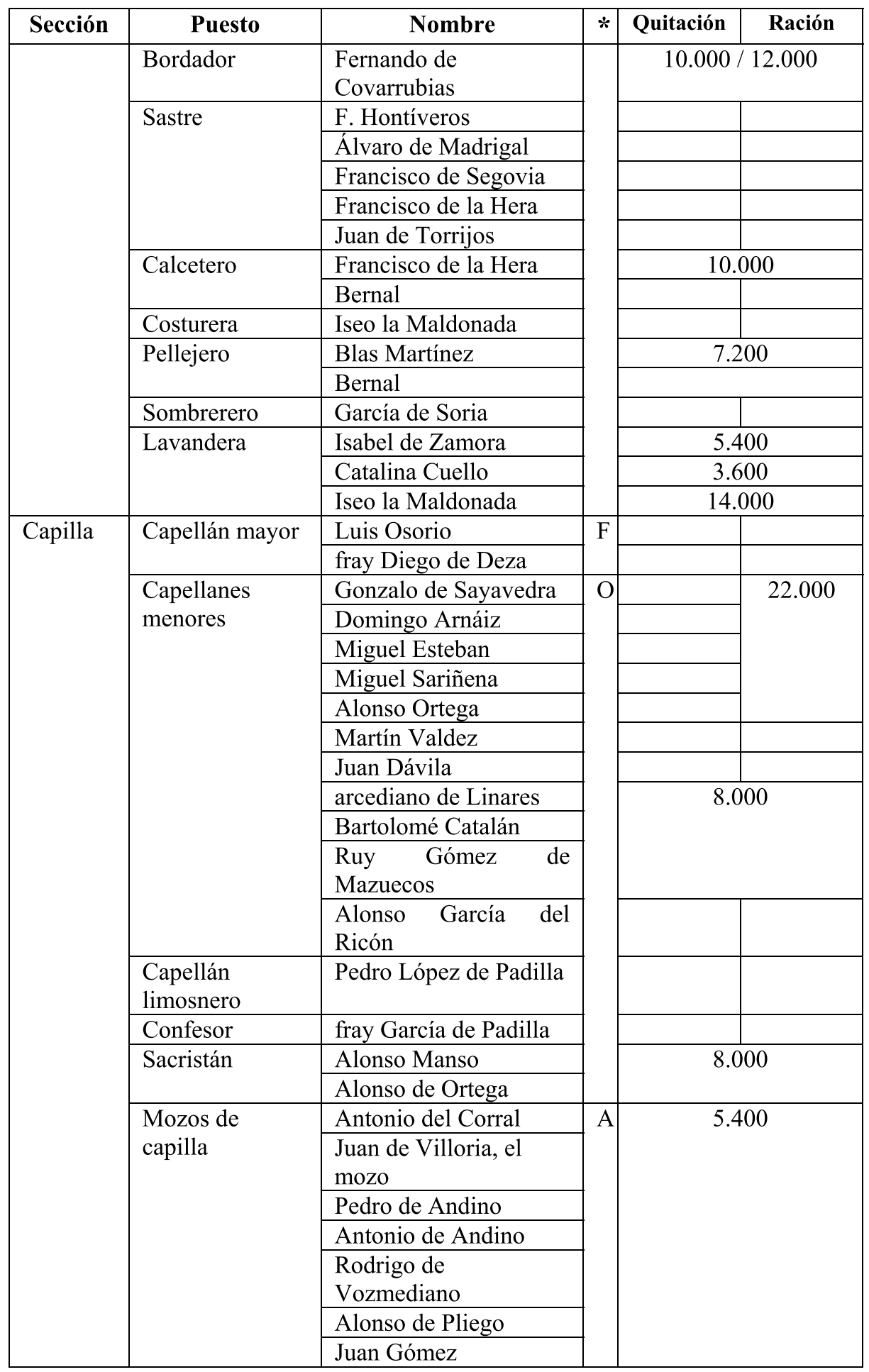




\begin{tabular}{|c|c|c|c|c|c|}
\hline Sección & \begin{tabular}{|l} 
Puesto \\
\end{tabular} & Nombre & $*$ & Quitación & Ración \\
\hline & & Juan Sarmiento & & & \\
\hline & & Fernando de Villoria & & & \\
\hline & & Fernando Martínez & & & \\
\hline & & Martín de Valdés & & & \\
\hline & & $\begin{array}{l}\text { Francisco ( o } \\
\text { Fernando) de la Vega }\end{array}$ & & & \\
\hline & & Sebastián de Conchada & & & \\
\hline & & Francisco de Orenes & & & \\
\hline & & Juan Vázquez & & & \\
\hline & & Gonzalo de Ortega & & & \\
\hline & & Rodrigo de la Vega & & & \\
\hline & & Benito Caballero & & & \\
\hline & & Alejo de Ribera & & & \\
\hline & & $\begin{array}{l}\text { Antonio de Arenas (o } \\
\text { Areñas) }\end{array}$ & & & \\
\hline & & Fernando de Solís & & & \\
\hline & & Alonso de Zamero & & & \\
\hline & & Francisco de León & & & \\
\hline & & Antonio de Obregón & & & \\
\hline & \multirow{6}{*}{$\begin{array}{l}\text { Reposteros de } \\
\text { capilla }\end{array}$} & Pedro de Espinosa & \multicolumn{3}{|c|}{6.500} \\
\hline & & Diego de Pisa & & \multicolumn{2}{|c|}{$6.500 / 7.200$} \\
\hline & & Diego de Santiesteban & & & \\
\hline & & Antonio de Castillo & & \multirow{2}{*}{\multicolumn{2}{|c|}{6.320}} \\
\hline & & Bernardino del Castillo & & & \\
\hline & & Francisco Calderón & & & \\
\hline & $\begin{array}{l}\text { Maestro de } \\
\text { capilla }\end{array}$ & Juan de Ancheta & $\mathrm{O}$ & $\begin{array}{l}20.000 \\
/ 30.000\end{array}$ & \\
\hline & \multirow[t]{5}{*}{ Ministril } & Pedro de Gracia & $\mathrm{A}$ & \multicolumn{2}{|c|}{$7.200 / 12.200$} \\
\hline & & Alonso de Gracia & & \multicolumn{2}{|c|}{7.200} \\
\hline & & Alonso el Negro & & & \\
\hline & & $\begin{array}{l}\text { Diego del Castillo y su } \\
\text { hijo }\end{array}$ & & & \\
\hline & & Jaime López de Aragón & & \multicolumn{2}{|c|}{$\frac{1}{7.200}$} \\
\hline & \multirow{2}{*}{$\begin{array}{l}\text { Ministril de } \\
\text { dulzaina }\end{array}$} & Miguel de Mena & & 12.000 & \\
\hline & & Jaime Rejón & & \multicolumn{2}{|c|}{$12.000 / 20.000$} \\
\hline & $\begin{array}{l}\text { Ministril de } \\
\text { rabel }\end{array}$ & Juan de Madrid & & \multirow{3}{*}{\multicolumn{2}{|c|}{$7.200 / 12.000$}} \\
\hline & \multirow[t]{2}{*}{ Tamboril } & Pedro de Narbona & & & \\
\hline & & Jaime Rejón & & & \\
\hline & \multirow[t]{6}{*}{ Trompetas } & Juan de Cieza & & \multicolumn{2}{|c|}{24.000} \\
\hline & & Fernando de Aguilera & & & \\
\hline & & Juan de Escalona & & & \\
\hline & & Juan de Salonia & & & \\
\hline & & Alonso de Valdenebro & & \multicolumn{2}{|c|}{25.000} \\
\hline & & Francisco de Medina & & & \\
\hline
\end{tabular}




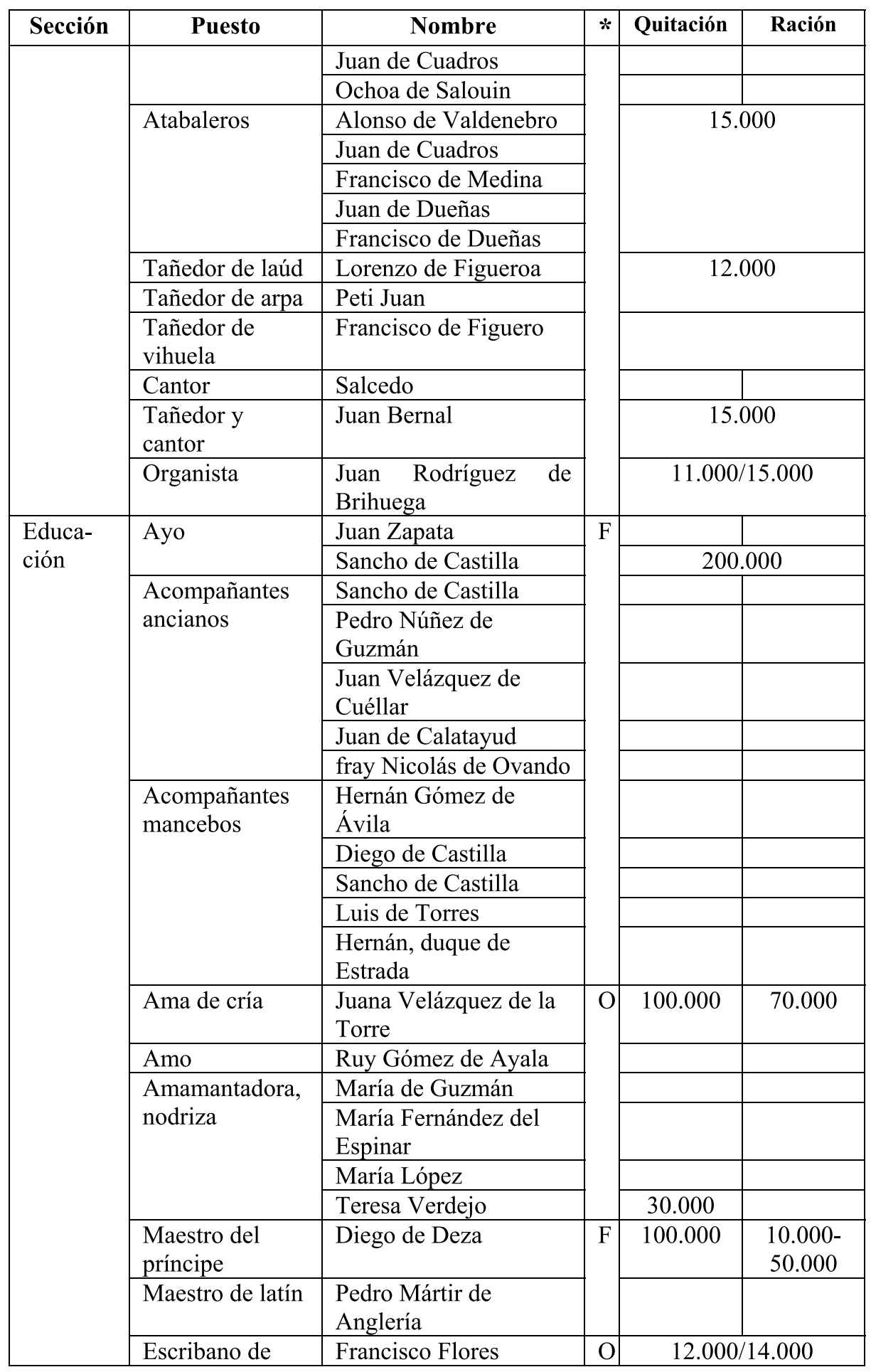




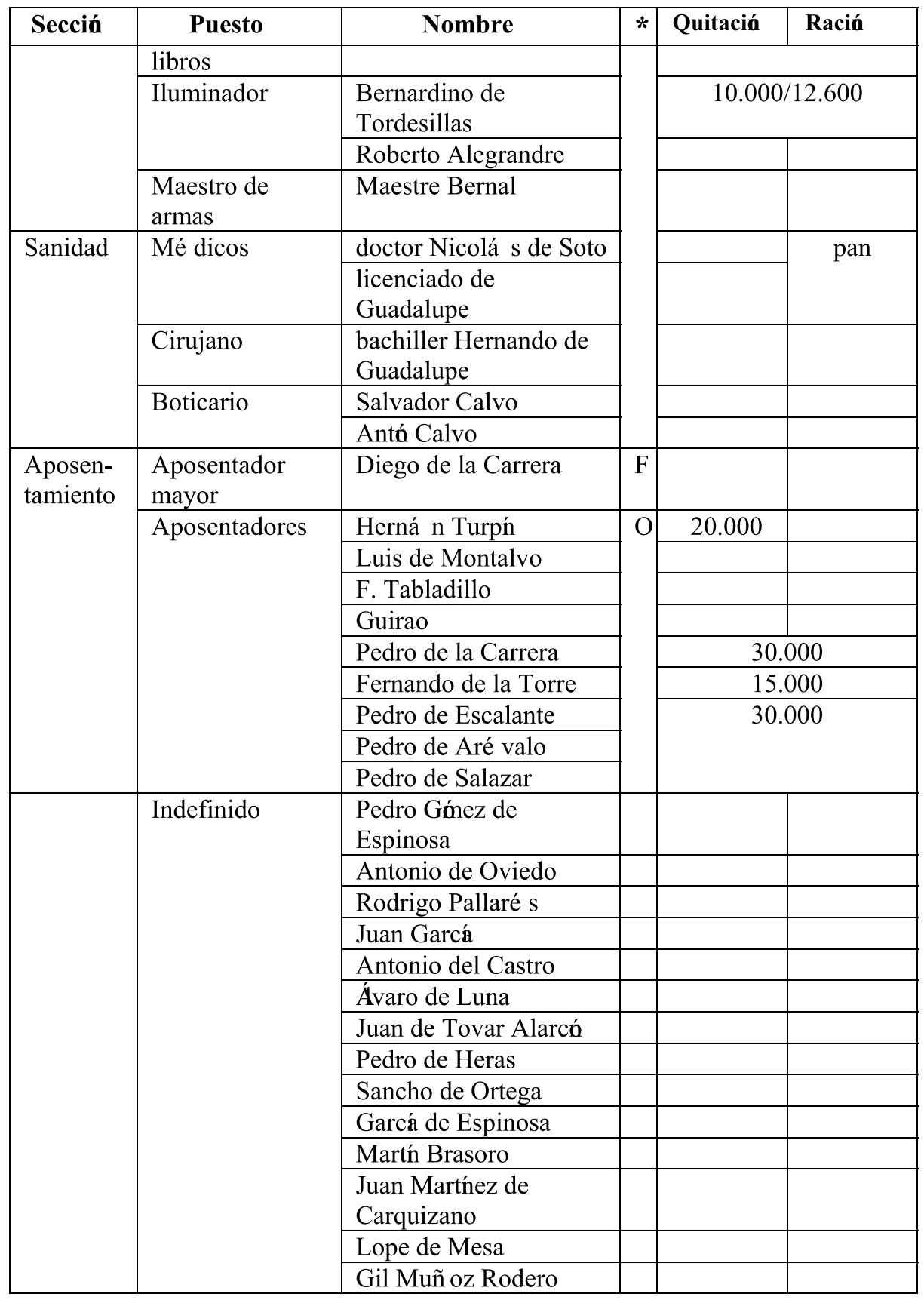

**Funcionarios de la casa del Prń cipe y/o de los Reyes Catłicos 
Tabla 3: Algunas ayudas de costa, quitaciones, raciones y otras en dinero dadas a algunos servidores del prícipe entre 1480-1495

\begin{tabular}{|c|c|c|c|c|}
\hline $\mathrm{A} \tilde{Q}$ & NOMBRE & OFICIO & MRS. & CONCEPTO \\
\hline \multirow[t]{2}{*}{1480} & & Amo y ama & 70.000 & Ració \\
\hline & Teresa de Verdejo & Nodriza & 30.000 & \\
\hline 1486 & \multirow[t]{2}{*}{ Diego de Deza } & \multirow[t]{2}{*}{ Maestro } & 100.000 & Quitació \\
\hline \multirow[t]{6}{*}{1487} & & & \multirow[t]{2}{*}{10.000} & Ayuda de costa \\
\hline & Gúnez Vallejo & Mozo de espuelas & & $\begin{array}{l}\text { Albricias de la } \\
\text { toma de Má laga }\end{array}$ \\
\hline & Sancho de Castilla & Ayo & 200.000 & \multirow[t]{2}{*}{ Quitaciń } \\
\hline & Diego de Deza & Maestro & 100.000 & \\
\hline & & Mozo & 1.095 & $\begin{array}{l}\text { Albricias de la } \\
\text { toma de Má laga }\end{array}$ \\
\hline & & Paje & 1.000 & $\begin{array}{l}\text { Enfermedad en } \\
\text { Guadalajara }\end{array}$ \\
\hline \multirow[t]{7}{*}{1488} & & Ama & 100.000 & \\
\hline & Francisco Guirao & Repostero de camas & 10.000 & $\begin{array}{l}\text { Quitació, mozo } \\
\text { y mula }\end{array}$ \\
\hline & Pablo Miranda & Criado & 3.000 & \multirow[t]{2}{*}{ Ayuda de costa } \\
\hline & Antonio de Andino & Mozo de capilla & 2.400 & \\
\hline & \multirow[t]{2}{*}{ Sancho de Castilla } & \multirow[t]{2}{*}{ Ayo } & 90.000 & Ayuda de costa \\
\hline & & & 200.000 & \multirow[t]{3}{*}{ Quitaciń } \\
\hline & Diego de Deza & Maestro & 100.000 & \\
\hline \multirow[t]{8}{*}{1489} & Juancho de Segura & Repostero de camas & 6.000 & \\
\hline & Francisco Guirao & Repostero de camas & 10.000 & $\begin{array}{l}\text { Quitaciń, mozo } \\
\text { y mula }\end{array}$ \\
\hline & $\begin{array}{l}\text { Juan Velá zquez de } \\
\text { Cué llar }\end{array}$ & Maestresala & 50.000 & \multirow[t]{3}{*}{ Quitació } \\
\hline & Diego de Deza & Maestro & 100.000 & \\
\hline & \multirow[t]{2}{*}{ Sancho de Castilla } & \multirow[t]{2}{*}{ Ayo } & 200.000 & \\
\hline & & & 90.000 & \multirow[t]{3}{*}{ Ayuda de costa } \\
\hline & Diego de Zorrilla & Portero & 485 & \\
\hline & Porris, inglé s & Cantor & 2.000 & \\
\hline \multirow[t]{4}{*}{1490} & Francisco Guirao & Repostero de camas & 10.000 & $\begin{array}{l}\text { Quitació, mozo } \\
\text { y mula }\end{array}$ \\
\hline & Jaime Rejń & Ministril & 7.200 & $\begin{array}{l}\text { Quitaciń } \\
\text { añ o } 1485\end{array}$ \\
\hline & \multirow[t]{2}{*}{ Sancho de Castilla } & \multirow[t]{2}{*}{ Ayo } & 200.000 & Quitaciń \\
\hline & & & 90.000 & Ayuda de costa \\
\hline \multirow[t]{5}{*}{1491} & Francisco Guirao & Repostero de camas & 10.000 & $\begin{array}{l}\text { Quitaciń, mozo } \\
\text { y mula }\end{array}$ \\
\hline & \multirow[t]{2}{*}{ Diego de Deza } & \multirow[t]{2}{*}{ Maestro } & 100.000 & Quitaciń \\
\hline & & & 30.000 & Ayuda de costa \\
\hline & \multirow[t]{2}{*}{ Sancho de Castilla } & \multirow[t]{2}{*}{ Ayo } & 200.000 & Quitaciń \\
\hline & & & 100.000 & Ayuda de costa \\
\hline
\end{tabular}




\begin{tabular}{|c|c|c|c|c|}
\hline $\mathrm{A} \tilde{\mathbb{Q}}$ & NOMBRE & OFICIO & MRS. & CONCEPTO \\
\hline & Sancho Ruiz & Cazador menor & 4.000 & \\
\hline \multirow[t]{9}{*}{1492} & \multirow[t]{2}{*}{ Diego de Deza } & \multirow[t]{2}{*}{ Maestro } & 30.000 & \\
\hline & & & 45.000 & \\
\hline & & $\begin{array}{l}\text { Escudero de Sancho } \\
\text { de Castilla }\end{array}$ & 485 & \\
\hline & \multirow{2}{*}{ Sancho de Castilla } & \multirow{2}{*}{ Ayo } & 200.000 & Quitaciń \\
\hline & & & 100.000 & Ayuda de costa \\
\hline & \multirow{2}{*}{$\begin{array}{l}\text { Juan Velá zquez de } \\
\text { Cué llar }\end{array}$} & \multirow{2}{*}{ Maestresala } & \multirow{2}{*}{50.000} & Quitaciń \\
\hline & & & & Ayuda de costa \\
\hline & Francisco Guirao & Repostero de camas & 10.000 & \multirow[t]{2}{*}{ Quitaciń } \\
\hline & Diego de Deza & Maestro & 100.000 & \\
\hline \multirow[t]{8}{*}{1493} & Monterroso & Cazador menor & 7.000 & \multirow[t]{5}{*}{ Ayuda de costa } \\
\hline & Juan de la Carrera & & & \\
\hline & Pedro de la Peñ a & Catarriberas & 8.000 & \\
\hline & Diego de Deza & Maestro & 50.000 & \\
\hline & Diego de Zorrilla & Repostero de camas & 4.000 & \\
\hline & $\begin{array}{l}\text { Juan Velá zquez de } \\
\text { Cué llar }\end{array}$ & Maestresala & 150.000 & \multirow[t]{3}{*}{ Quitació } \\
\hline & Sancho de Castilla & Ayo & 200.000 & \\
\hline & Francisco Guirao & Repostero de camas & 10.000 & \\
\hline \multirow[t]{10}{*}{1494} & Sancho Ruiz & \multirow[t]{3}{*}{ Cazador menor } & \multirow[t]{3}{*}{5.000} & \multirow[t]{6}{*}{ Ayuda de costa } \\
\hline & Monterroso & & & \\
\hline & Juan de la Carrera & & & \\
\hline & Pedro de la Peñ a & \multirow[t]{2}{*}{ Catarriberas } & \multirow[t]{2}{*}{3.000} & \\
\hline & Martń Caballero & & & \\
\hline & Diego de Zorrilla & Repostero de camas & 6.000 & \\
\hline & Sancho de Castilla & Ayo & 200.000 & \multirow[t]{4}{*}{ Quitació } \\
\hline & Francisco Guirao & Repostero de camas & 10.000 & \\
\hline & Diego de Deza & Maestro & 100.000 & \\
\hline & $\begin{array}{l}\text { Juan Velá zquez de } \\
\text { Cué llar }\end{array}$ & Maestresala & 150.000 & \\
\hline \multirow[t]{8}{*}{1495} & Juan de la Carrera & Cazador menor & 4.000 & Ayuda de costa \\
\hline & Sancho de Castilla & Ayo & 200.000 & \multirow[t]{5}{*}{ Quitació } \\
\hline & Francisco Guirao & Repostero de camas & 10.000 & \\
\hline & $\begin{array}{l}\text { Fray André s de } \\
\text { Miranda }\end{array}$ & $\begin{array}{lll}\begin{array}{l}\text { Maestro } \\
\text { princesa }\end{array} & \text { de } & \text { la } \\
\end{array}$ & 80.000 & \\
\hline & $\begin{array}{l}\text { Juan Velá zquez de } \\
\text { Cué llar }\end{array}$ & Maestresala & 150.000 & \\
\hline & Diego de Deza & Maestro & 100.000 & \\
\hline & Monterroso & Cazador & 3.000 & \multirow[t]{2}{*}{ Ayuda de costa } \\
\hline & Pedro de Torres & $\begin{array}{l}\text { Secretario } \\
\text { Consejo }\end{array}$ & 21.000 & \\
\hline
\end{tabular}



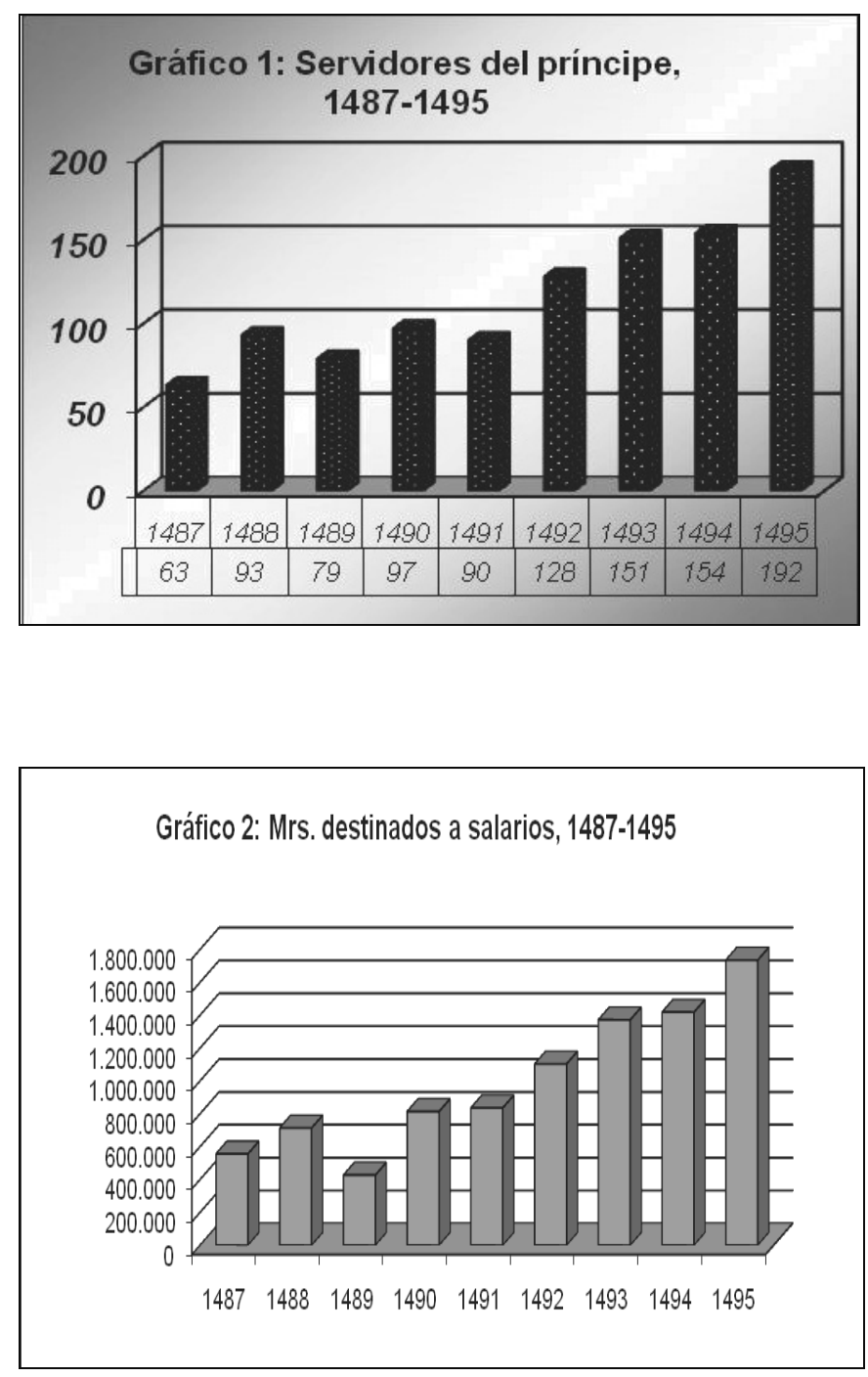

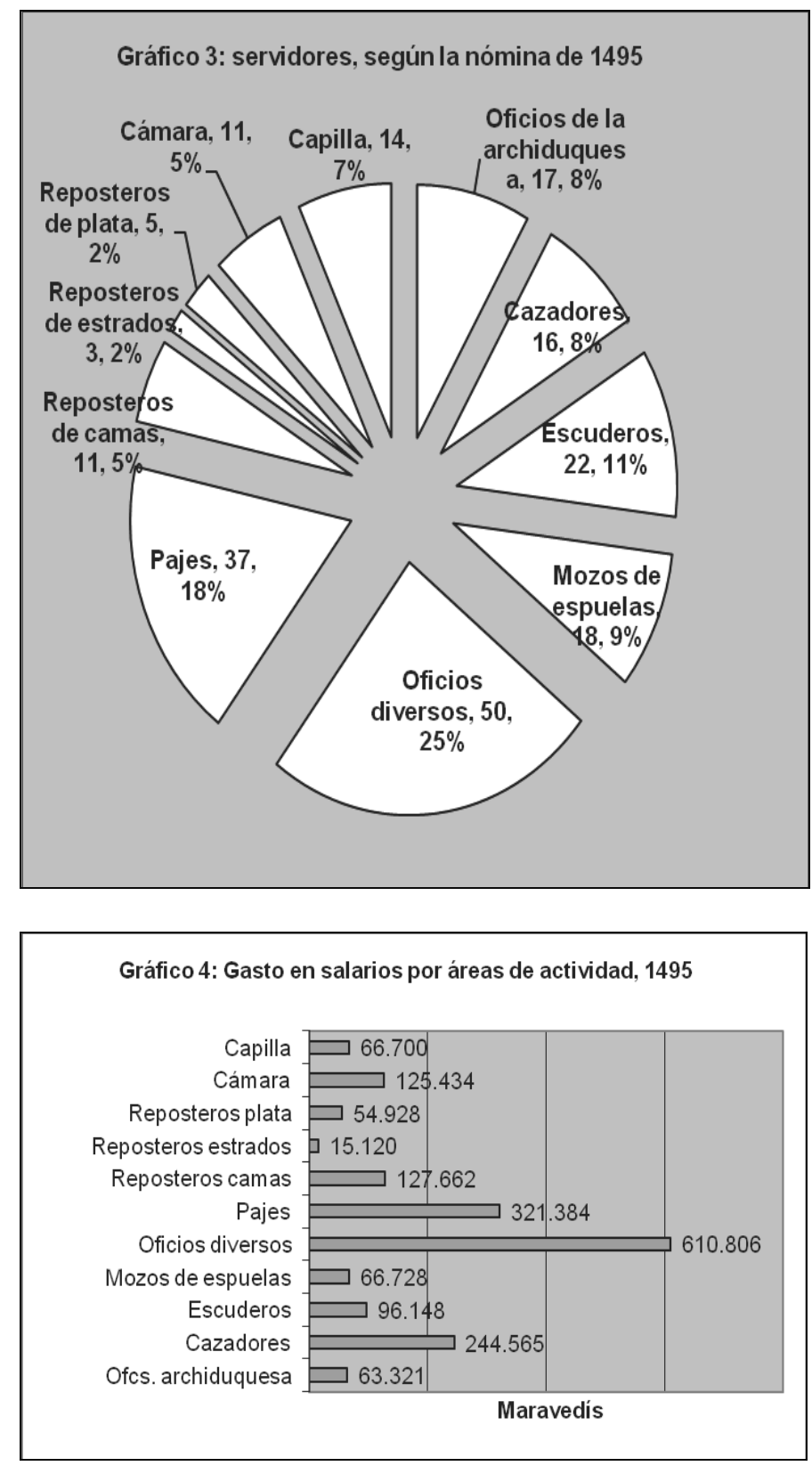

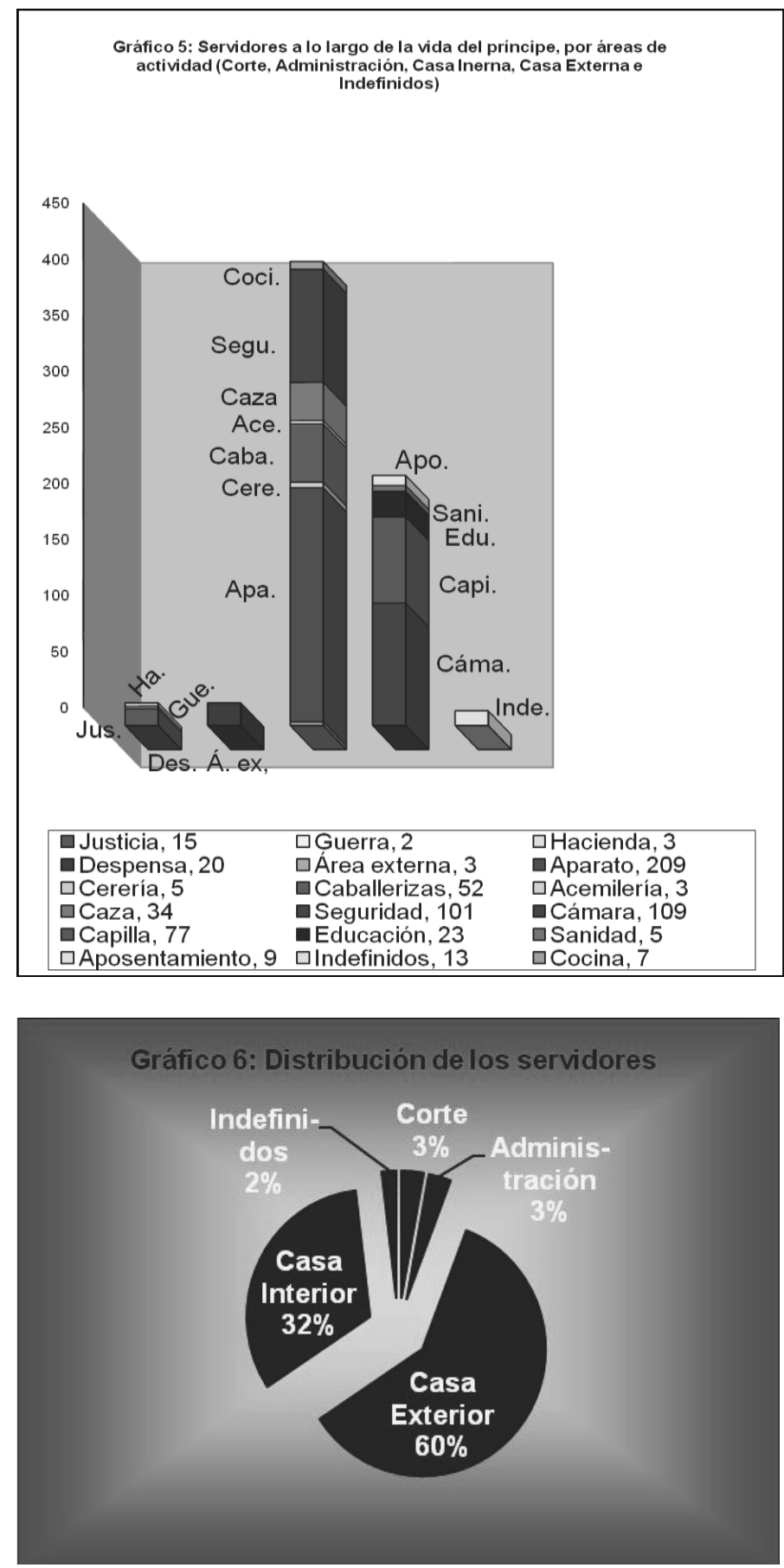